\title{
Role of myeloperoxidase in lung inflammation'
}

Citation for published version (APA):

Haegens, A. (2008). Role of myeloperoxidase in lung inflammation'. [Doctoral Thesis, Maastricht University]. Universiteit Maastricht. https://doi.org/10.26481/dis.20080606ah

Document status and date:

Published: 01/01/2008

DOI:

10.26481/dis.20080606ah

Document Version:

Publisher's PDF, also known as Version of record

\section{Please check the document version of this publication:}

- A submitted manuscript is the version of the article upon submission and before peer-review. There can be important differences between the submitted version and the official published version of record.

People interested in the research are advised to contact the author for the final version of the publication, or visit the DOI to the publisher's website.

- The final author version and the galley proof are versions of the publication after peer review.

- The final published version features the final layout of the paper including the volume, issue and page numbers.

Link to publication

\footnotetext{
General rights rights.

- You may freely distribute the URL identifying the publication in the public portal. please follow below link for the End User Agreement:

www.umlib.nl/taverne-license

Take down policy

If you believe that this document breaches copyright please contact us at:

repository@maastrichtuniversity.nl

providing details and we will investigate your claim.
}

Copyright and moral rights for the publications made accessible in the public portal are retained by the authors and/or other copyright owners and it is a condition of accessing publications that users recognise and abide by the legal requirements associated with these

- Users may download and print one copy of any publication from the public portal for the purpose of private study or research.

- You may not further distribute the material or use it for any profit-making activity or commercial gain

If the publication is distributed under the terms of Article $25 \mathrm{fa}$ of the Dutch Copyright Act, indicated by the "Taverne" license above, 


\section{Role of Myeloperoxidase in Lung Inflammation}


Printed by: Datawyse, Maastricht

ISBN: 978-90-9022897-6

(c) 2008 Astrid Haegens, Maastricht, the Netherlands

All rights reserved. No part of this book may be reproduced or transmitted, in any form or by any means, without written permission from the author.

The studies presented in this thesis were performed at the Nutrition and Toxicology Research Institute Maastricht (NUTRIM), which participates in the Graduate School VLAG (Food Technology, Agrobiotechnology, Nutrion, and Health Sciences), accredited by the Royal Netherlands Academy of Arts and Sciences (KNAW) 


\title{
Role of Myeloperoxidase in Lung Inflammation
}

\author{
Proefschrift
}

ter verkrijging van de graad van doctor aan de Universiteit Maastricht, op gezag van de Rector Magnificus Prof. Mr. G.P.M.F. Mols, volgens het besluit van het College van Decanen, in het openbaar te verdedigen op vrijdag 6 juni 2008 om 14.00 uur

door

Astrid Haegens 


\section{Promotoren}

Prof. dr. E.F.M. Wouters

Prof. dr. B.T. Mossman (University of Vermont, USA)

\section{Copromotor}

dr. J.H.J. Vernooy

\section{Beoordelingscommissie}

Prof. dr. J.W. Cohen Tervaert (voorzitter)

Prof. dr. C.A. Bruggeman

Prof. dr. G.G. Brusselle (UZ, Gent)

Prof. dr. P.S. Hiemstra (LUMC, Leiden)

Prof. dr. F.J. van Schooten

The publication of this thesis is financially supported by: Stichting Pulmonologie, Beun-de Ronde BV, Boehringer Ingelheim, CIRO-Horn and AstraZeneca. 


\section{Table of Contents}

$\begin{array}{lll}\text { Chapter } 1 & \text { General Introduction } & 7\end{array}$

Chapter 2 Myeloperoxidase modulates lung epithelial responses to 17 pro-inflammatory agents.

Chapter 3 Asbestos-induced lung inflammation and epithelial cell proliferation are altered in Myeloperoxidase-null mice.

Chapter 4 Myeloperoxidase deficiency attenuates LPS-induced acute 55 lung inflammation and subsequent lung epithelial injury.

Chapter 5 Myeloperoxidase attenuates LPS-induced airspace 75 enlargement.

Chapter 6 Airway epithelial NF-kB activation modulates asbestosinduced lung inflammation and mucin production in vivo.

Chapter 7 General Discussion

Chapter 8 Summary

Chapter 9 Samenvatting

\section{Appendices}

Dankwoord/Acknowledgements

Publications

Curriculum Vitae 

GENERAL INTRODUCTION 
Chapter 1 


\section{GENERAL INTRODUCTION}

\section{Neutrophilia in chronic and acute lung conditions}

Lung neutrophilia is a problem common to a variety of lung related diseases. Neutrophils are highly specialized members of the innate immune system and they are often the first immune cells to arrive at a site of infection. Their primary function is phagocytosis and destruction of microorganisms and foreign material. Under normal conditions neutrophils circulate through the bloodstream with a circulating half-life of about 7 hours and migrate through tissue for about 2-3 days searching for pathogens. However, during an invasion of pathogens or other foreign materials neutrophils are recruited to the site of inflammation and their life-span is increased. This delayed apoptosis is caused by granulocyte colony stimulating factor (G-CSF) present at sites of inflammation (1).

\subsection{Chronic Obstructive Pulmonary Disease}

Chronic obstructive pulmonary disease (COPD) is a chronic, progressive, irreversible disease of the respiratory system (2). It is characterized by chronic bronchitis, chronic bronchiolitis and emphysema (3). The severity of COPD has been linked to the level of lung inflammation in several studies $(4,5)$. Patients suffering from COPD have increased neutrophil levels during all stages of disease development (6) and increased neutrophil levels are reported in sputum of patients during disease exacerbations (7). Increased levels of myeloperoxidase, a marker of active neutrophilia, in bronchoalveolar lavage fluid (BALF) of COPD patients are well described $(8,9,10)$.

\subsection{Asbestosis}

Lung neutrophilia is also a key player in the development of asbestosis, a disease defined as bilateral diffuse interstitial fibrosis of the lungs caused by the inhalation of asbestos fibers (11). Increased neutrophil levels in BALF of asbestos-exposed men have been described $(12,13)$, as well as increased levels of the neutrophil chemoattractant interleukin (IL) -8 (14). A significant association was found between neutrophils in BALF and forced expiratory volume in 1 second $\left(\mathrm{FEV}_{1}\right)$ in long term asbestos workers (15).

\subsection{Acute Respiratory Distress Syndrome}

Not only chronic lung diseases exhibit neutrophilia. It can also have an acute character. Acute respiratory distress syndrome (ARDS) can develop in many serious conditions including sepsis, pneumonia, traumatic injury and major surgery $(16,17)$. Mortality is over $40 \%$, and there is no effective therapy apart from supportive measures (17). Elevation levels of IL-8 in BALF of at risk people can predict ARDS progression (18), and higher levels of IL-8 are present in BALF samples of nonsurvivors compared to survivors with ARDS (19).

Patients with lung diseases like idiopathic pulmonary fibrosis (20) and cystic fibrosis (21) also suffer from lung neutrophilia. It is furthermore a problem after lung transplantation, when patients develop bronchiolitis obliterans syndrome 
(BOS) in which increased lung neutrophilia together with an excessive repair mechanism lead to a severe decrease in lung function $(22,23)$.

\section{Development of lung neutrophilia}

Stimulation of the lung epithelium by inhaled microorganisms, but also noxious particles and gases, leads to up-regulation of pro-inflammatory signaling cascades in resident lung cells. This activation results in the increased production of chemokines by lung epithelial cells, but also by activated macrophages, monocytes, endothelium and various parenchymal cells (24). The best studied human chemokine in the development of lung neutrophilia is IL-8, also named CXCL8.

The initial steps in the neutrophil adhesion cascade include capture and rolling of circulating neutrophils and this process requires E-, L-, and P-selectin. This is followed by endothelial cell activation mediated by chemokines (25) resulting in neutrophil arrest and firm adhesion. This adhesion is mediated by integrins, heterodimeric transmembrane glycoproteins, in collaboration with intercellular adhesion molecules, intercellular cellular adhesion molecule (ICAM)-1, ICAM-2 and vascular cell adhesion molecule (VCAM)-1 (26). A series of events, including NF-KB translocation (27) and mitogen-activated protein kinase (MAPK) activation (27) in the neutrophil will lead to the up-regulation of CD11b surface expression (27). This will result in the paracellular or transcellular endothelial migration of neutrophils into the pulmonary capillary bed. Figure 1 shows the above described process step by step. When neutrophils enter affected tissue in an attempt to eliminate pathogens and other foreign agents, they have a variety of oxygen-dependent and -independent mechanisms to do so. Oxygen independent mechanisms include chemotaxis, phagocytosis, degranulation, and release of lytic and antimicrobial enzymes (28).

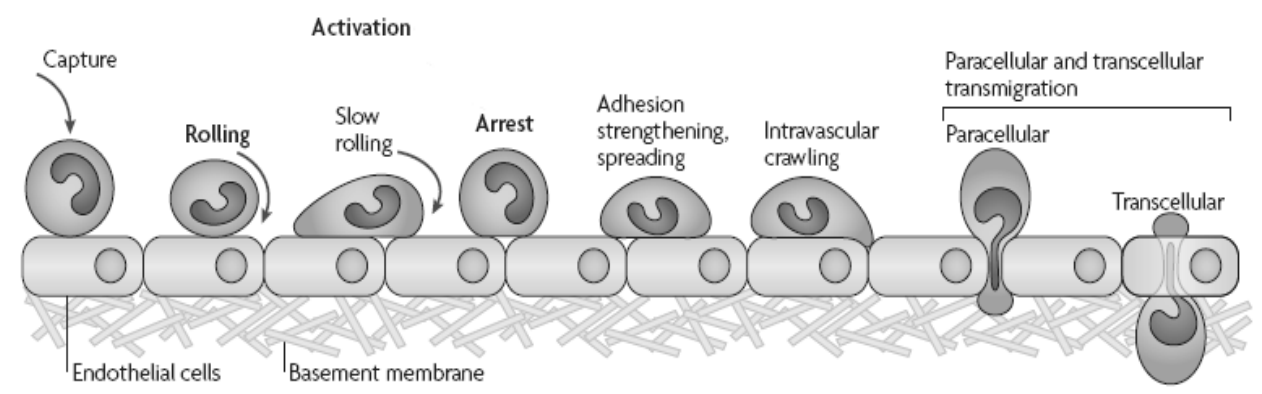

Figure 1: The neutrophil extravasation cascade, adapted from (46). The original three steps are shown in bold: rolling, which is mediated by selectins. The second step, activation is mediated by chemokines. Step number three, arrest followed by adhesion is mediated by integrins. 


\subsection{Oxygen dependent mechanisms in the neutrophil respiratory burst}

For a long time researchers believed that the main production of reactive oxygen species (ROS) by neutrophils was caused by the activity of the multiprotein complex, reduced nicotinamide adenine dinucleotide phosphate (NADPH) oxidase. This complex catalyses the formation of superoxide anion $\left(\mathrm{O}_{2}{ }^{-}\right)$, by transferring electrons from NADPH to $\mathrm{O}_{2}$ via a series of phosphorylation events (29). Later, other mechanisms capable of ROS production were recognized.

\section{Myeloperoxidase}

Myeloperoxidase (MPO) is an iron containing heme protein predominantly stored in granula of neutrophils and a key contributor to the respiratory burst of neutrophils. It is a product of a single gene (30), and its synthesis is initiated in the promyelocyte stage of neutrophil development and terminates at the beginning of the myeloid stage. At this time the MPO-containing azurophilic granula are distributed to daughter cells, where they mix with the newly formed peroxidase negative, specific (secondary) granula. Human monocytes also contain MPO-positive granules, although they are fewer in number than in neutrophils. The MPO-containing granula are formed in bone marrow promonocytes, are readily apparent in mature monocytes, but are generally lost when monocytes mature into tissue macrophages (31). MPO is first produced in an enzymatically inactive form, called apoproMPO, which is finally modified into mature MPO. Mature MPO consists of two identical dimers, each of which contains a heme prosthetic group (32). Mature MPO is shown in Figure 2.

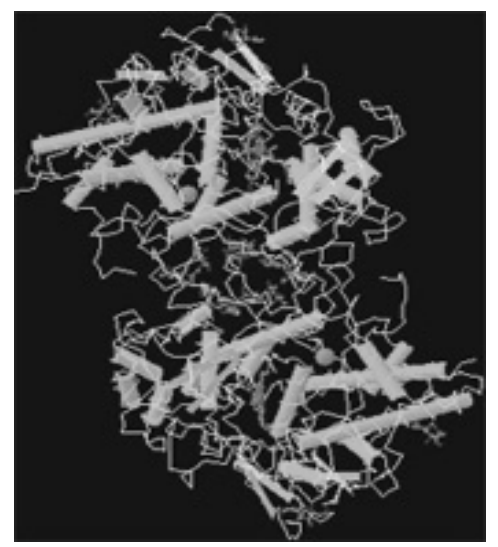

Figure 2: Chrystal structure of myeloperoxidase, consisting of two identical dimers, each of which contains a heme prosthetic group.

Enzymatic activity of MPO results mainly in the conversion of hydrogen peroxide $\left(\mathrm{H}_{2} \mathrm{O}_{2}\right)$ and chloride ions into hypochlorous acid $(\mathrm{HOCl})$, and is therefore an important enzyme in the host defence against bacteria, viruses and fungi (33). Patients suffering from MPO deficiency, however, generally do not have an increased frequency of infection, probably because other MPO-independent mechanism(s) with antimicrobial activity compensate for the lack of MPO.

Like NADPH oxidase, MPO also possesses tissue damaging capacities by its production of $\mathrm{HOCl}$ and other reactive oxidants, leading to increased levels of oxidative stress. $\mathrm{HOCl}$ production by MPO leads to the formation of chlorotyrosine (CITyr) residues (34). NO and nitrite also serve as biological substrates of MPO leading to the formation of nitrogen dioxide. Nitrogen dioxide promotes 
lipid peroxidation, protein nitration and thus the formation of nitrotyrosine $\left(\mathrm{NO}_{2} \mathrm{Tyr}\right)$, a post-translational modification and a contributor of inflammatory disease (35). An overview of the products mediated by the MPO system is given in Figure 3 (33).

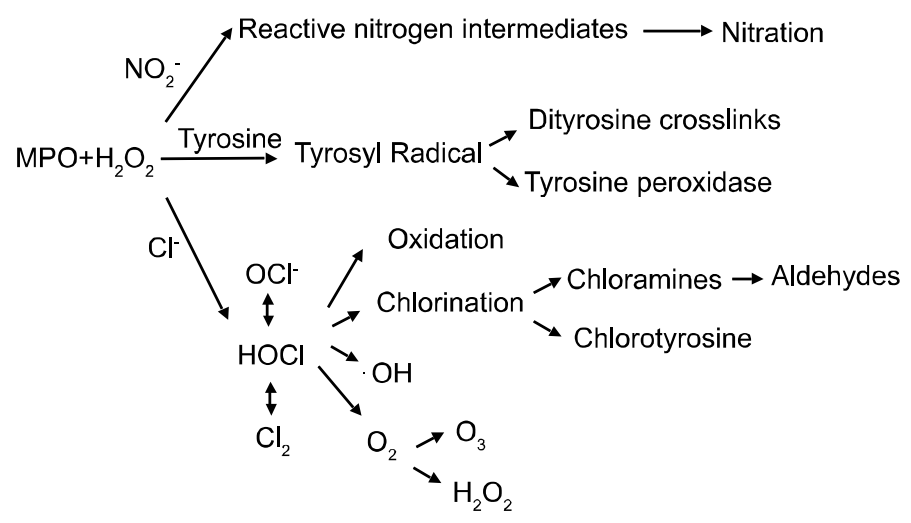

Figure 3: Products of the MPO-mediated antimicrobial system (33). $\mathrm{OH}$, Hydroxyl radical.

Recently, MPO has been shown to contribute to inflammation de-velopment independent of its enzymatic activity.

MPO was demonstrated to associate with the outer membrane of neutrophils by binding to $C D 11 \mathrm{~b} / \mathrm{CD} 18$ integrins, which are known to be centrally linked to neutrophil activation (27). In this manner MPO may contribute to neutrophil recruitment to the site of inflammation. In addition, MPO has been shown to stimulate the production of tumor necrosis factor $\alpha$ (TNF- $\alpha)$ and interferon $\alpha / \beta$ $(\mathrm{IFN}-\alpha / \beta)$ by peritoneal macrophages and hereby enhance target cell killing by macrophages (36).

\section{Lung epithelial NF-KB signaling}

Neutrophil chemo-attractants IL-6 and IL-8 are produced by lung epithelium, among other cell types. Both genes are regulated by NF-kB $(42,43)$ transcriptional activity. NF-KB is considered a master regulator of inflammation and immune processes (38). It has been implicated in several inflammatory lung diseases, like COPD (39), asbestosis (40) and asthma (41). Although the reactive agents triggering the lung epithelium are very different in these diseases, they all lead to NF-KB signaling.

$\mathrm{NF}-\mathrm{KB}$ activity is tightly controlled by the inhibitory protein, IKBa, which is complexed to NF-KB dimers to promote cytoplasmic retention and low basal transcriptional activity. Upon cellular stimulation, the IKB kinase complex phosphorylates $\mathrm{I} \mathrm{KB} \alpha$, causing its ubiquitination and degradation through the $26 \mathrm{~S}$ proteasome pathway. IKB degradation exposes the nuclear localization sequence of NF-KB, allowing its accumulation in the nucleus, binding to DNA, and stimulation of gene transcription. 


\section{Aims and outline of the thesis}

It is important that the consequences of neutrophilia for lung epithelial cells and responses to neutrophil exposure by epithelial cells will be known, since neutrophilia is a key contributor to lung diseases and is therefore of significant clinical relevance. The overall aim of this work was to investigate the consequences for lung epithelial cells to infiltrating neutrophils on molecular, protein and whole cell level. There was a specific focus on the contributing effects of the neutrophilic enzyme, MPO.

An in vitro model of lung neutrophilia was used to investigate basic mechanisms involved in lung neutrophilia. The uptake of MPO, MPO related DNA damage, and oxidative stress levels were investigated. Furthermore, the production of IL-8 and IL- 6 by lung epithelial cells was analyzed. Lastly, an attempt was made to elucidate whether lung epithelial cells respond differently to MPO, depending on the type of neutrophilia causing agents that the cells were primed with. Results of these studies are discussed in chapter 2.

Lung neutrophilia and the contribution of MPO to the development of neutrophilia in several lung diseases was investigated using in vivo models in combination with a MPO knock out approach. A transient acute lung inflammation was mimicked by intratracheally instilling a single dose of lipopolysaccharide (LPS) in the lungs (chapter 4). Subsequent development of lung neutrophilia and the contribution of MPO to this development were investigated. Lung epithelial cell damage was investigated at the DNA level (44), by measuring 8hydroxy-2'deoxyguanosine (8-OHdG) formation. Damage at the protein level was investigated by CITyr (45) and $\mathrm{NO}_{2}$ Tyr formation (35).

The contribution of MPO to chronic lung inflammation and emphysema was investigated by repeated instillation of LPS (chapter 5). In this chapter, an attempt was made to unravel the mechanisms behind the development of LPS-induced emphysema. Lung epithelial cell apoptosis, matrix metalloproteinases (MMPs) expression, and anti-oxidant status in the lungs of chronically exposed mice were explored.

The role of MPO in chrysotile asbestos-induced subchronic lung inflammation was investigated in chapter 3. Endpoints measured in this study were MPO localization and BALF was used to determine cell injury and lung inflammation. Furthermore, epithelial cell proliferation was addressed by Ki-67 expression and cyclin D1 localization.

Lastly, NF-kB activation in bronchiolar lung epithelial cell responses to acute, subchronic and chronic asbestos exposure was further investigated in chapter 6. Transgenic mice lacking NF-kB activation in bronchiolar epithelium were exposed to chrysotile asbestos and inflammatory cell profiles, cytokine production, as well as mucin production were investigated.

We report in this thesis a significant reduction of neutrophil influx in Mpo knock

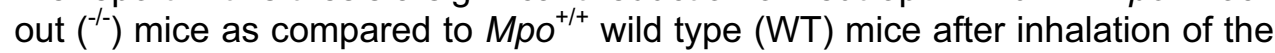
inflammatory fiber, chrysotile asbestos (chapter 3) (37) or, exposure to the cigarette smoke component, LPS (chapter 4). The consequences of these results for the conclusions of the studies described in this thesis and the conclusions themselves are further discussed and placed in context in chapter 7. 


\section{REFERENCES}

1. Aggarwal, A., C. S. Baker, T. W. Evans, and P. L. Haslam. 2000. G-CSF and IL-8 but not GM-CSF correlate with severity of pulmonary neutrophilia in acute respiratory distress syndrome. Eur Respir J 15:895.

2. 1995. Future directions for research on diseases of the lung. American Thoracic Society. Medical Section of the American Lung Association. This report was approved by the ATS Board of Directors in November 1994. Am J Respir Crit Care Med 152:1713.

3. Jeffery, P. K. 2001. Remodeling in asthma and chronic obstructive lung disease. Am J Respir Crit Care Med 164:S28.

4. O'Shaughnessy, T. C., T. W. Ansari, N. C. Barnes, and P. K. Jeffery. 1997. Inflammation in bronchial biopsies of subjects with chronic bronchitis: inverse relationship of CD8+ T lymphocytes with FEV1. Am J Respir Crit Care Med 155:852.

5. Peleman, R. A., P. H. Rytila, J. C. Kips, G. F. Joos, and R. A. Pauwels. 1999. The cellular composition of induced sputum in chronic obstructive pulmonary disease. Eur Respir J 13:839.

6. Hogg, J. C., F. Chu, S. Utokaparch, R. Woods, W. M. Elliott, L. Buzatu, R. M. Cherniack, R. M. Rogers, F. C. Sciurba, H. O. Coxson, and P. D. Pare. 2004. The nature of smallairway obstruction in chronic obstructive pulmonary disease. N Engl J Med 350:2645.

7. Papi, A., C. M. Bellettato, F. Braccioni, M. Romagnoli, P. Casolari, G. Caramori, L. M. Fabbri, and S. L. Johnston. 2006. Infections and airway inflammation in chronic obstructive pulmonary disease severe exacerbations. Am J Respir Crit Care Med 173:1114.

8. Keatings, V. M., and P. J. Barnes. 1997. Granulocyte activation markers in induced sputum: comparison between chronic obstructive pulmonary disease, asthma, and normal subjects. Am J Respir Crit Care Med 155:449.

9. Barczyk, A., E. Sozanska, M. Trzaska, and W. Pierzchala. 2004. Decreased levels of myeloperoxidase in induced sputum of patients with COPD after treatment with oral glucocorticoids. Chest 126:389.

10. Tumkaya, M., S. Atis, C. Ozge, N. Delialioglu, G. Polat, and A. Kanik. 2007. Relationship between airway colonization, inflammation and exacerbation frequency in COPD. Respir Med 101:729.

11. 1986. American Thoracic Society. Medical Section of the American Lung Association: The diagnosis of nonmalignant diseases related to asbestos. Am Rev Respir Dis 134:363.

12. Cullen, M. R., and W. W. Merrill. 1992. Association between neutrophil concentration in bronchoalveolar lavage fluid and recent losses in diffusing capacity in men formerly exposed to asbestos. Chest 102:682.

13. Brunetti, G., M. Delmastro, R. Fonte, G. Moscato, A. Bossi, P. Baiardi, A. Massola, and F. Meloni. 2003. Immunocytological and mineralogical study of bronchoalveolar lavage in a group of subjects exposed to asbestos. G Ital Med Lav Ergon 25:152.

14. Broser, M., Y. Zhang, C. Aston, T. Harkin, and W. N. Rom. 1996. Elevated interleukin-8 in the alveolitis of individuals with asbestos exposure. Int Arch Occup Environ Health 68:109.

15. Rom, W. N. 1992. Accelerated loss of lung function and alveolitis in a longitudinal study of non-smoking individuals with occupational exposure to asbestos. Am J Ind Med 21:835.

16. Bernard, G. R., A. Artigas, K. L. Brigham, J. Carlet, K. Falke, L. Hudson, M. Lamy, J. R. LeGall, A. Morris, and R. Spragg. 1994. Report of the American-European Consensus conference on acute respiratory distress syndrome: definitions, mechanisms, relevant outcomes, and clinical trial coordination. Consensus Committee. J Crit Care 9:72.

17. Murray, J. F., M. A. Matthay, J. M. Luce, and M. R. Flick. 1988. An expanded definition of the adult respiratory distress syndrome. Am Rev Respir Dis 138:720.

18. Donnelly, S. C., R. M. Strieter, S. L. Kunkel, A. Walz, C. R. Robertson, D. C. Carter, I. S. Grant, A. J. Pollok, and C. Haslett. 1993. Interleukin-8 and development of adult respiratory distress syndrome in at-risk patient groups. Lancet 341:643. 
19. Miller, E. J., A. B. Cohen, S. Nagao, D. Griffith, R. J. Maunder, T. R. Martin, J. P. Weiner-Kronish, M. Sticherling, E. Christophers, and M. A. Matthay. 1992. Elevated levels of NAP-1/interleukin-8 are present in the airspaces of patients with the adult respiratory distress syndrome and are associated with increased mortality. Am Rev Respir Dis 146:427.

20. Saleh, D., P. J. Barnes, and A. Giaid. 1997. Increased production of the potent oxidant peroxynitrite in the lungs of patients with idiopathic pulmonary fibrosis. Am J Respir Crit Care Med 155:1763.

21. Van Der Vliet, A., M. N. Nguyen, M. K. Shigenaga, J. P. Eiserich, G. P. Marelich, and C. E. Cross. 2000. Myeloperoxidase and protein oxidation in cystic fibrosis. Am J Physiol Lung Cell Mol Physiol 279:L537.

22. Estenne, M., and M. I. Hertz. 2002. Bronchiolitis obliterans after human lung transplantation. Am J Respir Crit Care Med 166:440.

23. Egan, J. J. 2004. Obliterative bronchiolitis after lung transplantation: a repetitive multiple injury airway disease. Am J Respir Crit Care Med 170:931.

24. Rollins, B. J. 1997. Chemokines. Blood 90:909.

25. Campbell, J. J., J. Hedrick, A. Zlotnik, M. A. Siani, D. A. Thompson, and E. C. Butcher. 1998. Chemokines and the arrest of lymphocytes rolling under flow conditions. Science 279:381.

26. Campbell, J. J., S. Qin, K. B. Bacon, C. R. Mackay, and E. C. Butcher. 1996. Biology of chemokine and classical chemoattractant receptors: differential requirements for adhesion-triggering versus chemotactic responses in lymphoid cells. J Cell Biol 134:255.

27. Lau, D., H. Mollnau, J. P. Eiserich, B. A. Freeman, A. Daiber, U. M. Gehling, J. Brummer, V. Rudolph, T. Munzel, T. Heitzer, T. Meinertz, and S. Baldus. 2005. Myeloperoxidase mediates neutrophil activation by association with CD11b/CD18 integrins. Proc Natl Acad Sci U S A 102:431.

28. Witko-Sarsat, V., P. Rieu, B. Descamps-Latscha, P. Lesavre, and L. HalbwachsMecarelli. 2000. Neutrophils: molecules, functions and pathophysiological aspects. Lab Invest 80:617.

29. Quinn, M. T., and K. A. Gauss. 2004. Structure and regulation of the neutrophil respiratory burst oxidase: comparison with nonphagocyte oxidases. J Leukoc Biol 76:760.

30. Morishita, K., M. Tsuchiya, S. Asano, Y. Kaziro, and S. Nagata. 1987. Chromosomal gene structure of human myeloperoxidase and regulation of its expression by granulocyte colony-stimulating factor. J Biol Chem 262:15208.

31. Bainton, D. F., J. L. Ullyot, and M. G. Farquhar. 1971. The development of neutrophilic polymorphonuclear leukocytes in human bone marrow. J Exp Med 134:907.

32. Zeng, J., and R. E. Fenna. 1992. X-ray crystal structure of canine myeloperoxidase at 3 A resolution. $J \mathrm{Mol}$ Biol 226:185.

33. Klebanoff, S. J. 2005. Myeloperoxidase: friend and foe. J Leukoc Biol 77:598.

34. Gujral, J. S., J. A. Hinson, and H. Jaeschke. 2004. Chlorotyrosine protein adducts are reliable biomarkers of neutrophil-induced cytotoxicity in vivo. Comp Hepatol 3 Suppl 1:S48.

35. van der Vliet, A., J. P. Eiserich, M. K. Shigenaga, and C. E. Cross. 1999. Reactive nitrogen species and tyrosine nitration in the respiratory tract: epiphenomena or a pathobiologic mechanism of disease? Am J Respir Crit Care Med 160:1.

36. Lefkowitz, D. L., K. C. Mills, N. Moguilevsky, A. Bollen, A. Vaz, and S. S. Lefkowitz. 1993. Regulation of macrophage function by human recombinant myeloperoxidase. Immunol Lett 36:43.

37. Haegens, A., A. van der Vliet, K. J. Butnor, N. Heintz, D. Taatjes, D. Hemenway, P. Vacek, B. A. Freeman, S. L. Hazen, M. L. Brennan, and B. T. Mossman. 2005. Asbestos-induced lung inflammation and epithelial cell proliferation are altered in myeloperoxidase-null mice. Cancer Res 65:9670.

38. Pahl, H. L. 1999. Activators and target genes of Rel/NF-kappaB transcription factors. Oncogene 18:6853. 
39. Yagi, O., K. Aoshiba, and A. Nagai. 2006. Activation of nuclear factor-kappaB in airway epithelial cells in patients with chronic obstructive pulmonary disease. Respiration 73:610.

40. Haegens, A., T. F. Barrett, J. Gell, A. Shukla, M. Macpherson, P. Vacek, M. E. Poynter, K. J. Butnor, Y. M. Janssen-Heininger, C. Steele, and B. T. Mossman. 2007. Airway Epithelial NF-\{kappa\}B Activation Modulates Asbestos-Induced Inflammation and Mucin Production In Vivo. J Immunol 178:1800.

41. Poynter, M. E., R. Cloots, T. van Woerkom, K. J. Butnor, P. Vacek, D. J. Taatjes, C. G. Irvin, and Y. M. Janssen-Heininger. 2004. NF-kappa B activation in airways modulates allergic inflammation but not hyperresponsiveness. J Immunol 173:7003.

42. Zhang, Y., M. Broser, and W. Rom. 1995. Activation of the interleukin 6 gene by Mycobacterium tuberculosis or lipopolysaccharide is mediated by nuclear factors NF IL 6 and NF-kappa B. Proc Natl Acad Sci U S A 92:3632.

43. Li, L. F., B. Ouyang, G. Choukroun, R. Matyal, M. Mascarenhas, B. Jafari, J. V. Bonventre, T. Force, and D. A. Quinn. 2003. Stretch-induced IL-8 depends on C-Jun NH2terminal and nuclear factor-kappaB-inducing kinases. Am J Physiol Lung Cell Mol Physiol 285:L464.

44. Knaapen, A. M., C. Albrecht, A. Becker, D. Hohr, A. Winzer, G. R. Haenen, P. J. Borm, and R. P. Schins. 2002. DNA damage in lung epithelial cells isolated from rats exposed to quartz: role of surface reactivity and neutrophilic inflammation. Carcinogenesis 23:1111.

45. Hazen, S. L., and J. W. Heinecke. 1997. 3-Chlorotyrosine, a specific marker of myeloperoxidase-catalyzed oxidation, is markedly elevated in low density lipoprotein isolated from human atherosclerotic intima. J Clin Invest 99:2075.

46. Ley, K., C. Laudanna, M. I. Cybulsky, and S. Nourshargh. 2007. Getting to the site of inflammation: the leukocyte adhesion cascade updated. Nat Rev Immunol 7:678. 


\section{MYELOPEROXIDASE MODULATES LUNG EPITHELIAL RESPONSES TO PRO- INFLAMMATORY AGENTS}

Astrid Haegens, Juanita H.J. Vernooy, Peter Heeringa, Brooke T. Mossman and Emiel F.M. Wouters

European Respiratory Journal

Vol 31, Issue 2, page 252-260, 2008 
Chapter 2 


\section{ABSTRACT}

During extensive inflammation, neutrophils undergo secondary necrosis causing myeloperoxidase (MPO) release which may damage resident lung cells. Recent observations suggest that MPO has pro-inflammatory properties, independent of its enzymatic activity. The aims of this study were to characterize MPO internalization by lung epithelial cells and to investigate the effect of MPO on oxidative stress, DNA damage and cytokine production by lung epithelial cells.

Human alveolar and bronchial epithelial cells were stimulated with MPO with or without priming the cells with pro-inflammatory stimuli. MPO protein was detected in cell cytoplasm. Expression of heme-oxygenase (HO)-1 and DNA strand breakage were determined. The production of interleukin (IL)-8 and -6 were measured.

Analyses of MPO stimulated cells demonstrated MPO presence in the cells. HO-1 expression was increased after MPO stimulation and increased further when cells were primed before MPO stimulation. MPO exposure also induced DNA strand breakage. Interestingly, MPO inhibited IL-8 production in bronchial, but not alveolar epithelium.

In conclusion, alveolar and bronchial epithelial cells can internalize MPO. Stimulation with MPO increases $\mathrm{HO}-1$ expression and DNA strand breakage, suggesting cell damaging capacity of MPO. In addition, MPO inhibited IL-8 production by bronchial epithelial cells, indicating a negative feedback loop for neutrophil recruitment. 


\section{INTRODUCTION}

Neutrophilia is a feature common to a number of inflammatory lung diseases including chronic obstructive pulmonary disease (COPD) (1), asbestosis (2), idiopathic pulmonary fibrosis (3) and adult respiratory distress syndrome (4) although the agents and events leading to the development of these diseases are very different. Independent of the cause of the chemotactic gradient, neutrophils are activated during their recruitment to the lung and release the contents of their granula into the pulmonary compartment. Excess amounts of neutrophils can lead to secondary necrosis of neutrophils as a result of inefficient clearance of apoptotic neutrophils by macrophages. During secondary necrosis, neutrophils release their lysosomal constituents which possibly affect resident lung cells (5).

Currently, over 50 neutrophil derived-toxins have been identified, including proteolytic enzymes and bacteriacidal proteins. The heme protein, myeloperoxidase (MPO), is the most abundant protein in neutrophils and represents $5 \%$ of their total protein content (6). MPO is synthesized as a precursor during myeloid differentiation in bone marrow, and its processing is completed before neutrophils enter the circulation $(7,8,9)$. A hallmark of neutrophil activation is their respiratory burst in which MPO plays a central role (10). MPO catalyses the conversion of hydrogen peroxide $\left(\mathrm{H}_{2} \mathrm{O}_{2}\right)$ and chloride ions into hypochlorous acid $(\mathrm{HOCl})$ and therefore it is an important enzyme in the host defence against bacteria, viruses and fungi (10). MPO may also damage tissue by its production of $\mathrm{HOCl}$ and other reactive oxidants. $\mathrm{HOCl}$ production by MPO leads to the formation of chlorotyrosine (CITyr) residues, a marker of neutrophilic inflammation (11). Nitric oxide (NO) and nitrite $\left(\mathrm{NO}_{2}{ }^{-}\right)$ also serve as biological substrates of MPO leading to the formation of nitrogen dioxide $\left(\mathrm{NO}_{2}\right) . \mathrm{NO}_{2}$ promotes protein nitration, lipid peroxidation and the oxidation of tyrosine yielding nitrotyrosine $\left(\mathrm{NO}_{2} \mathrm{Tyr}\right)$, a post-translational modification and a contributor of inflammatory disease (12). In addition to its role as a catalytically active protein generating reactive oxidants, MPO recently has been shown to elicit pro-inflammatory properties independent of its enzymatic activity. MPO was demonstrated to associate with the outer membrane of neutrophils by binding to CD11b/CD18 integrins, which are known to be linked to neutrophil activation (13). In this manner, MPO may contribute to neutrophil recruitment to sites of inflammation. In addition, MPO stimulates the production of tumor necrosis factor $\alpha$ (TNF- $\alpha)$ and interferon $\alpha / \beta$ (IFN- $\alpha / \beta)$ by peritoneal macrophages and thereby enhances their killing of target cells (14). Whether MPO released from neutrophils affects resident lung cells and their responses in the absence or presence of an initial inflammatory trigger is unknown.

Reactive oxygen species can be produced by MPO and since HO-1 is an indirect marker of oxidative stress, we hypothesized that MPO exposure would lead to HO-1 up-regulation and an increase in DNA cell damage. Neutrophil recruitment is induced by the production of chemoattractants at an inflamma- 
tory site therefore the production of IL- 8 and IL- 6 by lung epithelial cells was investigated.

Here we used bronchial and alveolar epithelial cells under basal (homeostatic) and primed conditions. These primed conditions were created by stimulating cells with lipopolysaccharide (LPS) to mimic lung infection, with asbestos to mimic asbestosis and phorbol 12-myristate 13-acetate (PMA) was used as positive control. The aims of our study were to 1) characterize MPO internalization by lung epithelial cells and 2) to investigate the effect of MPO on oxidative stress, DNA damage and IL- 8 and -6 production by lung epithelial cells under basal and inflammatory conditions. Our results demonstrate that alveolar and bronchial epithelial cells internalize MPO. Stimulation with MPO increases HO-1 expression and DNA strand breakage, suggesting that MPO is capable of damaging lung epithelial cells. In addition, MPO inhibits IL-8 production by bronchial epithelial cells, indicating that MPO may be involved in a negative feedback loop for the recruitment of neutrophils.

\section{MATERIALS AND METHODS}

Cells and stimulation Human bronchial epithelial cells (Beas-2B) and a human transformed alveolar epithelial cell line (A549) were obtained from the ATCC and cultured in RMPI 1640 (Gibco, Grand Island, NY) containing 10\% fetal bovine serum (FBS, Biochrome, Berlin, Germany), L-Glutamine (2 mM) and Penicillin/Streptomycin (both Invitrogen, Grand Island, NY). Tissue culture surfaces for the Beas-2B cells were coated with LHC basal medium containing $10 \%$ bovine serum albumin (both Biosource International, Camarillo, CA), 1 $\mathrm{mg} / \mathrm{ml}$ fibronectin and $2.9 \mathrm{mg} / \mathrm{ml}$ bovine collagen, Type 1 (both BD Biosciences, Bedford, MA). Cells were plated at a density of 20,000 cells $/ \mathrm{cm} 2$ for analyses of IL- 6 and IL-8 production, and at a density of 13,000 cells $/ \mathrm{cm} 2$ for immunofluorescence staining on coverslips and Western blot analysis. 18-24 hours prior to stimulation growth medium was replaced by medium containing 0.5\% FBS. LPS (Escherichia coli, 055:B5; Sigma, St. Louis, MO), PMA (Sigma, St. Louis, MO) and MPO (Calbiochem, San Diego, CA) stocks were prepared and stored at $-20^{\circ} \mathrm{C}$. National Institute of Environmental Health Sciences (NIEHS) processed crocidolite and chrysotile asbestos was always used fresh. Asbestos was weighed, UV-sterilized, suspended in $1 \mathrm{mg} / \mathrm{ml}$ in tissue culture medium and triturated $8 x$ through a 22-gauge needle to obtain a homogeneous suspension. When LPS, PMA or asbestos stimulation was followed by MPO stimulation, media from controls and pre-stimulated cells was replaced with fresh MPO containing RPMI 1640 with 0.5\% FBS. Supernatants were harvested and stored at $-20^{\circ} \mathrm{C}$ until used for ELISA.

\section{MPO detection}

Immunofluorescence staining in vitro Cells were washed $2 \mathrm{x}$ with ice-cold PBS followed by fixation with $4 \%$ paraformaldehyde for 5 minutes. Cells were permeabalized with 100\% ice-cold methanol for 3 minutes followed by two washes with PBS and blocking with $1 \%(\mathrm{w} / \mathrm{v})$ BSA in PBS for 30 minutes. In- 
cubation with rabbit anti-human MPO (0398, DAKO, Glostrup, Denmark) in $0.1 \%(w / v)$ BSA in PBS for 60 minutes was followed by incubation with goat anti-rabbit Texas Red (4010-07, Southern Biotechnology Associates, Birmingham, AL) for $30 \mathrm{~min}$ in the dark. Nuclei were stained with diamidino-2phenylindole. Negative controls by omitting primary antibody revealed no staining.

Immunohistochemistry on lung sections Peripheral lung specimens of patients undergoing lung surgery were processed immediately following resection by fixation in $10 \%$ phosphate-buffered formalin prior to embedding in paraffin. To verify that epithelial cells are affected by released MPO lung sections $(3 \mu \mathrm{m})$ from COPD or asbestosis patients were cut and deparafinized 3x $5 \mathrm{~min}$ in microclear, followed by $2 \times 5 \mathrm{~min} 100 \%$ ethanol. Endogenous peroxidase was blocked by incubation in $0.6 \% \mathrm{H} 2 \mathrm{O} 2$ in methanol for 15 minutes followed by hydrating through ethanols $(80 \%, 70 \%, 50 \%)$ to water. The sections were equilibrated in Tris-buffered saline (TBS) ( $\mathrm{pH} \mathrm{7.6)} \mathrm{for} 5$ minutes followed by 30 minute blocking with $20 \%$ normal swine serum in TBS-Tween20 $(0.01 \%)$ with $1 \%(w / v)$ BSA. A rabbit anti-human MPO (0398, DAKO) primary antibody diluted in TBS-Tween20 $(0.01 \%)$ with $1 \%(\mathrm{w} / \mathrm{v})$ BSA was incubated for $45 \mathrm{~min}$ utes followed by 30 minutes incubation with a swine anti-rabbit biotinylated secondary antibody (E0413, DAKO) and avidin-biotinylated horseradish peroxidase (K0377, DAKO). Enzymatic reactivity was visualized with HistoGreen (Linaris, Wertheim, Germany). Negative controls by omitting primary antibody revealed no staining.

Preparation of membrane and cytoplasmic fractions Cells were placed on ice and washed $2 x$ with ice-cold PBS. Cells were suspended in lysis buffer (25mM Tris, $\mathrm{pH} 8 / 2 \mathrm{mM} \mathrm{MgCl} / 5 \mathrm{mM} \mathrm{KCl} / 1 \mathrm{mM}$ Na orthovanadate/ $1 \mathrm{mM}$ phenylmethyl sulfonyl fluoride/ $10 \mathrm{mM} \mathrm{NaF} / 10 \mu \mathrm{g} / \mathrm{ml}$ Aprotinin/ $10 \mu \mathrm{g} / \mathrm{ml}$ Leupeptin), homogenized and vortexed for 10 seconds. Cell nuclei were spun down for $10 \mathrm{~min}$ at $1000 \mathrm{~g}$ at $4^{\circ} \mathrm{C}$. Supernatant was transferred to a new tube, and the membrane fraction was spun down for $30 \mathrm{~min}$ at $14,000 \mathrm{rpm}$ at $4^{\circ} \mathrm{C}$. Cytoplasmic fractions were transferred to new tubes and the membrane fractions were resuspended in lysis buffer. A portion of both fractions was saved for protein determination, prior to the addition of $4 \mathrm{x}$ Laemmli sample buffer $(0.25 \mathrm{M}$ Tris- $\mathrm{HCl} \mathrm{pH} 6.8,8 \%(\mathrm{w} / \mathrm{v})$ SDS, $40 \%(\mathrm{v} / \mathrm{v})$ glycerol, $0.4 \mathrm{M}$ DTT and $0.04 \%(\mathrm{w} / \mathrm{v})$ Bromophenol Blue). Next, samples were boiled for 5 minutes and stored at $-20^{\circ} \mathrm{C}$.

Preparation of nuclear extracts Cells were placed on ice and washed twice with ice-cold PBS. Cells were suspended in cytoplasmic buffer $(10 \mathrm{mM}$ Tris$\mathrm{HCl}$; $\mathrm{pH} 7.6 / 10 \mathrm{mM} \mathrm{KCl} / 1.5 \mathrm{mM} \mathrm{MgCl} / 1 \%$ TritonX-100/ 1mM dithiothreitol / $0.2 \mathrm{mM} \mathrm{Na}$ orthovanadate/ $0.4 \mathrm{mM}$ phenylmethyl sulfonyl fluoride/ $10 \mu \mathrm{g} / \mathrm{ml}$ Leupeptin/ $0.2 \mathrm{mM} \mathrm{NaF}$ ), vortexed vigorously and placed on ice for $15 \mathrm{~min}$. Then cell nuclei were spun down for $5 \mathrm{~min}$ at $10,000 \mathrm{~g}$ at $4^{\circ} \mathrm{C}$. Supernatant was transferred to a new tube and cell nuclei were washed once in cytoplasmic buffer by suspending, vortexing and centrifugation. The supernatant was dis- 
carded, and cell nuclei were suspended in nuclear buffer $(20 \mathrm{mM}$ Tris- $\mathrm{HCl}$; $\mathrm{pH} 7.6 / 0.4 \mathrm{mM} \mathrm{KCl} / 1.5 \mathrm{mM} \mathrm{MgCl} / 10 \%$ glycerol/ $1 \mathrm{mM}$ dithiothreitol/ $0.2 \mathrm{mM} \mathrm{Na}$ orthovanadate/ $0.4 \mathrm{mM}$ phenylmethyl sulfonyl fluoride/ $10 \mu \mathrm{g} / \mathrm{ml}$ Leupeptin/ $0.2 \mathrm{mM} \mathrm{NaFI}$ ). Cells were placed in a vertical rotator at $4^{\circ} \mathrm{C}$ for 30 minutes followed by centrifuging for $20 \mathrm{~min}$ at $14,000 \mathrm{~g}$ at $4^{\circ} \mathrm{C}$. Supernatant containing the nuclear proteins was transferred to new tube. A portion of the supernatant was saved for protein determination, prior to the addition of $4 x$ Laemmli sample buffer $(0.25 \mathrm{M}$ Tris-HCl pH 6.8, 8\% (w/v) SDS, 40\% (v/v) glycerol, 0.4M DTT and $0.04 \%(\mathrm{w} / \mathrm{v})$ Bromophenol Blue). Next, samples were boiled for 5 minutes and stored at $-20^{\circ} \mathrm{C}$.

Western Blot analysis Protein concentrations were determined using the Bradford protein Assay according to manufacturer's protocol (Bio-Rad, Hercu-

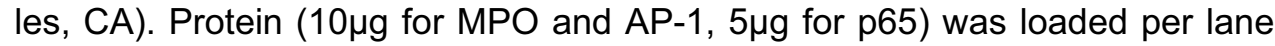
and separated on a polyacrylamide gel (Mini Protean 3 System, Bio-Rad), followed by transfer to a $0.45 \mu \mathrm{m}$ nitrocellulose membrane (Bio-Rad) by electroblotting. The membrane was blocked for 1 hour at room temperature in $5 \%$ $(\mathrm{w} / \mathrm{v})$ non-fat, dried milk diluted in TBS-Tween20 (0.05\%). Nitrocellulose blots were washed in TBS-Tween20 $(0.05 \%)$, followed by overnight $(\mathrm{o} / \mathrm{n})$ incubation $\left(4^{\circ} \mathrm{C}\right)$ with primary antibody (rabbit anti-MPO (0398, DAKO); rabbit anti-p65 (C20 sc-372, Santa Cruz Biotechnology, Santa Cruz, CA); rabbit anti-phospho cJun (Ser63) II (9261, Cell Signaling, MA)). After 3 washes of 20 minutes each, the blots were probed with HRP-conjugated anti-rabbit antibody (PI-1000, Vector Laboratories, Burlingame, CA) and visualized by chemiluminesence using Supersignal $囚 W e s t P i c o$ Chemiluminescent Substrate (Pierce Biotechnology, Rockford, IL) according to manufacturers' instructions and exposed to film (Biomax light film, KODAK).

Quantitative PCR detection of HO-1 and IL-8 expression Whole cell RNA was isolated using the RNeasy Mini Kit (Qiagen Inc., CA) according to manufacturer's protocol. Total RNA was reverse transcribed, using the Abgene Kit (Abgene, Epsom, UK) with random hexamer primers, and the resulting cDNA was amplified by real-time PCR using the MJ Research Opticon 2 (Biorad, Hercules, CA) with the following primers:
$\mathrm{HO}-1$
(F) 5'-CCAGCAACAAAGTGCAAGATTC-3' ;
(R) 5'-CTGCAGGAACTGAGGATGCTG-3' ;
IL-8
(F) 5' GGACAAGAGCCAGGAAGAAA 3';
$\beta$-actin
(R) 5' AAATTTGGGGTGGAAAGGTT 3' ;
(F) 5'-GGGACCTGACCGACTACCTC' ;
(R) 5'GGGCGATGATCTTGATCTTC'.

Each PCR reaction contained 1x SYBR $®$ Green PCR master mix (Applied Biosystems, Foster City, CA) and $0.3 \mu \mathrm{M}$ each of forward and reverse primer. Following an initial $10 \mathrm{~min}$ incubation at $95^{\circ} \mathrm{C}$, thermal cycling was performed using 45 cycles of $94^{\circ} \mathrm{C}$ for $15 \mathrm{sec}, 60^{\circ} \mathrm{C}$ for $30 \mathrm{sec}$ and $72^{\circ} \mathrm{C}$ for $30 \mathrm{sec}$. Gene expression was quantified using standard curves for the respective cDNA 
products. All changes in HO-1 and IL-8 CDNA levels were normalized to changes in $\beta$-actin cDNA.

Single cell gel electrophoresis (Comet assay) DNA strand breakage in epithelial cell preparations was assayed immediately after cell-isolation by the Comet assay. Fully frosted slides were coated with agarose and stored overnight at $4^{\circ} \mathrm{C}$. Epithelial lung cells were isolated by trypsinization, spun down and resuspended in $20 \mu \mathrm{l}$ cold PBS. Cells were mixed with $70 \mu \mathrm{l} 0.5 \%$ low melting point agarose, and added to the slides, on top of the first agarose layer using a cover glass. Slides were stored at $4^{\circ} \mathrm{C}$ for 3 minutes to allow solidification, cover glasses were removed and slides were immersed in lysis buffer $(2.5 \mathrm{M} \mathrm{NaCl} / 100 \mathrm{mM}$ EDTA/ $10 \mathrm{mM}$ Tris-base/ $250 \mathrm{mM} \mathrm{NaOH}$; $\mathrm{pH} 10)$ and stored overnight at $4^{\circ} \mathrm{C}$. The following day, slides were rinsed with distilled water and placed in an electrophoresis tank filled with ice-cold electrophoresis buffer $(300 \mathrm{mM} \mathrm{NaOH} / 1 \mathrm{mM}$ EDTA, $\mathrm{pH} 13)$ for $20 \mathrm{~min}$. Electrophoresis was conducted at $300 \mathrm{~mA}$ and $25 \mathrm{~V}$ for $20 \mathrm{~min}$. Slides were neutralized $3 \times 10 \mathrm{~min}$ using neutralization buffer $(0.4 \mathrm{M}$ Tris, $\mathrm{pH} 7.5)$. All steps after cell lysis were performed in the dark or under dimmed red light to prevent additional DNA damage.

ELISA IL-6 and IL-8 protein levels in culture supernatants were assayed in triplicate using ELISA kits specific for IL-6 and IL-8 (Sanquin, Amsterdam, the Netherlands) according to the manufacturer's instructions. The lower detection limit of IL-6 was $3.8 \mathrm{pg} / \mathrm{ml}$ and $9.0 \mathrm{pg} / \mathrm{ml}$ for IL-8.

Statistical analyses Data are expressed as Mean \pm SEM, unless stated otherwise. Statistical comparisons among experimental groups were performed with analysis of variance (ANOVA). Differences were considered to be statistically significant when $p \leq 0.05$.

\section{RESULTS}

\section{MPO uptake by human bronchial and alveolar epithelial cells}

Bronchial (Beas-2B) as well as alveolar (A549) epithelial cells were stimulated with MPO to determine the time frame of MPO internalization by these cells. Immunofluorescense staining demonstrated MPO protein on A549 and Beas2B cells (Figure 1A) after 24 hours of stimulation. Western blot analysis (Figure 1B) of cytoplasmic protein fractions showed that MPO was detectable in A549 cells after 30 minutes of stimulation and was still internalized after 24 hours of stimulation. In contrast to A549 cells, MPO content in Beas-2B cells peaked after 4 hours of stimulation and was decreased again after 24 hours. Priming of the cells with either LPS or PMA did not have an effect on intracellular levels of MPO (data not shown). To confirm our in vitro data on MPO uptake by lung epithelial cells, MPO was localized in human lung sections of patients with pulmonary neutrophilia suffering from COPD, acute broncho pneumonia and asbestosis. 
A. $\mathbf{A 5 4 9}$

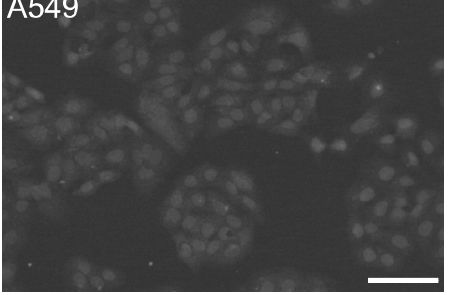

\section{A549}

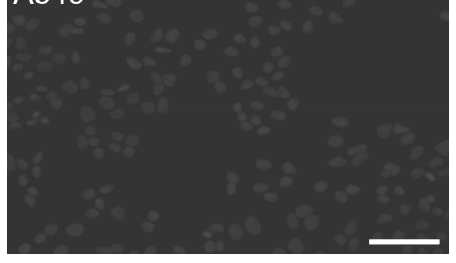

B. $\mathrm{A} 549$

Beas-2B

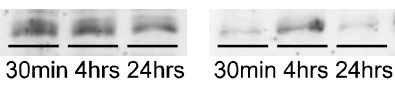

C.

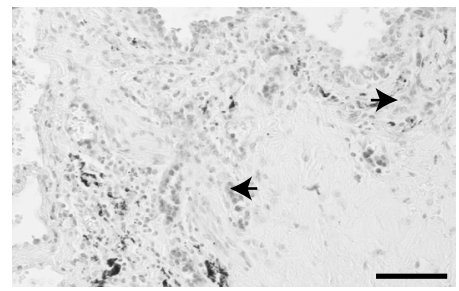

D.

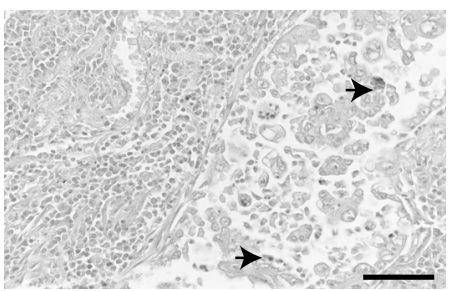

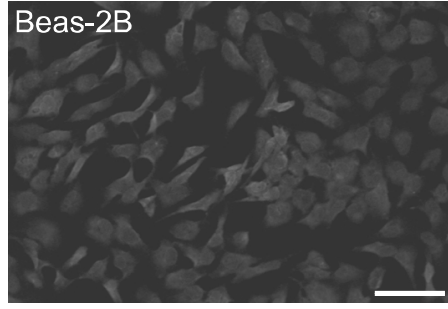

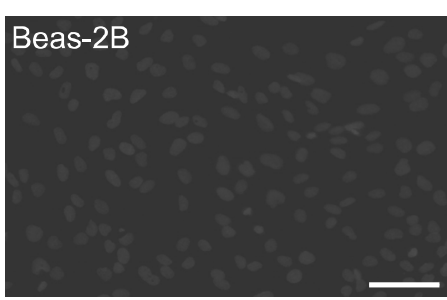

Figure 1: Localization of myeloperoxidase (MPO) in A549 and Beas-2B cells after MPO stimulation and immunohistochemical detection of MPO in human lung sections of patients with chronic obstructive pulmonary disease, acute broncho pneumonia or asbestosis. (A) Positive immunofluorescence staining of MPO on A549 and Beas-2B cells after 24 hours of MPO (40nM) stimulation (top). A549 cells show a diffuse staining pattern, whereas Beas-2B cells show a cytoplasmic staining but no nuclear staining. Untreated A549 and Beas-2B cells do not show MPO staining (bottom). Staining from one representative picture is shown. (B) Western blot analyses of MPO (1nM) stimulated A549 and Beas-2B cells showed that MPO was present in cell cytoplasm $30 \mathrm{~min}$ -

utes after MPO stimulation, but did not accumulate after 24 hours. Representative immunostaining for MPO on human lung sections of $(C)$ chronic obstructive pulmonary disease and $(D)$ asbestosis. Alveolar epithelial cells $(\leftarrow)$ in close proximity to degranulated neutrophils stained positive for MPO. Endothelial cells ( $)$ nearby intravascular un-degranulated neutrophils stained negative for MPO. (A) Internal scale bar $=25 \mu \mathrm{M}$. (C-D) Internal scale bar $=50 \mu \mathrm{M}$. 
Table I: Subject characteristics of patients with acute broncho pneumonia, chronic obstructive pulmonary disease or asbestosis

\begin{tabular}{|c|c|c|c|c|}
\hline & $\begin{array}{c}\text { Age, } \\
\text { years }\end{array}$ & $\begin{array}{c}\text { Gender, } \\
\mathrm{M} / \mathrm{F}\end{array}$ & $\begin{array}{c}\text { Smoking } \\
\text { status }\end{array}$ & Tissue collection \\
\hline COPD 1 & 70 & $\mathrm{M}$ & ex & LVRS \\
\hline COPD 2 & 73 & $\mathrm{M}$ & current & Tumor Resection \\
\hline COPD 3 & 66 & $\mathrm{M}$ & ex & Tumor Resection \\
\hline ABP 1 & 75 & $\mathrm{M}$ & ex & Tumor Resection \\
\hline ABP 2 & 72 & $\mathrm{M}$ & ex & Tumor Resection \\
\hline Asbestosis 1 & 51 & $\mathrm{M}$ & unknown & Tumor Resection \\
\hline Asbestosis 2 & 70 & $\mathrm{M}$ & unknown & Tumor Resection \\
\hline Asbestosis 3 & 77 & $\mathrm{M}$ & unknown & Tumor Resection \\
\hline
\end{tabular}

ABP: Acute Broncho Pneumonia; M: male; Exsmoker: quitting smoking for at least 6 months before the start of the study; LVRS: lung volume reduction surgery.

MPO exposure after primary stimulus results in increased oxidative stress

To investigate the influence of MPO on oxidative stress as a result of proinflammatory stimuli, cells were stimulated with MPO alone or primed with PMA, LPS, or crocidolite or chrysotile asbestos, followed by stimulation with MPO. MPO exposure of A549 (Figure 2A) and Beas-2B (Figure 2B) cells resulted in an increased $\mathrm{HO}-1$ expression, an indirect marker of oxidative stress. LPS was the only pro-inflammatory stimulus, besides from MPO, which could induce HO-1 expression significantly in A549 cells. MPO stimulation of cells primed with PMA or asbestos resulted in a significant increase of HO-1 expression as compared to priming control A549 cells (Figure 2A). In Beas-2B cells only asbestos priming resulted in increased $\mathrm{HO}-1$ expression. Asbestos priming followed by MPO stimulation had a synergistic effect on $\mathrm{HO}-1$ expression in Beas-2B cells (Figure 2B). 
A.

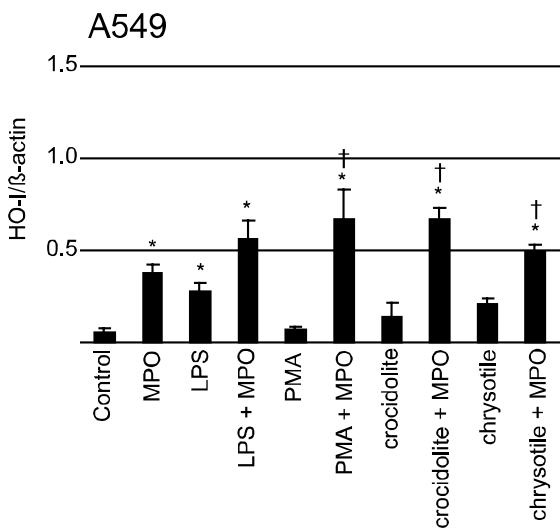

B.

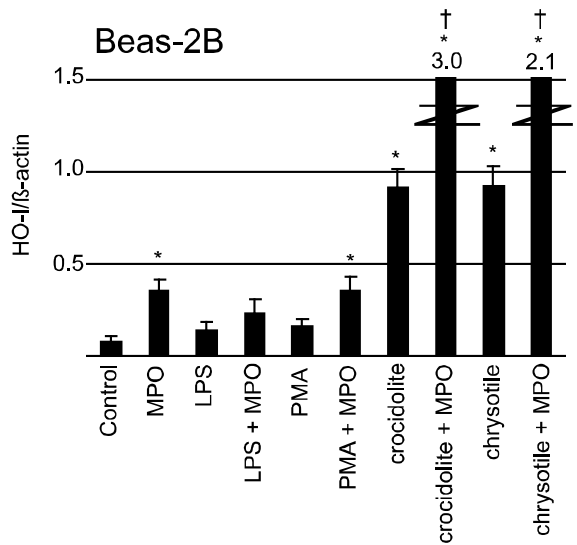

Figure 2: Quantitative PCR analysis of heme-oxygenase 1 (HO-1) messenger RNA after myeloperoxidase (MPO) stimulation in A549 (A) and Beas-2B (B) cells under basal and proinflammatory conditions. Cells were stimulated with MPO $(10 \mathrm{nM})$ for 24 hours, or primed for 12 hours with lipopolysaccharide (LPS) $(3 \mu \mathrm{g} / \mathrm{ml})$, Phorbol 12-myristate 13-acetate (PMA) (A549:10ng/ml, Beas-2B:20ng/ml) or asbestos $\left(6.25 \mu \mathrm{g} / \mathrm{cm}^{2}\right)$ followed by 12 hour MPO stimulation. (A) Stimulation with MPO increased HO-1 expression in A549 cells. Stimulation with MPO after pre-stimulation with PMA or asbestos, increased $\mathrm{HO}-1$ expression even further. (B) MPO stimulation of Beas-2B cells resulted in up-regulation of $\mathrm{HO}-1$ expression. Priming the cells with PMA or asbestos followed by of MPO stimulation resulted in a significant further increase of HO-1 expression. Representative data of 2 individual experiments are shown. Values are normalized against $\beta$-actin expression (mean \pm SEM). * $p \leq 0.05$ versus unstimulated cells. $\dagger p \leq 0.05$ versus primed control.

\section{MPO stimulation increases DNA damage}

MPO produces damaging reactive oxidants, like $\mathrm{HOCl}$ and $\mathrm{NO}_{2}$. The COMET assay was used to detect DNA strand break formation in lung epithelial cells after MPO exposure. MPO exposure resulted in a temporary increase in DNA strand breakage in both A549 (Figure 3A) and Beas-2B (Figure 3B) cells, starting 10 minutes after MPO exposure. DNA damage increased significance after 20 min and 30 minutes after MPO exposure the DNA strand breakage started to decline. 

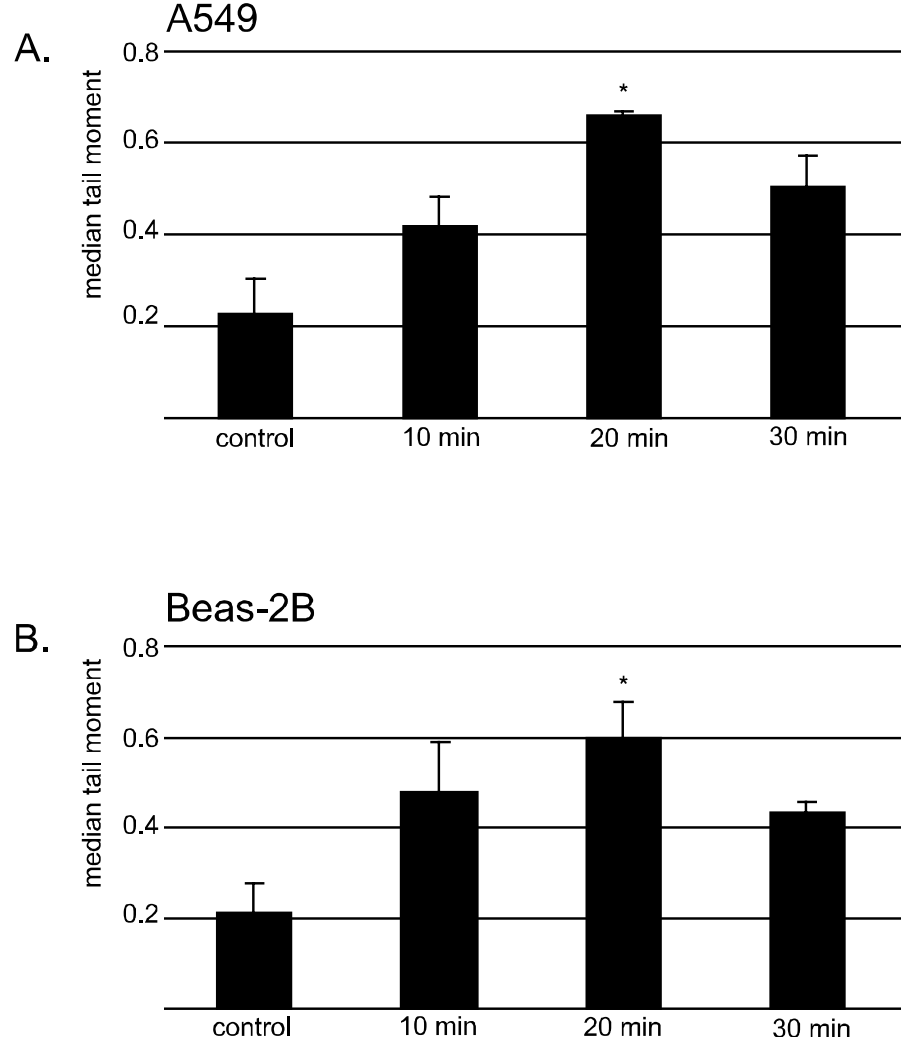

Figure 3: COMET assay analysis of DNA strand breakage after myeloperoxidase (MPO) stimulation in A549 (A) and Beas-2B (B) cells. MPO (40nM) exposure increases DNA strand breakage in both cell lines. A significant increase was reached after $20 \mathrm{~min}$ of MPO stimulation, and the level of DNA damage declined thereafter. Representative data of 3 individual experiments are shown. Values are graphed as median tail length (mean \pm SEM). * $p \leq 0.05$ versus unstimulated cells.

\section{IL-8 and IL-6 production are decreased after MPO stimulation of Beas-2B cells}

To investigate the influence of MPO on IL-8 and IL-6 production under basal and pro-inflammatory conditions, cells were primed with PMA, LPS, crocidolite or chrysotile asbestos or medium alone, and followed by stimulation with MPO. Figure 4A demonstrates that all pro-inflammatory stimuli caused an increase in IL-8 production by Beas-2B cells. Stimulation with MPO alone or after priming with PMA decreased IL-8 production significantly. These significant results were confirmed by analysis of IL-8 expression levels by Q-PCR (Figure 4B). IL-6 production by Beas-2B cells demonstrated a similar pattern as IL-8, although decreases were not significant (Figure 4C). MPO exposure of A549 cells, under basal and inflammatory conditions, did not influence IL-8 production, and IL-6 production was undetectable (data not shown). 
A.

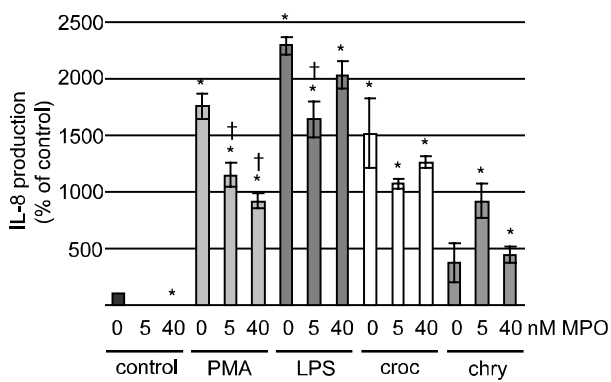

C.

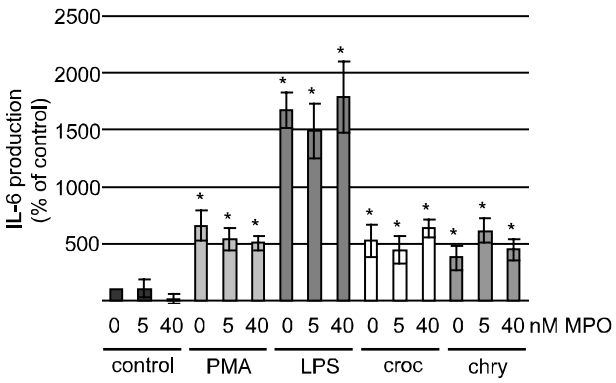

B

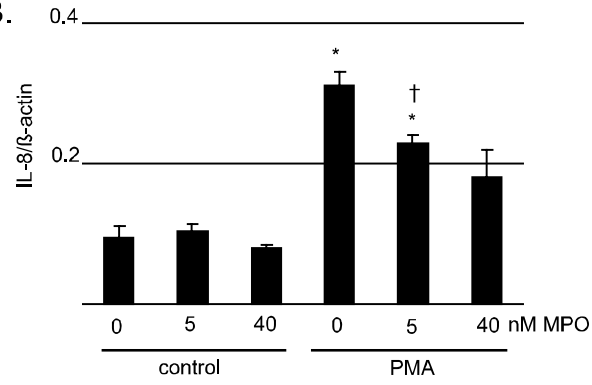

Figure 4: Detection of interleukin (IL)-8 production (ELISA) and expression (Q$\mathrm{PCR}$ ) and IL-6 production (ELISA) by Beas-2B cells under basal and proinflammatory conditions. Cells were stimulated with myeloperoxidase (MPO) for 24 hours, or primed for 24 hours with lipopolysaccharide (LPS) $(3 \mu \mathrm{g} / \mathrm{ml})$, Phorbol 12myristate 13-acetate (PMA) (A549:10 $\mathrm{ng} / \mathrm{ml}$, Beas-2B:20ng/ml) or asbestos $\left(6.25 \mu \mathrm{g} / \mathrm{cm}^{2}\right)$ followed by 24 hour MPO stimulation. (A) IL-8 production by Beas-2B cells is significantly decreased after MPO (40nM) stimulation alone or after priming with PMA followed by MPO stimulation. (B) ELISA results were confirmed by Q-PCR analysis of IL-8 expression after MPO stimulation alone or after priming with PMA followed by MPO stimulation. IL-8 expression levels are normalized against $\beta$-actin expression. (C) IL- 6 production by Beas-2B cells showed a similar pattern as IL-8, but the decreases were not significant. Croc $=$ crocidolite, Chry = chrysotile. Representative data of 3 individual experiments are shown. Values are graphed as percentage of unstimulated control $\left(=100 \%\right.$ ) (mean \pm SEM). ${ }^{*} p \leq 0.05$ versus unstimulated cells. $\dagger p \leq 0.05$ versus primed control.

\section{Activation of cell signaling pathways following cell stimulation}

The promoter regions of HO-I, IL-8 and IL-6 have binding sites for the transcription factors AP-1 and NF-KB. To investigate if MPO affects HO-I expression and IL-8 and IL-6 production via the transcription factor AP-1 and NF-KB in lung epithelial cells, A549 and Beas-2B cells were stimulated with LPS, PMA, asbestos or MPO, and AP-1 and NF-KB transcriptional activity was determined by western blot analyses. A 60 min stimulation of A549 cells with MPO did not affect transcriptional activity of either AP-1 or NF-kB (Figure 5A) or Beas-2B cells (data not shown).

Increased activity of NF-kB, measured by Rel A translocation, in A549 (Figure $5 B$ ) and Beas-2B cells (data not shown) was found after 60 min stimulation with LPS, PMA or crocidolite asbestos. 
A.

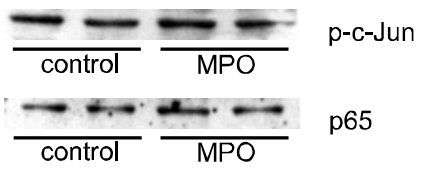

B.

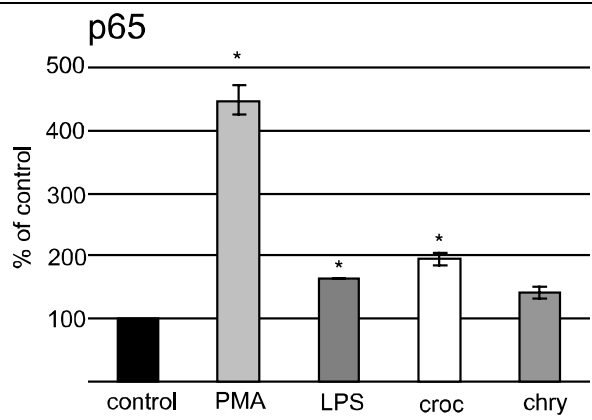

Figure 5: Western blot detection of Rel A and p-c-Jun in A549 cells. (A) Myeloperoxidase (MPO) (10nM) stimulation for 60 min did not increase Rel A translocation or c-Jun phosphorylation in A549 cells. (B) Rel A translocation is increased in A549 cells after 60 min stimulation with Phorbol 12-myristate 13-acetate (PMA) $(10 \mathrm{ng} / \mathrm{ml})$, lipopolysaccharide (LPS) $(3 \mu \mathrm{g} / \mathrm{ml})$ or asbestos $(6.25 \mu \mathrm{g} / \mathrm{cm} 2)$. Representative data of 2 individual experiments are shown. Croc $=$ crocidolite, Chry $=$ chrysotile. Signal intensity was determined with Phosphor Imager analysis, and expressed as relative (\%) to control. Values are graphed as mean \pm SEM. * $p \leq 0.05$ versus unstimulated cells.

\section{DISCUSSION}

The heme protein, MPO, is the most abundant protein in neutrophils (6) and therefore an important enzyme in innate immunity (10). More recently, MPO has been shown to elicit pro-inflammatory properties independent of its catalytic properties. We are the first to report here the effects of MPO on human lung epithelial cells and their responses in the absence or presence of an initial inflammatory trigger.

Using two techniques we demonstrate MPO uptake by bronchial and alveolar epithelium after MPO stimulation. Beas-2B cells showed similar staining patterns as small airway epithelial cells, reported by Yang (15), demonstrating MPO in the cytoplasm, but not in the nucleus. In contrast, A549 cells do not show a pronounced lack of nuclear staining. This suggests that MPO distribution after uptake varies between cell types. Neutrophils go through several stages of activation during the extravasation process. The majority of MPO content of neutrophils is released during the oxidative burst of neutrophils when neutrophils are fully activated and have entered a site of inflammation (16). With immunostaining of human lung tissue from COPD, acute broncho pneumonia and asbestosis patients with active neutrophilia we confirm our in vitro data and demonstrate that, not only epithelial cells but all cells in close proximity to activated and degranulated neutrophils are possible target cells for MPO. This is in line with literature describing MPO uptake by other cell types like fibroblasts (17) and endothelial cells (18).

The enzymatic activity of MPO results in the formation of $\mathrm{HOCl}$, which is a potent oxidant with cell damaging capacities. We demonstrate here an increase in lung epithelial cell DNA damage after incubation with purified MPO. This DNA damage is most likely due to $\mathrm{HOCl}$ production by $\mathrm{MPO}$. $\mathrm{HOCl}$ related normal bronchial epithelial cell damage has been reported before (19) and confirms our data using the COMET assay. In contrast to our findings, a 
decrease in DNA damage was observed when MPO was added to cell cultures provided with an $\mathrm{H}_{2} \mathrm{O}_{2}$ generating system (20). However, neutrophils and macrophages used in this study (20) produce reactive oxidant species themselves. It can therefore be speculated that these cell types are better protected against oxidative damage than lung epithelium, since lung epithelial cells do probably not produce reactive oxidants at the same magnitude as neutrophils and macrophages (21).

HO-1 is an important cytoprotective enzyme and widely accepted indirect marker of oxidative stress. Our data show an increase in $\mathrm{HO}-1$ expression by bronchial and alveolar epithelial cells after MPO stimulation. We first reported that crocidolite asbestos exposure leads to a significant increase of $\mathrm{HO}-1$ expression in human mesothelial cells (22), and this has recently been confirmed in an animal model (23). Here we show that both crocidolite and chrysotile, an iron-free asbestos, stimulate HO-1 expression in Beas-2B cells. More striking was the finding of a synergistic effect of MPO stimulation after asbestos priming on $\mathrm{HO}-1$ expression in both cell lines, which was not demonstrated with LPS or PMA. We speculate that $\mathrm{O}_{2}{ }^{-}$or $\mathrm{H}_{2} \mathrm{O}_{2}$ released by frustrated phagocytosis of long asbestos fibers $(24,25)$ synergize with nitrosating or oxygen free radicals produced by MPO.

We demonstrate here an increase in IL-8 and IL-6 production, both involved in the development of inflammation, after PMA or asbestos stimulation confirming published literature $(26,27,28)$. Here we show for the first time that MPO stimulation of PMA primed Beas-2B cells results in a significant decrease of IL8 production and a trend towards decreased IL- 6 production by Beas-2B cells. Novel as well are our data demonstrating that under basal conditions MPO can inhibit the production of IL-8 by Beas-2B cells. This may indicate a negative feedback loop for neutrophil recruitment. Cytokine production by A549 and Beas-2B cells is a serum dependent event as described previously (29), and because we performed our experiments under low serum conditions, this may explain why we were unable to detect basal production of IL-6 by A549 cells.

Since IL-8 and IL-6 are both known to be NF-KB and AP-1 regulated genes $(30,31)$, and the $\mathrm{HO}-1$ promoter region contains NF-KB and AP-1 binding sites, we hypothesized that MPO stimulation of A549 and Beas-2B would affect NF-kB or AP-1 transcriptional activity. To our surprise, neither NF-kB nor $A P-1$ was affected by MPO stimulation, although increases in NF-kB activity were observed with asbestos, LPS and PMA. We have reported previously that both NF-KB and AP-1 activity increases after exposure to crocidolite asbestos $(32,33)$ and NF-KB activity also has been demonstrated in lung epithelium after instillation of LPS (34). More research needs to be done to investigate the transcriptional mechanisms underlying $\mathrm{HO}-1$ expression and cytokine production after exposure of lung epithelial cells to MPO. Other candidate transcription factors involved in $\mathrm{HO}-\mathrm{I}$ expression are NrF2, Bach-1 and HIF-1 $\alpha$ (25).

This study puts forward novel mechanisms of MPO action, which may be important in the development of lung neutrophilia. A limitation of the study is however the use of epithelial cell lines, which may have lost some of their in 
vivo properties. Therefore, future studies using primary epithelial cell cultures as well as studies using in vivo models of acute lung inflammation will be necessary to investigate the role of MPO in the development of neutrophilic lung inflammation. For example studies using $\mathrm{Mpo}^{-/}$vs. WT mice have demonstrated a role for MPO in a chrysotile asbestos induced model of lung inflammation. The recruitment of neutrophils was significantly delayed in $\mathrm{Mpo}^{-/}$as compared to WT mice (35). In summary, the present study demonstrates that lung epithelial cells in close proximity to fully activated and degranulated neutrophils are possible target cells for MPO. In these cell types, MPO induced the expression of HO-I and increased DNA strand breakage, but has inhibitory effect on the production of pro-inflammatory chemokines IL-6 and IL-8 during homeostasis and secondary to PMA exposure.

\section{ACKNOWLEDGEMENTS}

The authors would like to thank Marco Kelders (Department of Respiratory Medicine, University Hospital Maastricht) for his technical assistance, RobertJan van Suylen (Department of Pathology, University Hospital Maastricht) for histological advice and Erik Verbeken (Department of Morphology and Molecular Pathology, Leuven University) for material support. P. Heeringa is supported by a grant from the Dutch Organization of Scientific Research (NWO VIDI grant 917.66.341). 


\section{REFERENCES}

1. Peleman, R. A., P. H. Rytila, J. C. Kips, G. F. Joos, and R. A. Pauwels. 1999. The cellular composition of induced sputum in chronic obstructive pulmonary disease. Eur Respir J 13:839.

2. Mossman, B. T., and A. Churg. 1998. Mechanisms in the pathogenesis of asbestosis and silicosis. Am J Respir Crit Care Med 157:1666.

3. Hunninghake, G. W., J. E. Gadek, T. J. Lawley, and R. G. Crystal. 1981. Mechanisms of neutrophil accumulation in the lungs of patients with idiopathic pulmonary fibrosis. J Clin Invest 68:259.

4. Tate, R. M., and J. E. Repine. 1983. Neutrophils and the adult respiratory distress syndrome. Am Rev Respir Dis 128:552.

5. Medan, D., L. Wang, X. Yang, S. Dokka, V. Castranova, and Y. Rojanasakul. 2002. Induction of neutrophil apoptosis and secondary necrosis during endotoxin-induced pulmonary inflammation in mice. J Cell Physiol 191:320.

6. Klebanoff, S. J. 2005. Myeloperoxidase: friend and foe. J Leukoc Biol 77:598.

7. Kawano, S., E. Tatsumi, N. Yoneda, S. Nagata, and N. Yamaguchi. 1993. Suppression of gene expression of myeloperoxidase (MPO) by gamma-interferon (IFN-gamma) in HL60 cells. Lymphokine Cytokine Res 12:81.

8. Nauseef, W. M. 1988. Myeloperoxidase deficiency. Hematol Oncol Clin North Am 2:135.

9. Tobler, A., C. W. Miller, K. R. Johnson, M. E. Selsted, G. Rovera, and H. P. Koeffler. 1988. Regulation of gene expression of myeloperoxidase during myeloid differentiation. J Cell Physiol 136:215.

10. Klebanoff, S. J. 1999. Myeloperoxidase. Proc Assoc Am Physicians 111:383.

11. Gujral, J. S., J. A. Hinson, and H. Jaeschke. 2004. Chlorotyrosine protein adducts are reliable biomarkers of neutrophil-induced cytotoxicity in vivo. Comp Hepatol 3 Suppl $1: S 48$.

12. Van Der Vliet, A., M. N. Nguyen, M. K. Shigenaga, J. P. Eiserich, G. P. Marelich, and C. E. Cross. 2000. Myeloperoxidase and protein oxidation in cystic fibrosis. Am J Physiol Lung Cell Mol Physiol 279:L537.

13. Lau, D., H. Mollnau, J. P. Eiserich, B. A. Freeman, A. Daiber, U. M. Gehling, J. Brummer, V. Rudolph, T. Munzel, T. Heitzer, T. Meinertz, and S. Baldus. 2005. Myeloperoxidase mediates neutrophil activation by association with CD11b/CD18 integrins. Proc Natl Acad Sci U S A 102:431.

14. Lefkowitz, D. L., K. C. Mills, N. Moguilevsky, A. Bollen, A. Vaz, and S. S. Lefkowitz. 1993. Regulation of macrophage function by human recombinant myeloperoxidase. Immunol Lett 36:43.

15. Yang, J. J., G. A. Preston, W. F. Pendergraft, M. Segelmark, P. Heeringa, S. L. Hogan, J. C. Jennette, and R. J. Falk. 2001. Internalization of proteinase 3 is concomitant with endothelial cell apoptosis and internalization of myeloperoxidase with generation of intracellular oxidants. Am J Pathol 158:581.

16. Faurschou, M., and N. Borregaard. 2003. Neutrophil granules and secretory vesicles in inflammation. Microbes Infect 5:1317.

17. Zabucchi, G., M. R. Soranzo, R. Menegazzi, P. Bertoncin, E. Nardon, and P. Patriarca. 1989. Uptake of human eosinophil peroxidase and myeloperoxidase by cells involved in the inflammatory process. J Histochem Cytochem 37:499.

18. Tiruppathi, C., T. Naqvi, Y. Wu, S. M. Vogel, R. D. Minshall, and A. B. Malik. 2004. Albumin mediates the transcytosis of myeloperoxidase by means of caveolae in endothelial cells. Proc Natl Acad Sci U S A 101:7699.

19. Kampf, C., and G. M. Roomans. 2001. Effects of hypochlorite on cultured respiratory epithelial cells. Free Radic Res 34:499.

20. Schraufstatter, I., P. A. Hyslop, J. H. Jackson, and C. G. Cochrane. 1988. Oxidantinduced DNA damage of target cells. J Clin Invest 82:1040.

21. Hansen, K., and B. T. Mossman. 1987. Generation of superoxide (O2-.) from alveolar macrophages exposed to asbestiform and nonfibrous particles. Cancer Res 47:1681. 
22. Janssen, Y. M., J. P. Marsh, M. P. Absher, E. Gabrielson, P. J. Borm, K. Driscoll, and B. T. Mossman. 1994. Oxidant stress responses in human pleural mesothelial cells exposed to asbestos. Am J Respir Crit Care Med 149:795.

23. Nagatomo, H., Y. Morimoto, T. Oyabu, M. Hirohashi, A. Ogami, H. Yamato, K. Kuroda, T. Higashi, and I. Tanaka. 2005. Expression of heme oxygenase-1 in the lungs of rats exposed to crocidolite asbestos. Inhal Toxicol 17:293.

24. Dennery, P. A. 2000. Regulation and role of heme oxygenase in oxidative injury. Curr Top Cell Regul 36:181.

25. Ryter, S. W., and A. M. Choi. 2005. Heme oxygenase-1: redox regulation of a stress protein in lung and cell culture models. Antioxid Redox Signal 7:80.

26. Kang, W., O. Nielsen, C. Fenger, J. Madsen, S. Hansen, I. Tornoe, P. Eggleton, K. B. Reid, and U. Holmskov. 2002. The scavenger receptor, cysteine-rich domain-containing molecule gp-340 is differentially regulated in epithelial cell lines by phorbol ester. Clin Exp Immunol 130:449.

27. Simeonova, P. P., and M. I. Luster. 1996. Asbestos induction of nuclear transcription factors and interleukin 8 gene regulation. Am J Respir Cell Mol Biol 15:787.

28. Simeonova, P. P., W. Toriumi, C. Kommineni, M. Erkan, A. E. Munson, W. N. Rom, and M. I. Luster. 1997. Molecular regulation of IL-6 activation by asbestos in lung epithelial cells: role of reactive oxygen species. J Immunol 159:3921.

29. Schulz, C., L. Farkas, K. Wolf, K. Kratzel, G. Eissner, and M. Pfeifer. 2002. Differences in LPS-induced activation of bronchial epithelial cells (BEAS-2B) and type II-like pneumocytes (A-549). Scand J Immunol 56:294.

30. Li, L. F., B. Ouyang, G. Choukroun, R. Matyal, M. Mascarenhas, B. Jafari, J. V. Bonventre, T. Force, and D. A. Quinn. 2003. Stretch-induced IL-8 depends on C-Jun NH2terminal and nuclear factor-kappaB-inducing kinases. Am J Physiol Lung Cell Mol Physiol 285:L464.

31. Zhang, Y., M. Broser, and W. N. Rom. 1994. Activation of the interleukin 6 gene by Mycobacterium tuberculosis or lipopolysaccharide is mediated by nuclear factors NF-IL6 and NF-kappa B. Proc Natl Acad Sci U S A 91:2225.

32. Heintz, N. H., Y. M. Janssen, and B. T. Mossman. 1993. Persistent induction of c-fos and c-jun expression by asbestos. Proc Natl Acad Sci U S A 90:3299.

33. Janssen, Y. M., A. Barchowsky, M. Treadwell, K. E. Driscoll, and B. T. Mossman. 1995. Asbestos induces nuclear factor kappa B (NF-kappa B) DNA-binding activity and NFkappa B-dependent gene expression in tracheal epithelial cells. Proc Natl Acad Sci U S A 92:8458.

34. Poynter, M. E., C. G. Irvin, and Y. M. Janssen-Heininger. 2003. A prominent role for airway epithelial NF-kappa B activation in lipopolysaccharide-induced airway inflammation. J Immunol 170:6257.

35. Haegens, A., A. van der Vliet, K. J. Butnor, N. Heintz, D. Taatjes, D. Hemenway, P. Vacek, B. A. Freeman, S. L. Hazen, M. L. Brennan, and B. T. Mossman. 2005. Asbestos-induced lung inflammation and epithelial cell proliferation are altered in myeloperoxidase-null mice. Cancer Res 65:9670. 


\section{ASBESTOS-INDUCED LUNG INFLAMMATION AND EPITHELIAL CELL PROLIFERATION ARE ALTERED IN MYELOPEROXIDASE-NULL MICE}

Astrid Haegens, Albert van der Vliet, Kelly J. Butnor, Nicholas Heintz, Douglas Taatjes, David Hemenway, Pamela Vacek, Bruce A. Freeman, Stanley L. Hazen, Marie Luise Brennan and Brooke T. Mossman

Cancer Research

Vol 65, page 9670-9677, 2005 
Chapter 3 


\section{ABSTRACT}

Asbestos fibers are carcinogens causing oxidative stress and inflammation, but the sources and ramifications of oxidant production by asbestos are poorly understood. Here, we show that inhaled chrysotile asbestos fibers cause increased myeloperoxidase activity in bronchoalveolar lavage fluids (BALF) and myeloperoxidase immunoreactivity in epithelial cells lining distal bronchioles and alveolar ducts, sites of initial lung deposition of asbestos fibers. In comparison with sham mice, asbestos-exposed myeloperoxidase-null $\left(\mathrm{Mpo}^{-/}\right)$and normal $\left(\mathrm{MpO}^{+/+}\right)$mice exhibited comparable increases in polymorphonuclear leukocytes, predominately neutrophils, in BALF after 9 days of asbestos inhalation. Differential cell counts on BALF revealed decreased proportions of macrophages and increased lymphocytes in all mice exposed to asbestos, but numbers were decreased overall in asbestos-exposed myeloperoxidase-null versus normal mice. Asbestos-associated lung inflammation in myeloperoxidase-null mice was reduced $(p \leq 0.05)$ in comparison with normal asbestosexposed mice at 9 days. Decreased lung inflammation in asbestos-exposed myeloperoxidase-null mice at 9 days was accompanied by increases $(p \leq 0.05)$ in Ki-67- and cyclin D1-positive immunoreactive cells, markers of cell cycle reentry, in the distal bronchiolar epithelium. Asbestos-induced epithelial cell proliferation in myeloperoxidase-null mice at 30 days was comparable to that found at 9 days. In contrast, inflammation and epithelial cell proliferation in asbestos-exposed normal mice increased over time. These results support the hypothesis that myeloperoxidase status modulates early asbestos-induced oxidative stress, epithelial cell proliferation, and inflammation. 


\section{INTRODUCTION}

Increases in polymorphonuclear leukocytes (PMN), predominantly neutrophils, are features of bronchoalveolar lavage fluid (BALF) samples and lung tissues in animal models of oxidant injury $(1,2,3)$ and in patients with inflammatory lung diseases such as asbestosis (4). Exposure to asbestos is also associated with the development of lung cancers and mesotheliomas, and inflammation is a hallmark of response to acute exposure to asbestos both in animals and humans $(5,6)$. One possible mediator of asbestos-associated inflammation is myeloperoxidase, a major constituent of neutrophils that generates hypochlorous acid $(\mathrm{HOCl})$ and reactive nitrogen species, including nitric oxide-derived inflammatory oxidants when nitrate and nitrite become available $(7,8)$. Nitration of tyrosine residues to 3-nitrotyrosine, a hallmark of inflammation as well as a footprint of many types of oxidative injury, may play a role in human lung disease (9) and is increased in the lungs of rats after asbestos inhalation (10). Myeloperoxidase can contribute to 3-nitrotyrosine formation in vivo and directly modulate inflammatory responses via regulation of nitric oxide bioavailability during inflammation $(11,12)$. Although myeloperoxidase seems to mediate host defense reactions through its microbicidal activity, its role in the development or modulation of inflammation after inhalation of exogenous oxidants is unclear. Moreover, how myeloperoxidase status affects the hyperplastic responses of lung epithelial cells that are critical to lung remodeling and/or carcinogenesis is of relevance to a broad realm of lung diseases.

After initial injury by airborne pathogenic fibers such as asbestos, epithelial cells undergo compensatory hyperplasia and metaplasia (13). Epithelial cell survival and re-epithelialization are thought to be critical to repair of the epithelium after damage, but unchecked epithelial cell proliferation may also be a risk factor in the development of lung cancers. Epithelial cells are also important contributors to chemokine and cytokine elaboration that may play a role in the inflammation of cancers, and fibroproliferative diseases of the lung (14).

Asbestos fibers induce localized oxidative stress through multiple mechanisms including impaired phagocytosis of longer $(>8 \mu \mathrm{m})$ fibers, by epithelial cells or alveolar macrophages, iron-dependent reactions occurring on the fiber surface, and by elicitation of an inflammatory response (15). After inhalation or intratracheal administration of asbestos fibers to rodents, an initial inflammatory response, characterized by increases in PMNs in BALF and lung tissues, is observed $(1,16-18)$. Increases in PMNs are also observed in the BALF and lungs of workers exposed to asbestos and individuals with a variety of pneumoconiosis $(19,20)$. The relationship between PMN influx and the development of lung inflammation or epithelial cell changes is not well understood.

Here, we used a well-characterized murine model of inflammation and bronchiolar epithelial cell proliferation (16) to show that brief inhalation of chrysotile asbestos causes increases in myeloperoxidase activity in BALF and immunoreactive protein in distal lung epithelium. We then compared the responses of myeloperoxidase-null ( $\mathrm{Mpo}^{-/-}$ref. 21) and normal $\left(\mathrm{MpO}^{+/+}\right)$mice at 9 and 30 days after initiation of asbestos inhalation. At these time points, both epithelial 
cell proliferation and inflammation are observed in this model (16). Our results show that asbestos-associated inflammation is delayed in myeloperoxidasenull mice. Moreover, the bronchiolar epithelial cells of asbestos-exposed myeloperoxidase-null mice exhibit significant increases in cyclin D1 immunoreactivity and Ki-67-positive epithelial cells, indications of proliferation and re-entry into the cell cycle at 9 days. These novel observations show that myeloperoxidase status affects patterns of acute inflammation and cell survival and/or proliferation, processes intrinsic to epithelial cell repair and hyperplasia.

\section{MATERIALS AND METHODS}

Myeloperoxidase assays To determine whether inhalation of asbestos caused release of myeloperoxidase into lavage fluids, a series of initial experiments were done on sham and asbestos-exposed C57BL/6 male mice (812 weeks old) obtained from Charles River (Wilmington, MA). Sham mice or those exposed to asbestos for 9 days ( $n=4-5 /$ group) were killed using an i.p. injection of sodium pentobarbital, and lungs lavaged with sterile $\mathrm{Ca}^{2+}$ - and $\mathrm{Mg}^{2+}$-free PBS (CMF-PBS) as described below in a total volume of $1 \mathrm{~mL}$. Fifteen micrograms of protein in $\sim 100 \mu \mathrm{L}$ of fresh bronchoalveolar lavage supernatant was immediately mixed with $100 \mu \mathrm{L}$ of fresh 3,3'-5,51tetramethylbenzidine reagent prepared from a stock solution of $300 \mathrm{mmol} / \mathrm{L}$ sodium acetate buffer $(\mathrm{pH} \mathrm{5.4),} 15 \mathrm{mmol} / \mathrm{L}$ tetramethylbenzidine prepared in dimethylformamide, and $60 \mathrm{mmol} / \mathrm{L} \mathrm{H}_{2} \mathrm{O}_{2}$. All chemicals were from Sigma (St. Louis, MO). The oxidation of tetramethylbenzidine by myeloperoxidase was measured at $630 \mathrm{~nm}$ over a 20-minute period, with readings every 5 minutes.

Myeloperoxidase-null $\left(\mathrm{Mpo}^{-/}\right)$mice Gene-targeted myeloperoxidase-null $\left(\mathrm{Mpo}^{-/}\right)$mice $(21)$ and normal $\left(\mathrm{Mpo}^{+/+}\right)$littermates were bred into the C57BL/6 background ( $>95 \%$ congenic) to allow direct comparison with our previous experiments using this strain (16). All mice were obtained from the animal facility of the University of Alabama at Birmingham and screened serologically for the absence of mouse hepatitis virus. Eight- to 12-week-old mice were housed and allowed to acclimate for 1 week in a HEPA-filtered clean air environment under controlled conditions of temperature, humidity, and light and provided food and water ad libitum before the initiation of inhalation exposures.

Inhalation protocol Previous time course experiments using chrysotile asbestos in inhalation experiments with $\mathrm{C} 57 \mathrm{BL} / 6$ mice showed that neutrophilic influx in BALF samples peaked at 10 days, whereas proliferation of bronchiolar epithelium and alveolar duct cells was maximal between 14 and 30 days (16). Based on these observations, $\mathrm{Mpo}^{-/-}$and normal $\left(\mathrm{Mpo}^{+/+}\right)$littermates were exposed to either ambient air or National Institutes of Environmental Health Sciences reference samples of chrysotile asbestos for 6 hours per day, 5 days a week, for a total of 9 or 30 days. The chemical and physical characteristics of National Institutes of Environmental Health Sciences chrysotile asbestos have been previously described (22). Asbestos fibers were aerosolized using a 
modified Timbrell generator to generate a target concentration of 7 to 10 $\mathrm{mg} / \mathrm{m}^{3}$ air, as previously described (23). Aerosol characteristics and concentrations were measured daily using a Sierra cascade impactor. All procedures were approved by the University of Vermont Institutional Animal Care and Use Committee.

Bronchoalveolar lavage procedures and assays on bronchoalveolar lavage fluids Following asbestos exposure for 9 days, four groups of mice ( $\mathrm{MpO}^{-}$ /- sham, $\mathrm{Mpo}^{+/+}$sham, $\mathrm{Mpo}^{-/}$asbestos, and $\mathrm{Mpo}^{+/+}$asbestos; $n=4 /$ group) received a lethal dose of pentobarbital, and the trachea was cannulated with polyethylene tubing. Lungs were then lavaged with sterile CMF-PBS in a total volume of $1 \mathrm{~mL}$. Total cells in bronchoalveolar lavage were enumerated, and 2 x $10^{4}$ cells were centrifuged onto glass slides at $800 \mathrm{rpm}$. Cytospins were stained using the Hema3 kit (Biochemical Sciences, Inc., Swedesboro, NJ), and differential cell counts were done on 500 cells/mouse. Total protein in BALF was determined on cell-free BALF supernatant stored at $-80^{\circ} \mathrm{C}$ with the Bio-Rad protein assay (Bio-Rad Laboratories, Hercules, CA). A lactate dehydrogenase assay to indicate lytic activity was done on BALF supernatant using the Cytotox 96 nonradioactive cytotoxicity assay (Promega, Madison, WI) according to the manufacturer's protocol. Results were quantified by spectrophotometry.

Histopathology and scoring of inflammation The lungs from additional mice ( $n=4 /$ group/time point) at both 9 and 30 days were instilled through the trachea with CMF-PBS at a constant pressure of $14 \mathrm{~cm} \mathrm{H} 2 \mathrm{O}$ and placed in $4 \%$ paraformaldehyde at $4^{\circ} \mathrm{C}$ overnight for fixation of the tissue before embedding of tissue blocks in paraffin. Lung sections were cut at a 5- $\mu \mathrm{m}$ thickness for immunohistochemistry as described below, or stained with H\&E. The 30-day lung sections were also stained using Masson's trichrome technique for the detection of collagen as an indication of fibrosis (16). Inflammation was scored by a certified pathologist (K. Butnor) using a blind code for identification of slides and an inflammation scale from 1 to 4 ; with 1 indicating absent inflammation, 2 showing mild predominantly lymphocytic inflammation restricted to peribronchiolar regions, 3 indicating moderate peribronchiolar mononuclear neutrophilic inflammation with minimal extension into adjacent tiers of alveoli, and 4 as severe mixed peribronchiolar and adjacent alveolar inflammation.

Ki-67 immunoperoxidase technique The expression of Ki-67 protein is a requirement for progression through the cell division cycle and is an accurate marker of cell proliferation (24). To quantitate bronchiolar epithelial cell proliferation, lung sections from 9-day sham- and asbestos-exposed $\mathrm{Mpo}^{-/-}$and $\mathrm{Mpo}^{+/+}$mice were deparaffinized in xylene, rehydrated through a series of graded ethanols, and equilibrated in water. Antigen retrieval was then done using a 1:10 dilution in PBS of 10x DAKO target retrieval solution (DAKO, Carpinteria, CA) in a $95^{\circ} \mathrm{C}$ water bath for 40 minutes followed by 20 minutes of cooling to room temperature. Sections were then treated with DAKO peroxi- 
dase block for 30 minutes followed by a 5-minute wash in TBS before incubation in DAKO serum-free protein block for 30 minutes. Sections were then immersed in $50 \mu \mathrm{L}$ of a 1:25 dilution of monoclonal rat anti-mouse Ki-67 primary antibody (DAKO), a 1:600 dilution of biotinylated anti-rat IgG secondary antibody (Vector Laboratories, Burlingame, CA), a 1:25 dilution of rat whole serum (Zymed, South San Francisco, CA), and 1\% bovine serum albumin in PBS at room temperature for 30 minutes before blocking of excess secondary antibody with normal rat serum for 1.5 hours. Negative controls were incubated in PBS without primary antibody, and all sections incubated overnight at $4^{\circ} \mathrm{C}$ in a humidified chamber. The following day, sections were washed twice in 1x TBS, treated for 30 minutes with horseradish peroxidase streptavidin (Vector) and incubated in 3,3'-diaminobenzidine (DAKO) for 3 minutes. Sections were then rinsed in double-distilled water, counterstained for 30 seconds in hematoxylin, dehydrated through increasing concentrations of ethanol, and washed in xylene twice for 15 minutes before coverslips were mounted in Histomount (Zymed). Slides were then examined by light microscopy using an Olympus BX50 upright microscope (Olympus America, Inc., Lake Success, NY) with associated MagniFier software. The number of Ki-67-positive immunoreactive epithelial cells was determined on a total of at least five distal bronchioles on duplicate lung sections per animal.

Myeloperoxidase and cyclin D1 immunofluorescence in lung sections To confirm the negative status of $\mathrm{Mpo}^{-/}$mice (with respect to expression of myeloperoxidase) and to determine if myeloperoxidase and cyclin D1 immunoreactivity was associated with epithelial cells of $\mathrm{Mpo}^{+/+}$mice, lung sections from sham and asbestos-exposed $\mathrm{Mpo}^{-/}$and $\mathrm{Mpo}^{+/+}$mice were deparaffinized in xylene for 5 minutes (twice), rehydrated through a graded series of ethanols, and equilibrated in water. Slides were then boiled in 1x DAKO target retrieval solution for 40 minutes, and cooled for 20 minutes. After a wash in 1x PBS for 5 minutes, sections were blocked with $10 \%$ normal goat serum (Jackson ImmunoResearch Laboratories, West Grove, PA) diluted in PBS. A polyclonal rabbit anti-myeloperoxidase 562 (a kind gift from Marie Luise Brennan, Cleveland Clinic, Cleveland, $\mathrm{OH}$ ) or a polyclonal rabbit anti-cyclin D1 (Labvision Corporation, Fremont, $\mathrm{CA}$ ) were diluted in $1 \%$ bovine serum albumin in PBS, and slides were incubated overnight at $4^{\circ} \mathrm{C}$. After washing with PBS, slides were incubated with a 1:400 dilution of AlexaFluor 647-conjugated goat antirabbit IgG (Molecular Probes, Eugene, OR) in PBS for 1 hour at room temperature. SYTOX Green (1:1000, Molecular Probes) in PBS was used as a counterstain for nuclei. Controls included slides incubated with secondary antibody alone. Sections of mouse intestinal epithelium were used as positive controls for cyclin D1 immunoreactivity. Negative controls for cyclin D1 included sections of normal lungs and intestine incubated with secondary antibody alone. Slides were examined by using a Bio-Rad MRC 1024ES confocal scanning laser microscope system (Bio-Rad Laboratories). 
Statistical analysis Data were analyzed using two-way ANOVA and StudentNewman-Keul's tests to adjust for multiple pair-wise differences. $p \leq 0.05$ between groups were considered significant.

\section{RESULTS}

Myeloperoxidase activity is increased in bronchoalveolar lavage fluids and observed in distal bronchiolar epithelial cells in normal $\left(\mathrm{Mpo}^{+/+}\right)$mice after inhalation of asbestos

To determine if myeloperoxidase activity was increased in BALF from C57BL/6 mice after inhalation of asbestos, we did a number of experiments to optimize detection of myeloperoxidase in cell-free BALF at 9 days, i.e., the peak time of asbestos-induced inflammation (16). Myeloperoxidase activity was not detected in BALF from sham mice using protein concentrations of up to $50 \mu \mathrm{g}$ (Figure 1, top, solid lines). Conversely, fresh lavage samples from four asbestos-exposed mice showed linear reactions over a 20-minute period (Figure 1, top, dashed lines).

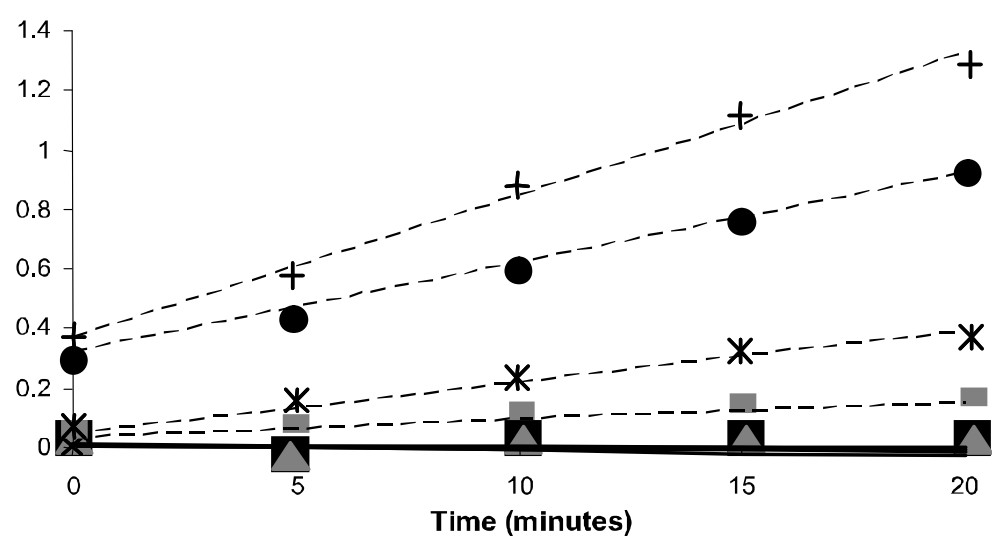

Figure 1: Myeloperoxidase activity in BALF. Fifteen micrograms of protein in $100 \mu \mathrm{L}$ of BALF supernatant from sham- and asbestos-exposed C57BL/6 mice $(n=4 / g r o u p)$ was mixed with $100 \mu \mathrm{L}$ tetramethylbenzidine reagent, and the oxidation of tetramethylbenzidine was measured at $630 \mathrm{~nm}$ over a 20 -minute period. All sham mice showed no increases in activity (solid lines), whereas the four asbestos-exposed mice showed linear release kinetics over time (dashed lines). 


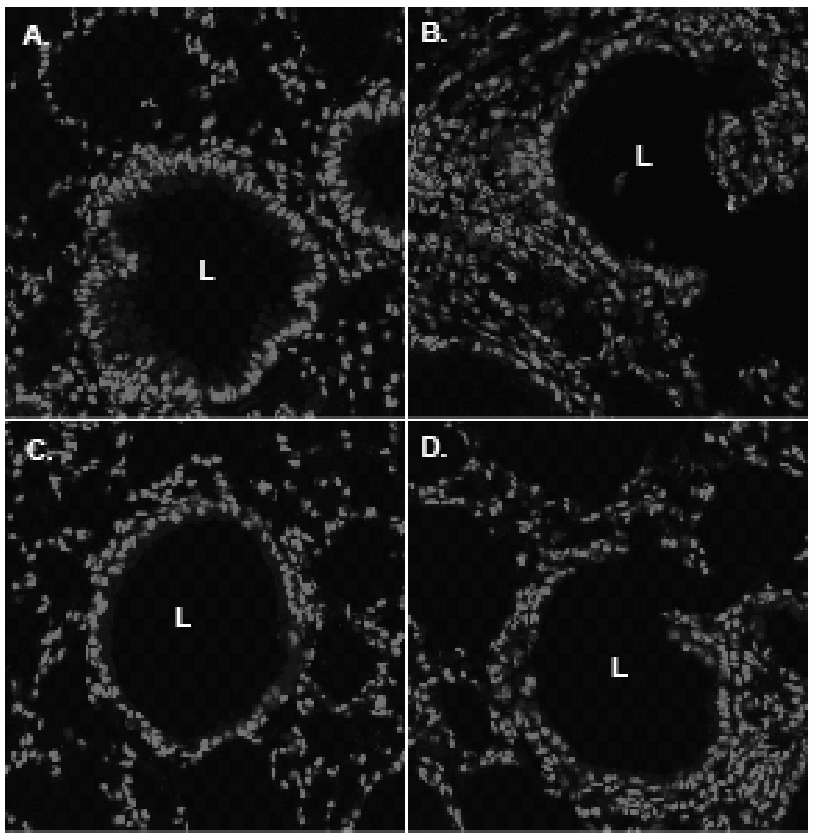

Figure 1A-D: Myeloperoxidase immuno-localization in bronchiolar epithelial cells (bottom). Anti-myeloperoxidase reactivity (red), and nuclei stained with SYTOX Green (green). Representative images of lung tissue sections stained for myeloperoxidase and examined by confocal scanning laser microscope. A, 9-day shamexposed normal $\left(\mathrm{Mpo}^{+/+}\right)$; B, 9-day asbestos-exposed normal $\left(\mathrm{Mpo}^{+/+}\right) ; \mathrm{C}$, 9-day sham-exposed $\mathrm{Mpo}^{--}$; D, 9day asbestos-exposed $\mathrm{Mpo}^{-/}$. All original magnifications, $400 \mathrm{X}$

We then focused on whether myeloperoxidase protein could be detected in bronchiolar or alveolar duct epithelial cells of normal mice, as these are the cell types encountering asbestos fibers at sites of deposition and progenitor cells of asbestos-induced lung cancer. Immunohistochemistry revealed that sham control mice showed no detectable myeloperoxidase in bronchiolar epithelium or surrounding tissue (Figure 1A), but after inhalation of asbestos, myeloperoxidase was observed in the cytoplasm of distal bronchiolar epithelial cells (Figure 1B). No myeloperoxidase was observed in either sham or asbestosexposed null mice (Figure $1 \mathrm{C}$ and $\mathrm{D}$ ).

\section{Patterns of asbestos-associated inflammation are delayed in $\mathrm{Mpo}^{\left.\gamma^{-}\right)}$null mice}

Chrysotile asbestos-induced markers of inflammation in BALF have been previously characterized in our murine model at various time periods after initial exposures to asbestos. PMN influx in BALF peaks at 9 days (16). In line with earlier data, total protein in BALF and lactate dehydrogenase levels, an indication of lung permeability reflecting dead or dying cells as well as plasma proteins, were elevated $(\mathrm{p} \leq 0.05)$ in asbestos-exposed $\mathrm{Mpo}^{+/+}$and $\mathrm{Mpo}^{-/-}$mice in comparison with sham mice (Figure $2 \mathrm{~A}$ and $\mathrm{B}$ ). In comparison with respective sham groups, total inflammatory cell numbers in BALF also did not change significantly in asbestos-exposed normal or MPO-null mice (Figure 2C). However, fewer cells were noted in BALF samples from myeloperoxidase-null in comparison with normal $\left(\mathrm{Mpo}^{+/+}\right)$sham mice $(\mathrm{p} \leq 0.05)$. This was due to a significant decrease $(p \leq 0.05)$ in alveolar macrophages in $\mathrm{Mpo}^{-/}$mice (Figure 2D). Compared with sham controls, both normal and $\mathrm{Mpo}^{-/}$asbestos-exposed mice 
exhibited increases $(p \leq 0.05)$ in the number of neutrophils and lymphocytes. However, $\mathrm{Mpo}^{-/}$mice showed lower $(\mathrm{p} \leq 0.05)$ numbers of macrophages and lymphocytes than normal mice in response to asbestos (Figure 2D).

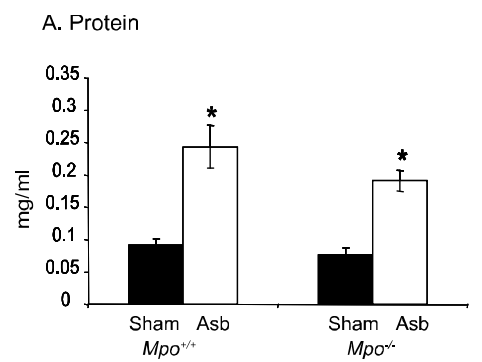

C. Total Cell Counts

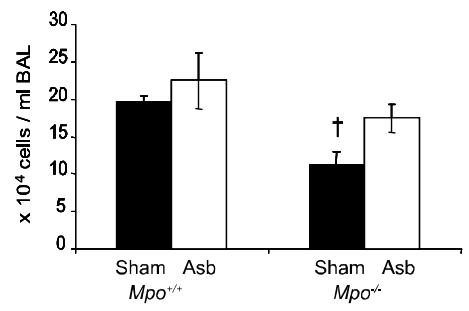

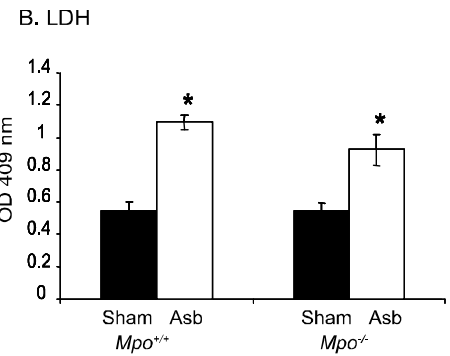

D. Differenatial Cell Counts in BAL

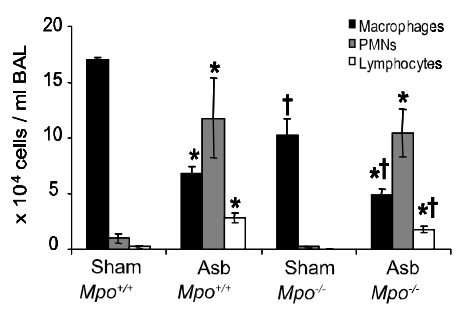

Figure 2: Markers of cell injury and inflammation in bronchoalveolar lavage. Total protein $(A)$ and lactate dehydrogenase $(B)$ are significantly increased $(p \leq 0.05)$ in asbestos-exposed $(+$ Asb) animals in comparison with sham controls at 9 days. Total $(C)$ and differential cell counts $(D)$ on bronchoalveolar lavage samples from sham- and asbestos-exposed (+Asb) mice at 9 days. Columns, mean; bars, $\pm S E$; * significantly different $(p \leq 0.05)$ from shams in each group; † significantly different $(p \leq 0.05)$ from respective $\mathrm{Mpo}^{+/+}$group.

Lung histopathology at 9 days supported the results of BALF studies. In normal $\mathrm{MpO}^{+/+}$mice, inhalation of asbestos caused a characteristic influx of macrophages into alveolar tissue and peribronchiolar mononuclear and neutrophilic inflammation that was not observed in sham mice (Figure 3B and 4A). The lungs of $\mathrm{Mpo}^{-/}$mice showed no inflammatory response to asbestos at this time point (Figure $3 \mathrm{C}$ and $4 \mathrm{~A}$ ). However, at 30 days, inflammation scores of both normal and $\mathrm{Mpo}^{-/}$asbestos-exposed mice were comparable and significantly increased ( $p \leq 0.05$; Figure $3 E, F$, and $4 B$ ) in comparison with respective sham controls (Figure 3D and 4B). 


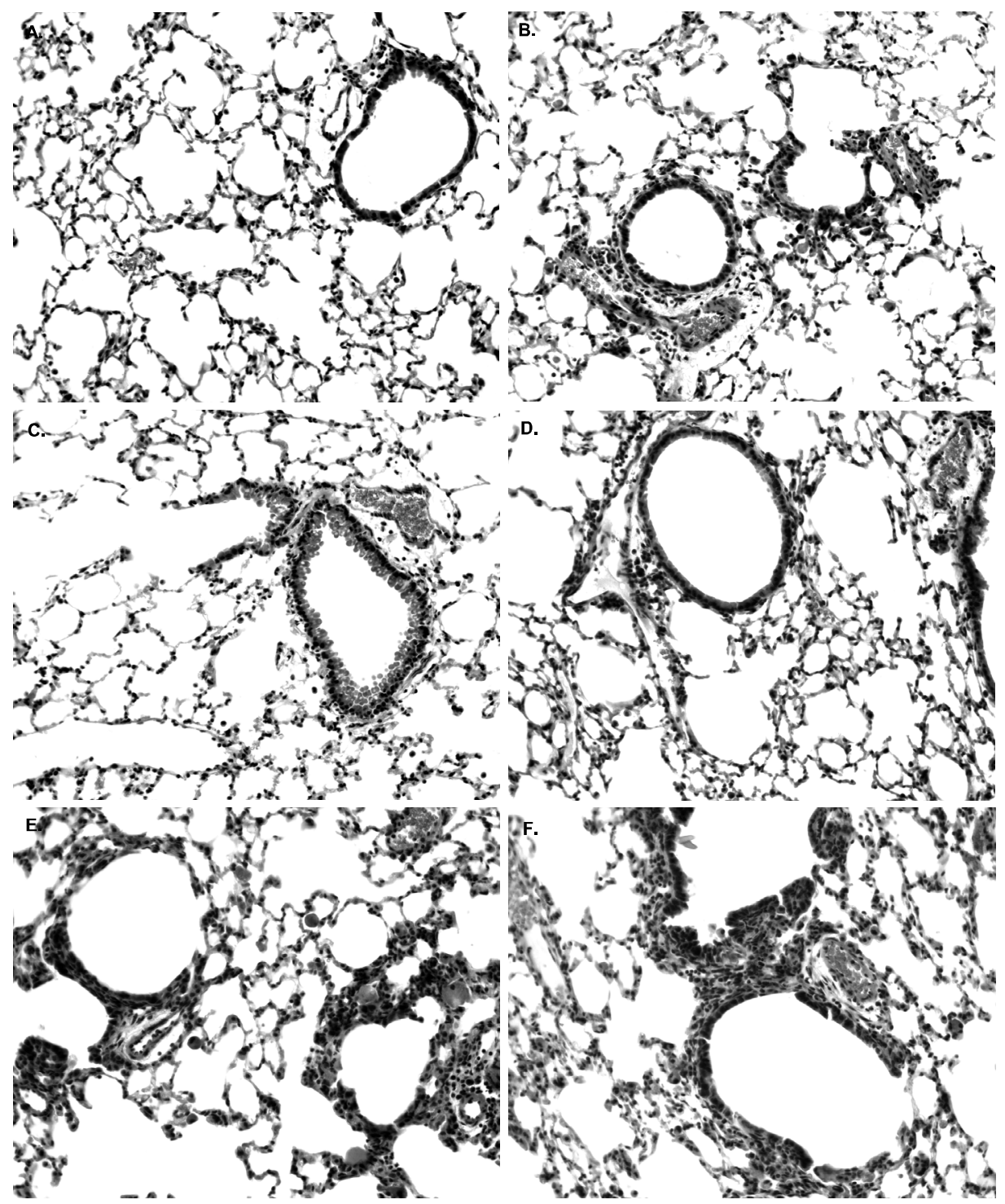

Figure 3: Histopathologic findings in lungs at 9 (A-C) and 30 (D-F) days (H\&E stained sections). A, 9-day sham $\mathrm{Mpo}^{+/+}$lung shows no inflammation; B, 9-day asbestos-exposed $\mathrm{Mpo}^{+/+}$ lung showing mild peribronchiolar mononuclear inflammation and scattered alveolar macrophages; C, 9-day asbestos-exposed $\mathrm{Mpo}^{-/}$lung demonstrating essentially absent inflammation; D, 30-day sham $\mathrm{Mpo}^{-/}$lung is devoid of inflammation; E, 30-day asbestos-exposed $\mathrm{Mpo}^{+/+}$lung features moderate neutrophilic and mononuclear inflammation extending from the bronchiolar epithelium into surrounding alveoli. Moderate intra-alveolar macrophage infiltration is also present; F, 30-day asbestos-exposed $\mathrm{Mpo}^{-/}$lung exhibits moderate mixed peribronchiolar inflammation. All original magnifications, 200X. 
A. 9 days

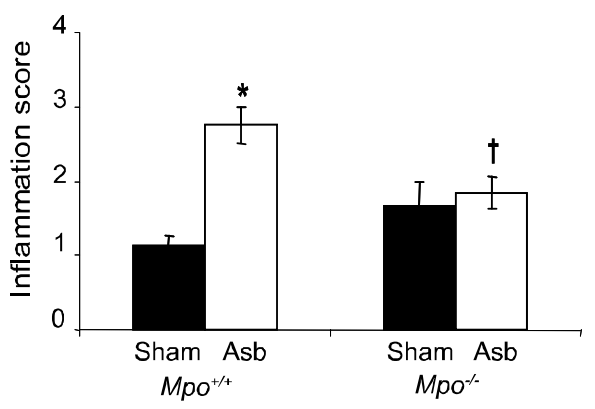

B. 30 days

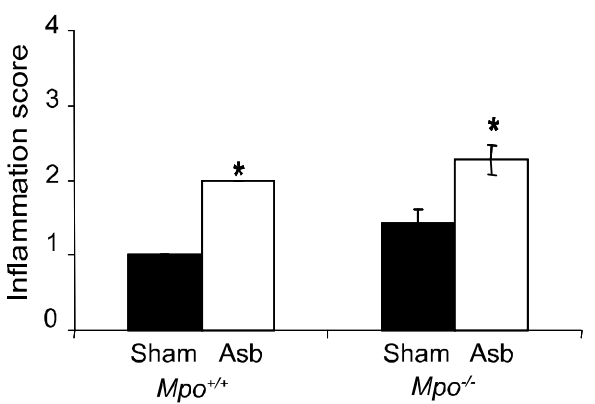

Figure 4: Grading of peribronchiolar inflammation in lungs at 9 (A) and 30 (B) days. Columns, mean; bars, $\pm \mathrm{SE}$; * significantly different $(p \leq 0.05)$ from shams in each group; $\dagger$ significantly different $(p \leq 0.05)$ from respective $\mathrm{Mpo}^{+/+}$group.

Asbestos-associated epithelial cell proliferation is increased in the distal bronchioles of $\mathrm{Mpo}^{-/-}$mice in comparison with normal mice

We and others have shown that incorporation of $5^{\prime}$ bromodeoxyuridine is increased in the bronchiolar epithelium of rodents after inhalation of chrysotile asbestos $(16,25)$. This technique requires preinjection of mice or implantation of mini-pumps containing bromodeoxyuridine and does not differentiate between unscheduled, unsuccessful, DNA synthesis or cell proliferation. In contrast, incorporation of $\mathrm{Ki}-67$ is a sensitive and specific immunocytochemical method not requiring injection of a precursor into animals and measuring the number of epithelial cells progressing through the cell division cycle (24). In comparison with sham control groups (Figure 5), increases in the number of Ki-67-positive bronchiolar epithelial cells were observed in both asbestosexposed groups at 9 days - whereas numbers of Ki-67-positive cells doubled in normal mice, myeloperoxidase-null mice showed $\sim 4$-fold increases $(p \leq 0.05)$ in the number of proliferating cells. At 30 days, the number of Ki-67-positive cells was increased in asbestos-exposed $\mathrm{Mpo}^{+/+}$mice and comparable to levels in asbestos-exposed $\mathrm{Mpo}^{-/}$mice. 


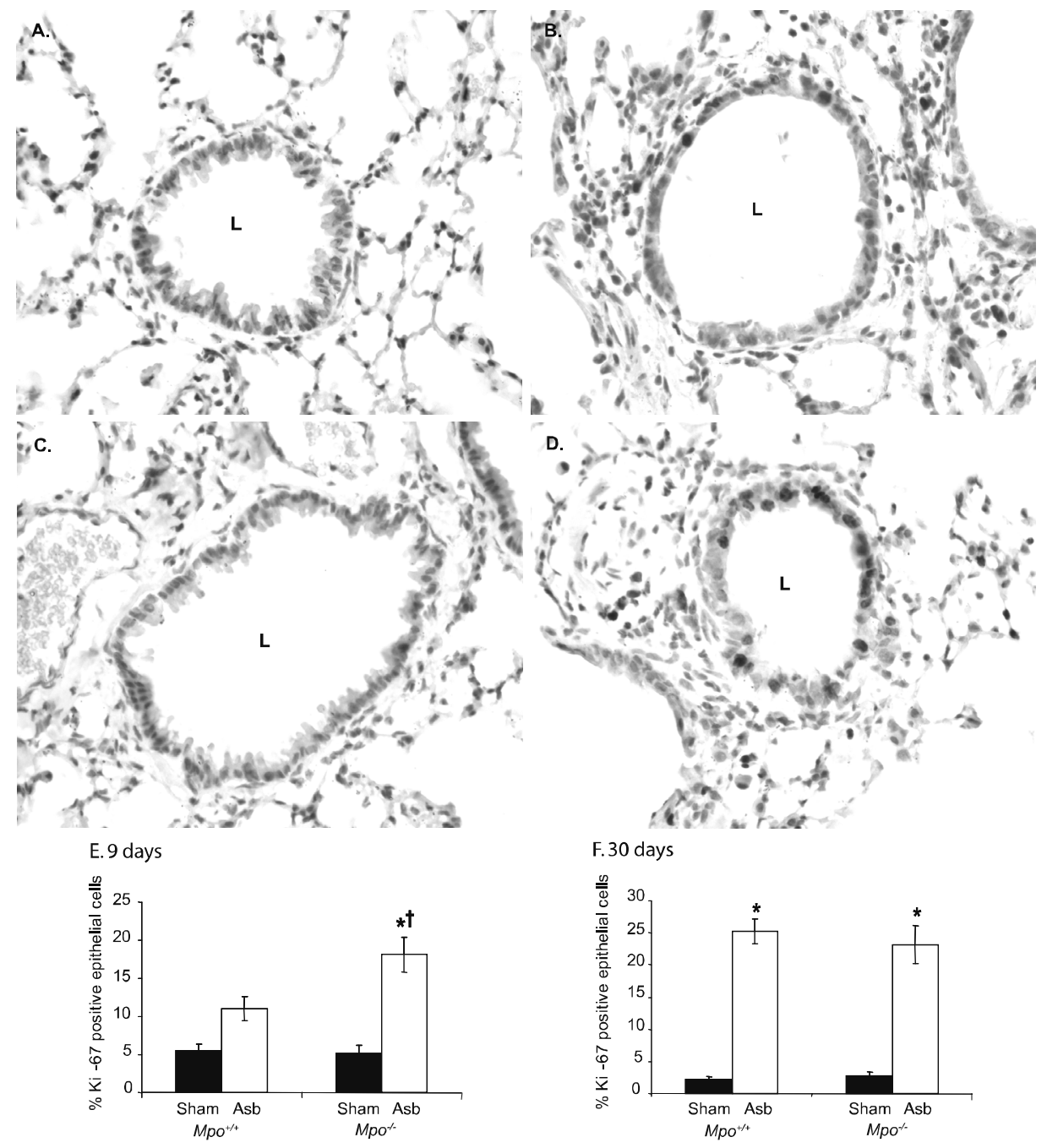

Figure 5: Ki-67 immunoperoxidase staining to show replicating distal bronchiolar epithelial cells in lungs of mice at 9 days. A, sham $\mathrm{Mpo}^{+/+} ; \mathrm{B}$, asbestos-exposed $\mathrm{Mpo}^{+++} ; \mathrm{C}$, sham $\mathrm{Mpo}^{-/-}$ ; D, asbestos-exposed $\mathrm{Mpo}^{--}$; L, bronchiolar lumen. All original magnifications, 400X. Quantitation of Ki-67-positive distal bronchiolar epithelial cells at $9(\mathrm{E})$ and $30(\mathrm{~F})$ days. Columns, mean; bars, \pm SE; * significantly different $(p \leq 0.05)$ from sham groups; †significantly different $(p \leq 0.05)$ from asbestos-exposed $\mathrm{Mpo}^{+/+}$group. 
Cyclin D1 is a marker of cell cycle progression that has been previously uncharacterized in models of lung injury. To confirm our quantitative results using $\mathrm{Ki}-67$ to delineate cells not in $\mathrm{G}_{0}$, we also examined immunolocalization of cyclin D1 comparatively in the distal bronchiolar region and alveolar duct junctions, sites of initial fiber deposition (25), in sham and asbestos-exposed mice. As shown in Figure. 6, dual fluorescence studies using SYTOX Green to demonstrate nuclei, showed that both nuclear (yellow indicating colocalization of
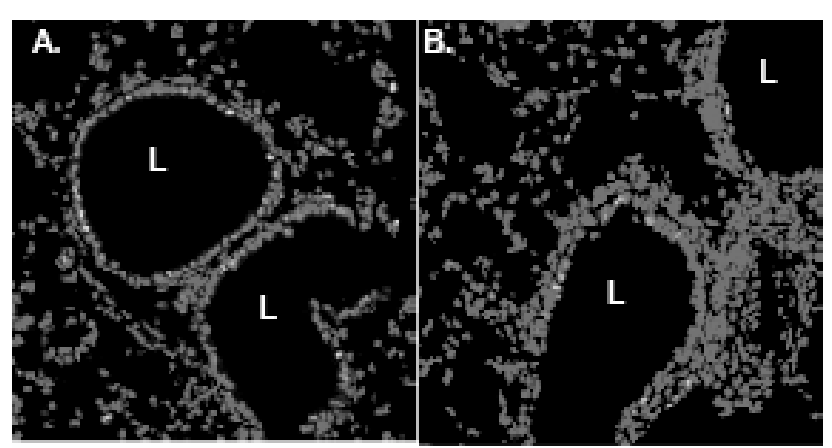

cyclin D1, with nucleus) and cytoplasmic fluorescence (red) occurred predominantly in distal bronchiolar epithelial cells. Cyclin D1 immunofluorescence was occasionally observed in sham normal (Figure 6A) and $\mathrm{Mpo}^{-/}$ mice (Figure 6B). However, it was more pre-
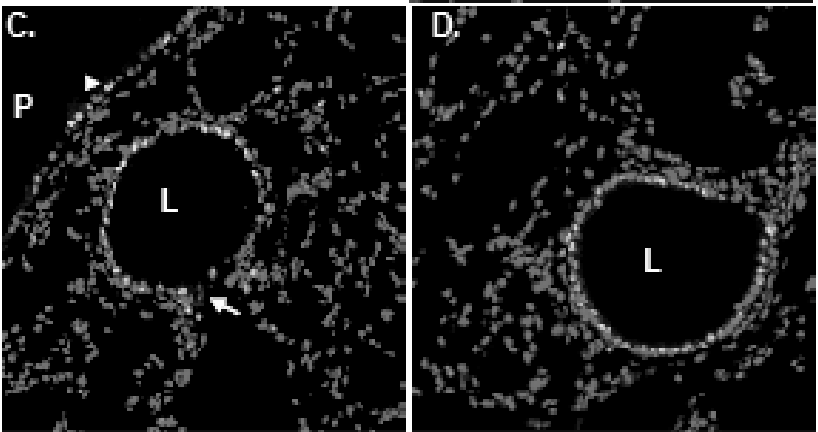
dominant in asbestosexposed groups (Figure 6C and D), particularly in $\mathrm{Mpo}^{-/}$mice, where it was also observed in mesothelial cells (arrowhead) and at sites of alveolar duct junctions (arrow). Although quantitation of cyclin D1 cells in epithe-

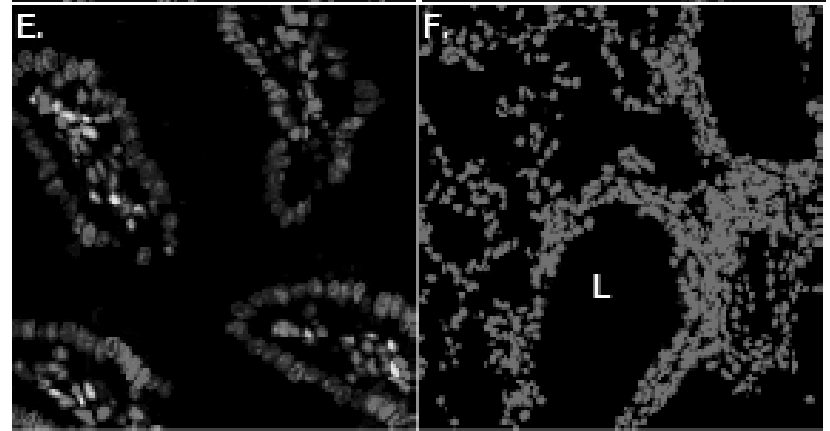
lium was not feasible due to its infrequent expression and colocalization in both the nucleus and cytoplasm, trends of expression in various groups of mice were similar to those observed with Ki-67 labeling.

Figure 6: Immunofluorescent localization of cyclin D1 by confocal scanning laser microscopy in lung sections at 9 days. Representative images of lung tissue sections stained with an antibody to cyclin D1 (red) or SYTOX Green (green) to stain nuclei. Yellow, overlap of signals indicating colocalization (see arrow and arrowhead). A, sham $\mathrm{Mpo}^{-/} ; \mathrm{B}$, sham $\mathrm{Mpo}^{+/+} ; \mathrm{C}$, asbestos-exposed $\mathrm{Mpo}^{-/}$; D, asbestos-exposed $\mathrm{Mpo}^{+/+}$; $\mathrm{E}$, mouse intestine (+, control); $\mathrm{F}$, lung section stained with secondary antibody alone (-, control); L, lumen of distal bronchiole; $P$, pleural space. All original magnifications, 400X. 


\section{DISCUSSION}

We show for the first time that myeloperoxidase is an important factor in the acute inflammatory response to inhaled asbestos. Because asbestos is an oxidative stress (15) and a potent inflammatory agent in lung and pleura (4, 26, 27 ), our findings may be relevant to the inflammation and proliferation of cells observed after exposure to a number of carcinogenic environmental toxicants. Our initial interest in the role of myeloperoxidase in asbestos-induced inflammation stemmed from observations that PMNs are the predominant cell type infiltrating the lung after brief inhalation or intratracheal exposures to asbestos (4). Although neutrophils produce a plethora of chemokines and cytokines after inhalation of oxidant gases and oxidant-generating particulates such as asbestos or silica, myeloperoxidase production by neutrophils has been classically linked to its microbicidal and inflammatory effects via the generation of the halogenating oxidant, $\mathrm{HOCl}$. Although $\mathrm{HOCl}$ is the major reactive species generated by myeloperoxidase, recent work shows that myeloperoxidase also participates in nitrotyrosine formation in some, but not all, neutrophil-rich animal models of inflammation (28). Because asbestos is known to induce inducible nitric oxide synthase in alveolar macrophages (29) and nitrotyrosine formation in rat lungs which subsequently develop inflammation and fibrosis (10), the myeloperoxidase-catalyzed formation of nitric oxide-derived inflammatory oxidants might also be critical in the early pathogenesis of asbestos-associated diseases.

Here, we show that myeloperoxidase enzyme activity occurs in PMN-rich BALF after inhalation of asbestos by mice. Moreover, we show that myeloperoxidase protein is found in the distal bronchiolar epithelium at alveolar duct bifurcations, sites of asbestos fiber deposition. Increased myeloperoxidase activity in homogenized lung tissues in an amiodarone-induced rat model of pulmonary fibrosis and its decrease with indicators of fibrosis (lung hydroxyproline, transforming growth factor- $\beta 1$ expression, etc.), have been documented after gastric intubation of the antioxidant and anti-inflammatory agent, curcumin (30), but the cell types expressing myeloperoxidase under these circumstances were unclear. Our results support the hypothesis that myeloperoxidase is generated predominantly by PMNs, but has the capacity to cross the epithelium, presumably by pinocytosis or phagocytosis as do asbestos fibers (31). This model is supported by a study showing myeloperoxidase immunoreactivity in the alveolar epithelial compartment of lung tissues from patients with sickle cell disease or those undergoing lung transplant rejection (32).

A number of in vitro models show that high concentrations of oxidants cause cytotoxicity or cytostasis, whereas lower concentrations cause cell proliferation and transformation $(33,34)$. Likewise, asbestos is an agent causing cell injury at higher concentrations and proliferation at lower concentrations in airway epithelial cells in vitro (35). The fact that myeloperoxidase and asbestos might cooperatively contribute to oxidant-associated cell damage is supported by many observations showing that these agents increase oxidative stress in lung 
tissue $(17,34)$. For example, myeloperoxidase in the sputum of patients with cystic fibrosis enhances cell death after addition of generating systems of hydrogen peroxide to human tracheobronchial epithelial cells (36). In asbestosexposed $\mathrm{Mpo}^{-/}$mice, initial oxidant profiles in lung tissue may be lower than those in asbestos-exposed $\mathrm{Mpo}^{+/+}$mice, thus favoring an environment promoting cell survival and mitogenesis. Our data thus support a model whereby acute epithelial cell proliferation by asbestos is initially curtailed under increased oxidative stress in $\mathrm{Mpo}^{+/+}$mice. However, as inhalation of asbestos ensues from 9 to 30 days, it is known that oxidative stress-inducing fibers accumulate and inflammation increases $(1,6,9,37)$. These factors may explain why the numbers of Ki-67 immunoreactive epithelial cells are comparable in both normal and myeloperoxidase-null mice at 30 days.

Cyclin D1 and its partner, cyclin-dependent kinase 4 , promote $G_{1}$ to $S$ phase progression via phosphorylation of the retinoblastoma protein. The exciting discovery that cyclin D1 is expressed in pulmonary epithelial cells, and that expression corresponds with quantitative trends in asbestos-induced proliferation, as assayed by Ki-67 labeling, provides some insight into the molecular mechanisms of oxidant-induced proliferation. We have previously shown that initial injury and subsequent proliferative effects of asbestos in vitro and in vivo are linked to stimulation of the extracellular signal-regulated kinases, ERK1/2 and ERK5 in epithelial cells (38-41). Increased ERK phosphorylation is linked causally to increased activation and expression of the activator protein-1 (AP1) family members, c-fos, fra-1 (ERK1/2) and c-Jun (ERK5) in pulmonary cells as well as elevated AP-1 activity (41-43). $\mathrm{HOCl}$ also activates ERK1/2, growth arrest, and apoptosis in human umbilical vein endothelial cells, and loss of viability is enhanced when the survival pathway, ERK1/2, is inhibited (44). These results also suggest the importance of AP-1-mediated gene expression in $\mathrm{HOCl}$-induced cell responses. Because cyclin D1 is an AP-1-dependent gene (45), it may be a key player in the induction of asbestos-induced cell cycle reentry and progression. Our immunolocalization results in lung epithelium in vivo are consistent with recently published observations in neonatal rat cardiomyocytes in vitro where cyclin D1 localization is predominantly cytoplasmic (46). However, when cyclin D1 is ectopically expressed in the nucleus of postnatal cardiocytes in vivo, cell cycle reentry, as evaluated by the expression of $\mathrm{Ki}-67$, is increased. This observation and recent work from our group (47) suggests that trafficking and accumulation of cell signaling proteins and transcription factors in the nucleus may be important in the induction of responses to oxidants.

In summary, our results show that myeloperoxidase activity is increased in lavage fluid after inhalation of asbestos fibers. Myeloperoxidase also localizes in bronchiolar epithelial cells in asbestos-exposed mice where it may act directly to cause alterations in epithelial cells. Our data reveal that myeloperoxidase status is functionally important not only in the control of epithelial cell proliferation in response to asbestos but also in the induction of asbestosinduced inflammation. The inflammatory profiles of BALF in asbestos-exposed normal and $\mathrm{Mpo}^{-/-}$mice did not reflect differences in the number of PMNs, but 
rather decreases in alveolar macrophages and lymphocytes in $\mathrm{Mpo}^{-/}$mice. It is therefore tempting to speculate that myeloperoxidase catalyzed $\mathrm{HOCl}$ directly or through signaling pathways involving tyrosine nitration affects redoxsensitive transcription factors, such as AP-1 or nuclear factor $\mathrm{kB}$, that are linked to chemokine elaboration and influx of macrophages and lymphocytes. The fact that, myeloperoxidase plays a critical role in initial asbestosassociated epithelial cell repair responses and inflammation may be important in the prevention of asbestos- and oxidant-related lung cancers.

\section{ACKNOWLEDGEMENTS}

Grant support: PO1 grant HL67004 from the National Heart, Lung, and Blood Institute.

The costs of publication of this article were defrayed in part by the payment of page charges. This article must therefore be hereby marked advertisement in accordance with 18 U.S.C. Section 1734 solely to indicate this fact.

We thank Maria Stern from the Cell Imaging Core and Microscopy Imaging Center (University of Vermont) for technical assistance with immunocytochemistry. Daniel Bullard, PhD (Department of Microbiology, University of Alabama at Birmingham) kindly provided and typed the mice for studies here. Veronique Andriessen, Maximilian MacPherson, Beth Langford-Corrigan, and Laurie Sabens provided valuable technical assistance. 


\section{REFERENCES}

1. Quinlan T, Marsh J, Janssen $Y$, et al. Dose responsive increases in pulmonary fibrosis after inhalation of asbestos. Am J Respir Crit Care Med 1994;149:795-802.

2. Zhao Q, Simpson LG, Driscoll KE, Leikauf GD. Chemokine regulation of ozone-induced neutrophil and monocyte inflammation. Am J Physiol 1998;274:L39-46.

3. Hubbard AK, Timblin CR, Shukla A, Rincon M, Mossman BT. Activation of NF- $\mathrm{B}$ dependent gene expression by silica in lungs of luciferase reporter mice. Am J Physiol Lung Cell Mol Physiol 2002;282:L968-75.

4. Mossman B, Churg A. Mechanisms in the pathogenesis of asbestosis and silicosis. Am J Respir Crit Care Med 1998;157:1666-80.

5. Craighead J, Abraham J, Churg A, et al. The pathology of asbestos-associated diseases of the lungs and pleural cavities: diagnostic criteria and proposed grading schema. Report of the Pneumoconiosis Committee of the College of American Pathologists and the National Institute for Occupational Safety and Health. Arch Pathol Lab Med 1982;106:544-96.

6. Manning C, Vallyathan V, Mossman B. Diseases caused by asbestos: mechanisms of injury and disease development. Int Immunopharmacol 2002;2:191-200.

7. Eiserich JP, Hristova M, Cross CE, et al. Formation of nitric oxide-derived inflammatory oxidants by myeloperoxidase in neutrophils. Nature 1998;391:393-7.

8. Gaut JP, Byun J, Tran HD, et al. Myeloperoxidase produces nitrating oxidants in vivo. J Clin Invest 2002;109:1311-9.

9. van der Vliet A, Eiserich JP, Shigenaga M, Cross CE. Reactive nitrogen species and tyrosine nitration in the respiratory tract: epiphenomina or pathobiological mechanism of disease. Am J Respir Crit Care Med 1999;160:1-9.

10. Tanaka S, Choe N, Hemenway D, Zhu S, Matalon S, Kagan E. Asbestos inhalation induces reactive nitrogen species and nitrotyrosine formation in the lungs and pleura of the rat. J Clin Invest 1998;102:445-54.

11. Baldus S, Eiserich JP, Mani A, et al. Endothelial transcytosis of myeloperoxidase confers specificity to vascular ECM proteins as targets of tyrosine nitration. J Clin Invest 2001;108:1759-70.

12. Eiserich JP, Baldus S, Brennan ML, et al. Myeloperoxidase, a leukocyte-derived vascular NO oxidase. Science 2002;296:2391-4.

13. Mossman BT, Craighead JE, MacPherson BV. Asbestos-induced epithelial changes in organ cultures of hamster trachea: inhibition by retinyl methyl ether. Science 1980;207:311-3.

14. Miller MD, Krangel MS. Biology and biochemistry of the chemokines: a family of chemotactic and inflammatory cytokines. Crit Rev Immunol 1992;12:17-46.

15. Shukla A, Gulumian M, Hei T, Kamp D, Rahman Q, Mossman B. Multiple roles of oxidants in the pathogenesis of asbestos-induced diseases. Free Radic Biol Med 2003;34:1117-29.

16. Robledo R, Buder-Hoffmann S, Cummins A, Walsh E, Taatjes D, Mossman B. Increased phosphorylated ERK immunoreactivity associated with proliferative and morphologic lung alterations following chrysotile asbestos inhalation in mice. Am J Pathol 2000;156:130716.

17. BeruBe K, Quinlan T, Moulton G, et al. Comparative proliferative and histopathologic changes in rat lungs after inhalation of chrysotile or crocidolite asbestos. Toxicol Appl Pharmacol 1996;137:67-74.

18. Smith C, Batcher S, Catanzaro A, Abraham J, Phalen R. Sequence of bronchoalveolar lavage and histopathologic findings in rat lungs early in inhalation asbestos exposure. $J$ Toxicol Environ Health 1987;20:147-61.

19. Yang KY, Arcaroli JJ, Abraham E. Early alterations in neutrophil activation are associated with outcome in acute lung injury. Am J Respir Crit Care Med 2003;167:1567-74.

20. Crapo J, Miller F, Mossman B, Pryor W, Kiley J. NHLBI workshop summary. Environmental lung diseases. Relationship between acute inflammatory responses to air pollutants and chronic lung disease. Am Rev Respir Dis 1992;145:1506-12. 
21. Brennan M, MM A, Shih $D$, et al. Increased atherosclerosis in myeloperoxidase-deficient mice. J Clin Invest 2001;107:419-30.

22. Campbell W, Huggins C, Wylie A. U.S. Bureau of Mines Report of Investigations, No. 8452; 1980.

23. Hemenway D, MacAskill S. Design, development and test results of a horizontal flow facility. Am Ind Hyg Assoc J 1982;43:874-9.

24. Scholzen T, Gerdes J. The Ki-67 protein: from the known and the unknown. J Cell Physiol 2000;182:311-22.

25. Brody A, Overby L. Incorporation of tritiated thymidine by epithelial and interstitial cells in bronchiolar-alveolar regions of asbestos-exposed rats. Am J Pathol 1989;134:133-40.

26. Mossman B, Gee J. Asbestos related disease. N Engl J Med 1989;320:1721-30.

27. Mossman B, Bignon J, Corn M, Seaton A, Gee J. Asbestos: scientific developments and implications for public policy. Science 1990;247:294-301.

28. Brennan ML, $\mathrm{Wu} \mathrm{W}, \mathrm{Fu} \mathrm{X}$, et al. A tale of two controversies: defining both the role of peroxidases in nitrotyrosine formation in vivo using eosinophil peroxidase and myeloperoxidase-deficient mice, and the nature of peroxidase-generating reactive nitrogen species. J Biol Chem 2002;277:17415-27.

29. Quinlan T, BeruBe K, Hacker M, et al. Mechanisms of asbestos-induced nitric oxide production by rat alveolar macrophages in inhalation and in vitro models. Free Radic Biol Med 1998;24:778-88.

30. Punithavathi D, Venkatesan N, Babu M. Protective effects of curcumin against amiodarone-induced pulmonary fibrosis in rats. Br J Pharmacol 2003;139:1342-50.

31. Churg A, Stevens B. Enhanced retention of asbestos fibers in the airways of human smokers. Am J Respir Crit Care Med 1995;151:1409-13.

32. Baldus S, Eiserich J, Brennan M, Jackson R, Alexander C, Freeman B. Spatial mapping of pulmonary and vascular nitrotyrosine reveals the pivotal role of myeloperoxidase as a catalyst for tyrosine nitration in inflammatory diseases. Free Radic Biol Med 2002;33:1010-9.

33. Li J, Holbrook NJ. Common mechanisms for declines in oxidative stress tolerance and proliferation with aging. Free Radic Biol Med 2003;35:292-9.

34. Luczak K, Balcerczyk A, Soszynski M, Bartosz G. Low concentration of oxidant and nitric oxide donors stimulate proliferation of human endothelial cells in vitro. Cell Biol Int 2004;28:483-6.

35. Sesko A, Cabot M, Mossman B. Hydrolysis of inositol phospholipids precedes cellular proliferation in asbestos-stimulated tracheobronchial epithelial cells. Proc Natl Acad Sci U S A 1990;87:7385-9.

36. Van Der Vliet A, Nguyen MN, Shigenaga MK, Eiserich JP, Marelich GP, Cross CE. Myeloperoxidase and protein oxidation in cystic fibrosis. Am J Physiol Lung Cell Mol Physiol 2000;279:L537-46.

37. Quinlan T, BeruBe K, Marsh J, et al. Patterns of inflammation, cell proliferation, and related gene expression in lung after inhalation of chrysotile asbestos. Am J Pathol 1995;147:728-39.

38. Manning $C$, Cummins $A$, Jung $M$, et al. A mutant epidermal growth factor receptor targeted to lung epithelium inhibits asbestos-induced proliferation and proto-oncogene expression. Cancer Res 2002;62:4169-75.

39. Buder-Hoffmann S, Palmer C, Vacek P, Taatjes D, Mossman B. Different accumulation of activated extracellular signal-regulated kinases (ERK 1/2) and role in cell-cycle alterations by epidermal growth factor, hydrogen peroxide, or asbestos in pulmonary epithelial cells. Am J Respir Cell Mol Biol 2001;24:405-13.

40. Cummins A, Palmer C, Mossman B, Taatjes D. Persistent localization of activated extracellular signal-regulated kinases (ERK1/2) is epithelial cell-specific in an inhalation model of asbestosis. Am J Pathol 2003;162:713-20.

41. Scapoli L, Ramos-Nino M, Martinelli M, Mossman B. Src-dependent ERK5 and Src/EGFR-dependent ERK1/2 activation is required for cell proliferation by asbestos. Oncogene 2004;23:805-13. 
42. Zanella C, Timblin C, Cummins A, et al. Asbestos-induced phosphorylation of epidermal growth factor receptor is linked to c-fos expression and apoptosis. Am J Physiol Lung Cell Mol Physiol 1999;277:L684-93.

43. Ramos-Ninos M, Timblin C, Mossman B. Mesothelial cell transformation requires increased AP-1 binding activity and ERK-dependent Fra-1 expression. Cancer Res 2002;62:6065-9.

44. Midwinter R, Vissers M, Winterbourn C. Hypochlorous acid stimulation of the mitogenactivated protein kinase pathway enhances cell survival. Arch Biochem Biophys 2001;394:13-20.

45. Reddy S, Mossman B. Role and regulation of activator protein-1 in toxicant-induced responses of the lung. Am J Physiol Lung Cell Mol Physiol 2002;283:L1161-78.

46. Tamamori-Adachi $M$, Ito $H$, Sumrejkanchanakij $P$, et al. Critical role of cyclin D1 nuclear import in cardiomyocyte proliferation. Circ Res 2003;92:e12-9.

47. Burch PM, Yuan Z, Loonen A, Heintz NH. An extracellular signal-regulated kinase 1- and 2-dependent program of chromatin trafficking of c-Fos and Fra-1 is required for cyclin D1 expression during cell cycle reentry. Mol Cell Biol 2004;24:4696-709. 


\section{MYELOPEROXIDASE DEFICIENCY ATTENUATES LPS-INDUCED ACUTE LUNG INFLAMMATION AND SUBSEQUENT EPITHELIAL INJURY}

Astrid Haegens, Juanita H.J. Vernooy, Peter Heeringa, Sarah Bolton, Robert Jan van Suylen, Chad Steele, Yasuaki Aratani, Brooke T. Mossman, Emiel F.M. Wouters

Submitted 
Chapter 4 


\section{ABSTRACT}

Lung neutrophilia is common to a variety of lung diseases. The production of reactive oxygen and nitrogen species during neutrophils oxidative burst has been associated with protein and DNA damage. Myeloperoxidase (MPO) is an enzyme stored in the granula of neutrophils. It is important in the host defence because it generates the reactive oxidant, hypochlorous acid. MPO enzyme activity also results in the formation of the protein adduct chlorotyrosine and the formation of reactive nitrogen species.

We hypothesized that MPO contributes to the development of lung neutrophilia and the subsequent oxidative stress and damage by LPS to cellular and molecular structures in the lung. To test this hypothesis wild type (WT) and $\mathrm{Mpo}^{-/-}$ mice were given a single LPS instillation after which the development of lung neutrophilia, oxidative stress, DNA damage and nitrotyrosine formation were examined. $\mathrm{Mpo}^{-/}$mice demonstrated a decreased lung neutrophilia that peaked earlier compared to neutrophilia in WT mice. Oxidative stress, indirectly measured by heme-oxygenase 1 (ho-1) expression and DNA damage, assessed by 8-hydroxy-2'deoxyguanosine (8-OHdG) staining were however not different in LPS exposed WT and $\mathrm{Mpo}^{-/}$mice. Nitrotyrosine formation was decreased in LPS exposed $\mathrm{Mpo}^{-/}$mice compared to WT mice. These results indicate that MPO not only contributes to protein modification, but also promotes the development of lung neutrophilia. 


\section{INTRODUCTION}

Neutrophilia is a feature common to all stages of chronic obstructive pulmonary disease (COPD) (1) and increased neutrophil levels are reported in induced sputum of COPD patients during exacerbations (2). Neutrophilia is also a key player in lung disorders such as acute respiratory distress syndrome (3), idiopathic pulmonary fibrosis (4), asbestosis (5) and cystic fibrosis (7). Reactive oxygen and nitrogen species (ROS/RNS) produced during the oxidative burst of neutrophils, contribute significantly to tissue damage. Nitrotyrosine $\left(\mathrm{NO}_{2} \mathrm{Tyr}\right)$ formation is a marker of neutrophilia related protein modification $(6,7)$. A recent study has reported increased levels of $\mathrm{NO}_{2}$ Tyr positive inflammatory cells and MPO in sputum of severe COPD patients (8). Besides from protein damage, lung neutrophilia is associated with DNA damage in the respiratory tract, as described in a recently published review (9).

MPO has been described as a protein with pro-inflammatory properties independent of its enzymatic activity (10). We have recently reported data demonstrating a significant reduction of neutrophil influx in Mpo knock out $\left(^{-{ }_{-}}\right)$mice as compared to $\mathrm{Mpo}^{+/+}$wild type (WT) mice after inhalation of the inflammatory fiber chrysotile asbestos (11). This clearly implicates that MPO plays a critical role in the development of asbestos induced lung inflammation.

In this study the hypothesis that MPO contributes to the development of lung neutrophilia and the subsequent oxidative stress and damage by LPS to cellular and molecular structures in the lung is tested. This was done by exposing $\mathrm{Mpo}^{-/-}$and WT mice to a single intratracheal instillation of LPS to induce transient lung neutrophilia.

The development of lung neutrophilia was examined by quantification of neutrophil influx and MPO activity. $\mathrm{NO}_{2}$ Tyr formation in lungs was analyzed as markers of neutrophil related oxidative protein modification. Furthermore, oxidative DNA damage was investigated by 8-hydroxy-2'deoxyguanosine (8$\mathrm{OHdG}$ ) staining. Oxidative stress was examined by heme-oxygenase 1 (ho-1) expression. HO-1 is an anti-oxidant and therefore an indirect marker of oxidative stress. Lastly, cytokine and chemokine expression in lungs and BALF were investigated.

Our results show that LPS exposure results in a dramatic increase in MPO activity in WT mice. Neutrophil influx in response to LPS exposure is significantly decreased in $\mathrm{Mpo}^{-/}$mice compared to WT mice. Ho-1 expression levels increased after LPS exposure but similar levels were observed in WT and $\mathrm{MpO}^{-/}$mice, as were 8-OHdG levels. $\mathrm{NO}_{2}$ Tyr formation was significantly increased after LPS exposure, but reduced in $\mathrm{Mpo}^{-/}$compared to WT mice. Lastly, LPS exposed $\mathrm{MpO}^{-/}$mice demonstrated an altered pattern of IL-6, keratinocyte-derived chemokine (KC), MIP-1 $\alpha$, RANTES, IL-13 and IFN- $\gamma$ in BALF in comparison to WT mice. Although measures of oxidative damage were unchanged, data suggest that MPO not only plays an important role in the development of lung neutrophilia, but also contributes to $\mathrm{NO}_{2} \mathrm{Tyr}$ formation 
to proteins in resident lung cells and altered chemokine and cytokine production that may govern inflammatory responses.

\section{MATERIALS AND METHODS}

Animals and treatment 12-wk-old male WT C57BL/6 mice were obtained from Charles River (Maastricht, The Netherlands). $\mathrm{Mpo}^{-/}$mice were generated by Y. Aratani (12) and bred into the C57BL/6 background. Mice were housed individually in standard laboratory cages and allowed food and water ad libitum throughout the experiments. The studies were carried out under a protocol approved by the Institutional Animal Care Committee of Maastricht University. WT C57BL/6 and $\mathrm{Mpo}^{-/}$mice $(\mathrm{n}=6$ per group) were anesthetized with a mix of $75 \mathrm{mg} / \mathrm{kilog}$ ram ketamine (Nimatek, Auv Cuijk, The Netherlands) and 3mg/kg xylazine (Sedamun, Auv Cuijk, The Netherlands), and acute lung inflammation was induced by intratracheal instillation of $20 \mu \mathrm{g}$ LPS (Escherichia coli, serotype O55:B5, Sigma, St.Louis, MO) dissolved in $50 \mu$ sterile $0.9 \% \mathrm{NaCl}$ as described previously (13). Sham mice were instilled with $50 \mu \mathrm{LPS}$-free sterile $0.9 \% \mathrm{NaCl}$. After intratracheal instillation, mice were kept in an upright position for 10 minutes to allow the fluid to spread throughout the lungs. Mice were sacrificied $1,2,3,4$ or 5 days after LPS instillation with $115 \mathrm{mg} / \mathrm{kg}$ sodium pentobarbital (Ceva Sante Animale, Maassluis, the Netherlands) and right lung lobes were removed and snap frozen at $-80^{\circ} \mathrm{C}$. Left lung lobes were prepared for immunohistochemistry as described below. Separate animals were used for collection of bronchoalveolar lavage fluid (BALF).

Myeloperoxidase activity assay MPO activity was determined using a Myeloperoxidase Assay Kit (CytoStore, Calgary, Canada) according to manufacturer's protocol. Briefly, approximately $50 \mu \mathrm{g}$ of snap frozen lung from LPS and sham treated animals was homogenized in $1 \mathrm{ml}$ cold sample buffer and centrifuged at $4^{\circ} \mathrm{C}$ for 5 minutes at $14,000 \mathrm{rpm}$. MPO activity was determined in 20 $\mu \mathrm{l}$ supernatants in duplicate using development reagent. Activity was measured over 25 seconds at $450 \mathrm{~nm}$. Development reagent without sample was used as a control.

Immunohistochemistry After thoracotomy the left lung was inflated with $10 \%$ zinc-buffered formalin ( $\mathrm{pH} \mathrm{5.5)}$ at a pressure of $20 \mathrm{~cm} \mathrm{H}_{2} \mathrm{O}$ through the trachea and subsequently fixed in $10 \%$ zinc-buffered formalin for 24 hours. After paraffin embedding, $4 \mu \mathrm{m}$ sections were cut and mounted on slides.

MPO staining Lung sections from sham and LPS-exposed mice were deparaffinized, and endogenous peroxidase activity was blocked with $0.3 \% \mathrm{H}_{2} \mathrm{O}_{2}$ in methanol. Sections were blocked using $20 \%(\mathrm{v} / \mathrm{v})$ normal swine serum in TBS for 30 min. MPO was detected using a polyclonal rabbit anti-MPO antibody (0398, DAKO, Glostrup, Denmark) followed by a swine anti-rabbit biotin labelled secondary antibody (E0413, DAKO). Labeling was visualised using avidin-biotin peroxidase (K0377, DAKO) and histogreen (Linaris, Wertheim, Germany). 
8-OHdG staining Sections were deparaffinized and endogenous peroxidase activity was blocked as described above. Antigen retrieval was performed by microwave treatment in Vector Unmasking Fluid (Vector Laboratories, Burlingame, CA). Primary antibody mouse anti-mouse 8-OHdG (N45.1, Japan Institute for the Control of Aging) was used together with the Mouse on Mouse Kit (Vector Laboratories, Burlingame, CA) according to manufacturer's protocol. Labeling was visualized with avidin-biotin peroxidase (Vector Laboratories) and 3,3'-diaminobenzidine (DAKO). Controls include omitting primary antibody and isotype control lgG1 (DAKO). Both controls were negative.

$\mathrm{NO}_{2} \mathrm{Ty}$ r staining Sections were deparaffinized and blocked as described above. Antigen retrieval was performed by microwave treatment in $10 \mathrm{mM}$ citrate buffer ( $\mathrm{pH}$ 6.0). Primary antibody mouse anti- $\mathrm{NO}_{2}$ (189542, Cayman Chemical, Ann Arbor, MI) was used together with the Mouse on Mouse Kit. Labeling was visualized as described above. Staining controls were performed by omitting primary antibodies and revealed no staining.

Quantification of neutrophil influx and $\mathrm{NO}_{2}$ Tyr formation in lung tissue H\&E stained sections were used to quantify infiltration of neutrophils into lungs. At a magnification of 200X, random fields were selected and the number of infiltrated still intact neutrophils was counted. At least 5 fields per section were analyzed. $\mathrm{NO}_{2}$ Tyr formation was scored blindly by 3 separate observers and scaled 1-5 with: 1 indicating no $\mathrm{NO}_{2}$ Tyr staining; 2 showing light staining in areas of $\mathrm{NO}_{2} \mathrm{Tyr}$ formation; 3 indicating clear $\mathrm{NO}_{2} \mathrm{Tyr}$ formation without intense stained areas; 4 showing local intense staining; and 5 as intense $\mathrm{NO}_{2} \mathrm{Tyr}$ formation through the entire section.

Quantitative PCR detection of ho-1 expression Total lung RNA was isolated using the RNeasy Mini Kit (Qiagen Inc., CA) according to manufacturer's protocol. Total RNA was reverse transcribed, using the Abgene Kit (Abgene, Epsom, UK) with random decamers and oligo dT primers, and the resulting cDNA was amplified by real-time PCR using the MylQ5 (Biorad, Hercules, CA) with the following primers: ho-1 (Forward) 5'-CCGCCTTCCTGCTCAACAT-3', (Reverse) 5'-CATCTGTGAGGGACTCTGGTCTT-3', Calnexin (Forward) 5'GCAGCGACCTATGATTGACAACC-3, (Reverse) 5'- GCTCCAAACCAATAGCACTGAAAGG -3'. Each PCR reaction contained 1X SYBR® Green PCR master mix (Applied Biosystems, Foster City, CA) and $0.3 \mu \mathrm{M}$ each of forward and reverse primer. Following, an initial $10 \mathrm{~min}$ incubation at $95^{\circ} \mathrm{C}$, thermal cycling was performed using 45 cycles of $94^{\circ} \mathrm{C}$ for $15 \mathrm{~s}, 60^{\circ} \mathrm{C}$ for $30 \mathrm{~s}$ and $72^{\circ} \mathrm{C}$ for 30 s. Gene expression was quantified using standard curves for the respective cDNA products. All changes in ho-1 cDNA levels were normalized to changes in calnexin cDNA as a "housekeeping" gene.

Taqman gene expression assay Quantitative PCR amplifications were performed according to manufacturer's protocol on an ABI Prism 7900HT Sequence Detection System (Applied Biosystems, Applera Nederland, Nieuwekerk a/d IJssel, The Netherlands), using 384 wells plates precoated with 
Taqman primer/probes from Applied Biosystems (low density array format). Table 1 shows the genes and respective Assay IDs for the predesigned TaqMan probe and primer sets (Applied Biosystems) used. The binding probes were 5'-labeled with a 6-carboxyfluorescein dye and a non-fluorescent quencher at the $3^{\prime}$ end. All assays span exon-intron boundaries and cover the major transcript forms. Ten $\mu$ l of cDNA was mixed with $40 \mu \mathrm{l}$ of nuclease-free water and $50 \mu \mathrm{l}$ of TaqMan Universal PCR Master Mix. One hundred $\mu \mathrm{l}$ of the sample-specific PCR mixture was loaded into 1 sample port; the cards were centrifuged twice for $1 \mathrm{~min}$ at $1200 \mathrm{rpm}$ and sealed to prevent well-to-well contamination. The cards were placed in the Micro Fluidic Card Sample Block of an ABI Prism 7900 HT Sequence Detection System (Applied Biosystems). The thermal cycling conditions were $2 \mathrm{~min}$ at $50^{\circ} \mathrm{C}$ and $10 \mathrm{~min}$ at $94.5^{\circ} \mathrm{C}$, followed by 40 cycles of $30 \mathrm{~s}$ at $97^{\circ} \mathrm{C}$ and $1 \mathrm{~min}$ at $59.7^{\circ} \mathrm{C}$. Relative quantitation of gene expression was calculated on the expression of the house keeping gene gapdh according to the comparative $\mathrm{Ct}$ method $\left(\Delta \mathrm{Ct}=\mathrm{Ct}_{\text {gene of interest }}-\mathrm{Ct}_{\text {gapdh }}\right)$. Comparison of gene expression in different samples was performed based on the differences in $\Delta \mathrm{Ct}$ of individual samples $(\Delta \Delta \mathrm{Ct})$.

Table I: Gene Array ID's

\begin{tabular}{|c|c|}
\hline \multicolumn{2}{|c|}{ CYTOKINE RECEPTORS } \\
\hline TNFr1 $\alpha$ & Mm00441875_m1 \\
\hline TNFr1 $\beta$ & Mm00441889_m1 \\
\hline CHEMOKINE RECEPTORS \\
\hline CCR1 & Mm00438260_s1 \\
\hline CXCR1 & Mm00731329_s1 \\
\hline CXCR2 & Mm00438258_m1 \\
\hline \multicolumn{2}{|c|}{ TOLL LIKE RECEPTORS } \\
\hline TLR-4 & Mm00445274_m1 \\
\hline \multicolumn{2}{|c|}{ CYTOKINES } \\
\hline IL-6 & Mm00446190_m1 \\
\hline TNF- $\alpha$ & Mm00443258_m1 \\
\hline IL-10 & Mm00439616_m1 \\
\hline IL-1 $\beta$ & Mm00434228_m1 \\
\hline \multicolumn{2}{|c|}{ CHEMOKINES } \\
\hline MIP-1 $\alpha$ & Mm00441258_m1 \\
\hline KC & Mm00433859_m1 \\
\hline RANTES & Mm01302428_m1 \\
\hline MIP-2 & Mm00436450_m1 \\
\hline MCP-1 & Mm00441242_m1 \\
\hline GAPDH & Mm99999915_g1 \\
\hline
\end{tabular}

Bioplex analysis of plasma cytokines and chemokines To quantify cytokine and chemokine levels in BALF, a multiplex suspension protein array was performed using the Bioplex Protein Array System and a Mouse cytokine 23-plex panel (BioRad, Hercules, CA) as described in (14). This method of analysis is based on Luminex ${ }^{\mathrm{TM}}$ technology and simultaneously measures IL-1 $\alpha$, IL- $1 \beta$, IL2, IL-3, IL-4, IL-5, IL-6, IL-9, IL-10, IL12(p40), IL-12(p70), IL-13, IL-17, TNF- $\alpha$, RANTES, MIP-1 $\alpha$, MIP- $1 \beta$, MCP-1, KC, G-CSF, GM-CSF, IFN-Y and Eotaxin protein. Briefly, anticytokine/chemokine antibody conjugated beads were added to individual wells of 96-well filter plate and adhered using vacuum filtration. After washing, $50 \mu \mathrm{l}$ of pre-diluted of standards (range between $32,000 \mathrm{pg} / \mathrm{ml}$ and $1.95 \mathrm{pg} / \mathrm{ml}$ ) or plasma samples were added and the filter plate shaken at $300 \mathrm{rpm}$. Thereafter, the filter plate was washed, and $25 \mu \mathrm{l}$ of 
pre-diluted multiplex biotin-conjugated antibody was added. After washing, 50 $\mu \mathrm{l}$ of pre-diluted streptavidin conjugated phycoerythrin was added followed by an additional wash and the addition of $125 \mu$ of Bio-plex buffer to each well. The filter plate was analyzed using the Bio-Plex Protein Array System, and concentrations of each cytokine and chemokine were determined using BioPlex Manager Version 3.0 software.

Statistical Analysis Data were reported as mean \pm SEM. Data were analyzed using the Mann-Whitney $U$ test. Values of $p \leq 0.05$ between groups were considered significant.

\section{RESULTS}

\section{Development of acute lung neutrophilia after intratracheal LPS instil- lation}

To determine MPO activity at each time point during inflammation and to confirm $\mathrm{Mpo}^{-/}$status, total MPO activity was determined in lung tissue of WT and $M^{-/-}$mice after LPS exposure. Figure 1 shows a time dependent increase in MPO activity after LPS exposure in WT animals. MPO activity peaks 2-3 days after instillation and decreases to control levels after 4 days. $\mathrm{Mpo}^{-/-}$mice do not demonstrate MPO activity.

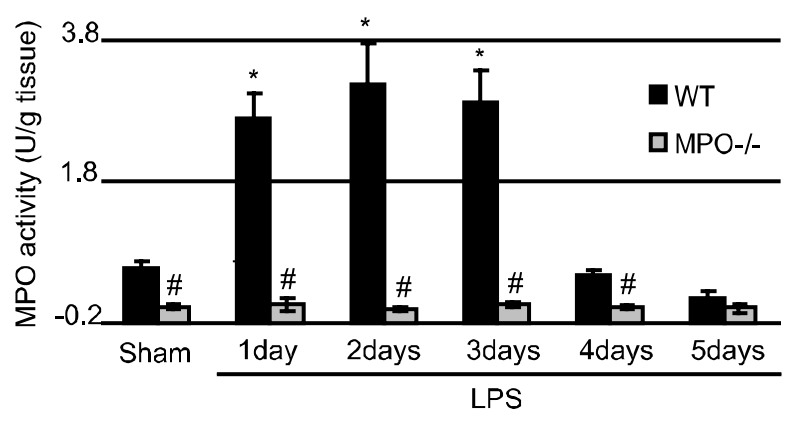

Figure 1: Increases in MPO activity in whole lung homogenates from LPS-exposed WT, but not $\mathrm{MpO}^{-/-}$mice. MPO activity increased rapidly after LPS instillation and returned back to normal 4 days post exposure. Absence of MPO activity in sham and LPS-exposed $\mathrm{Mpo}^{-/-}$mice confirms their knock-out status. Values are represented as mean \pm SEM. * $p \leq 0.05$ in comparison to respective sham group. \# $p$ $\leq 0.05$ in comparison to LPS exposed WT mice.

To localize MPO in the lungs of WT animals and to confirm the absence of MPO activity in $\mathrm{Mpo}^{-/}$mice, sections were stained for MPO. WT animals exposed to LPS showed MPO staining in neutrophil clusters through out the lung (Figure 2B). While no MPO staining occurred in WT sham (A) and both sham and LPS exposed $\mathrm{Mpo}^{-/}$mice $(\mathrm{C}, \mathrm{D})$ in lung. 


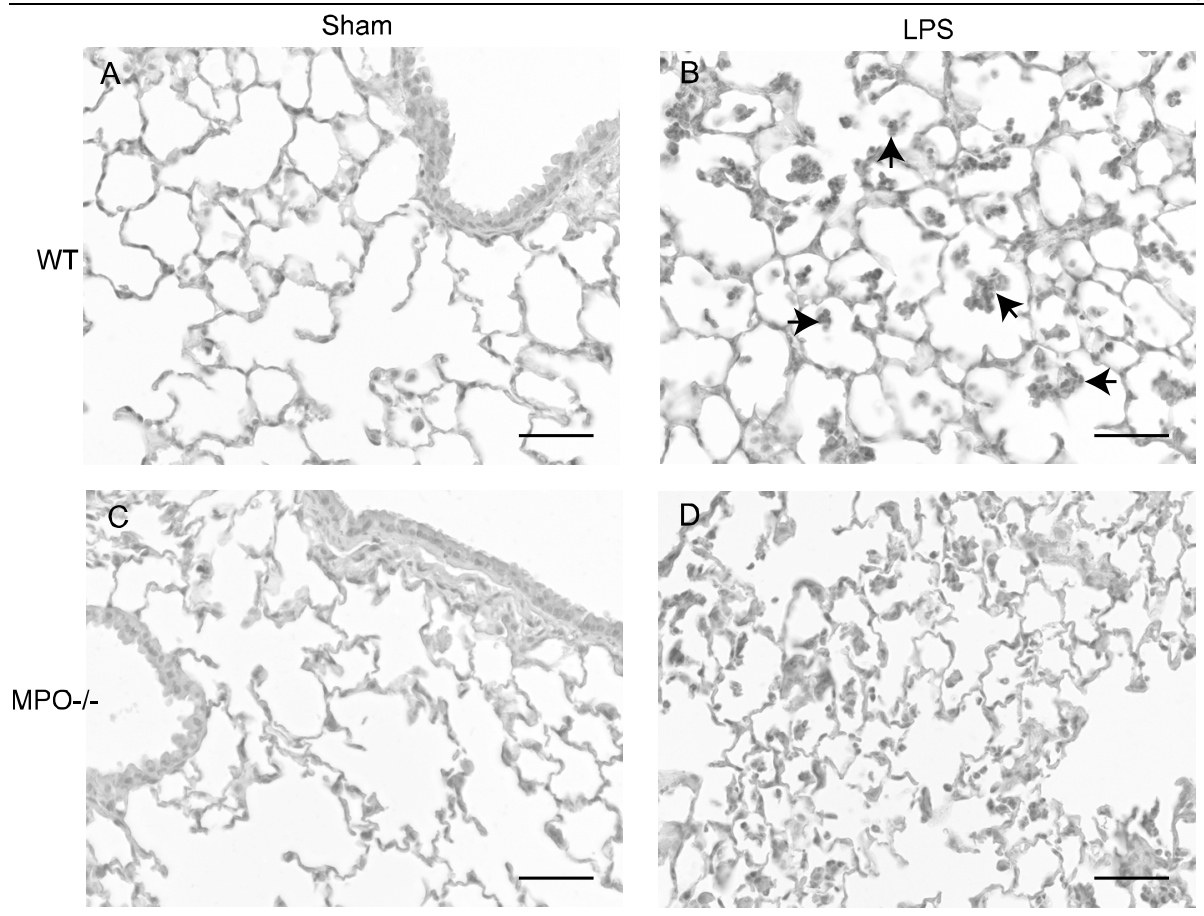

Figure 2: LPS exposure increases MPO levels in WT mouse lungs that are localized in clusters of infiltrating neutrophils. Paraffin sections of sham and LPS-exposed WT and $\mathrm{Mpo}^{-/}$ mice were stained for MPO. A, Sham WT. B, LPS WT. C, Sham Mpo ${ }^{-/}$. D, LPS-exposed $\mathrm{Mpo}^{-/-}$mice lack MPO staining. Bars $=50 \mu \mathrm{m}$.

In line with MPO activity data above we demonstrate in Figure 3 a striking increase in neutrophil influx in WT mice that peaks 3 days post exposure and returns to control levels 5 days after exposure. LPS exposed $\mathrm{MpO}^{-/}$mice show a striking decrease in neutrophil influx as compared to WT mice. Moreover, in comparison to WT mice lung neutrophilia in $\mathrm{Mpo}^{-/}$mice peaks earlier, namely 2 days post exposure and returns to control levels by day 5 .

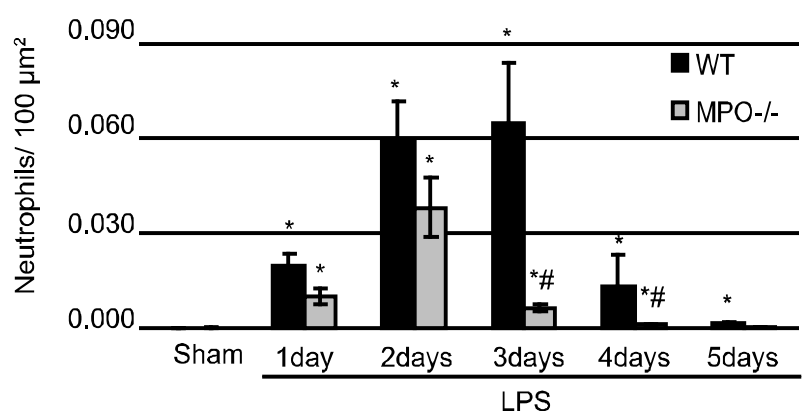

Figure 3: Decreased neutrophil influx after LPS exposure in lungs of $\mathrm{Mpo}^{-/}$mice lungs as compared to WT mouse lungs. Quantification of neutrophil influx on H\&E stained paraffin sections demonstrated an inflammatory peak at 2-3 days post exposure. Values are represented as mean \pm SEM. * $p \leq 0.05$ in comparison to respective ham. \# $\mathrm{p} \leq 0.05$ in comparison to LPS-exposed WT mice. 
Increased anti-oxidant expression as a result of increased total oxidative stress in LPS- exposed WT and $\mathrm{Mpo}^{-/-}$mice

Ho-1 mRNA expression was examined in whole lung RNA of LPS exposed WT and, $\mathrm{Mpo}^{-/}$mice as a general marker of oxidative stress. Indeed, LPS induced an increase in ho-1 expression in WT and $\mathrm{Mpo}^{-/}$mouse lungs as shown in Figure 4A significant from sham groups at all times, i.e. 4 and 5 days. $\mathrm{Mpo}^{-/-}$ mice showed similar ho-1 expression levels compared to WT mice. The expression of ho-1 relative to amount of neutrophil infiltration in lung, however, was higher in $\mathrm{Mpo}^{-/}$mice compared to WT mice (Figure 4B).

A

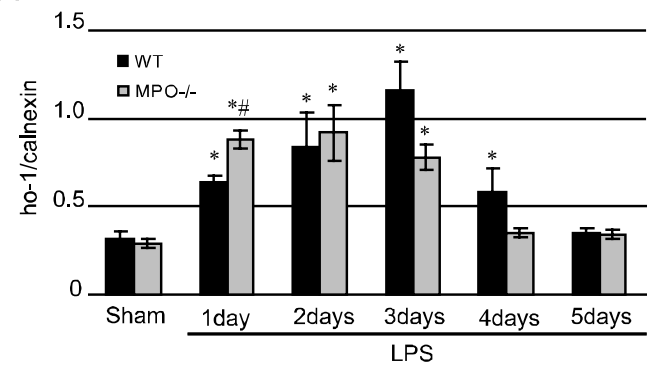

B

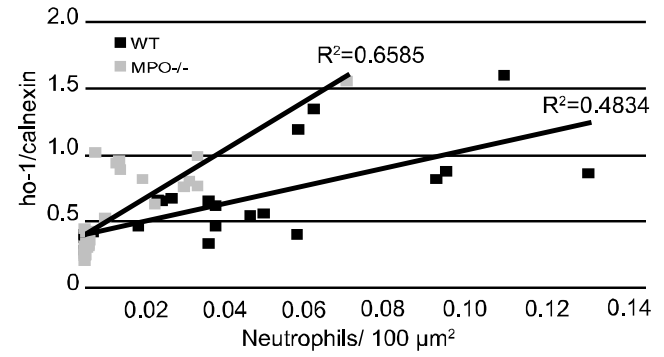

Figure 4: LPS instillation results in increased mRNA expression of ho-1 in WT and $\mathrm{Mpo}^{-/}$mice. A) Whole lung mRNA was isolated and ho-1 expression was analyzed by Q-PCR and normalized against calnexin expression. Ho-1 expression increased after LPS instillation, but similar levels were found in WT and $\mathrm{Mpo}^{-/-}$ mice. Values are represented as mean \pm SEM. B) Ho-1 expression correlated with number of infiltrating neutrophils, but the expression of ho-1 relative to neutrophil infiltration was higher in $\mathrm{Mpo}^{-/}$mice compared to WT. ${ }^{*} p \leq 0.05$ in comparison to respective sham. \# $p \leq 0.05$ in comparison to LPS exposed WT mice.

\section{Oxidative stress-induced 8-OHdG DNA damage in WT and $\mathrm{Mpo}^{-/-}$mice}

Lung neutrophilia is known to induce oxidative stress related DNA damage to lung epithelial cells $(9,15)$. The contribution of MPO to possible DNA damage by LPS was investigated by $8-\mathrm{OHdG}$ determination. Figure $5 \mathrm{~A}$ and $5 \mathrm{~B}$ demonstrate that immunohistochemical analysis of $8-\mathrm{OHdG}$ revealed $80-90 \%$ positive nuclei in bronchiolar and alveolar epithelial cells in sham treated animals. These same levels were also found in LPS-treated WT and $\mathrm{Mpo}^{-/-}$mice (Figure $5 \mathrm{C}-\mathrm{D}$ ). All infiltrating neutrophils in LPS treated mice stained positive for 8OHdG. 

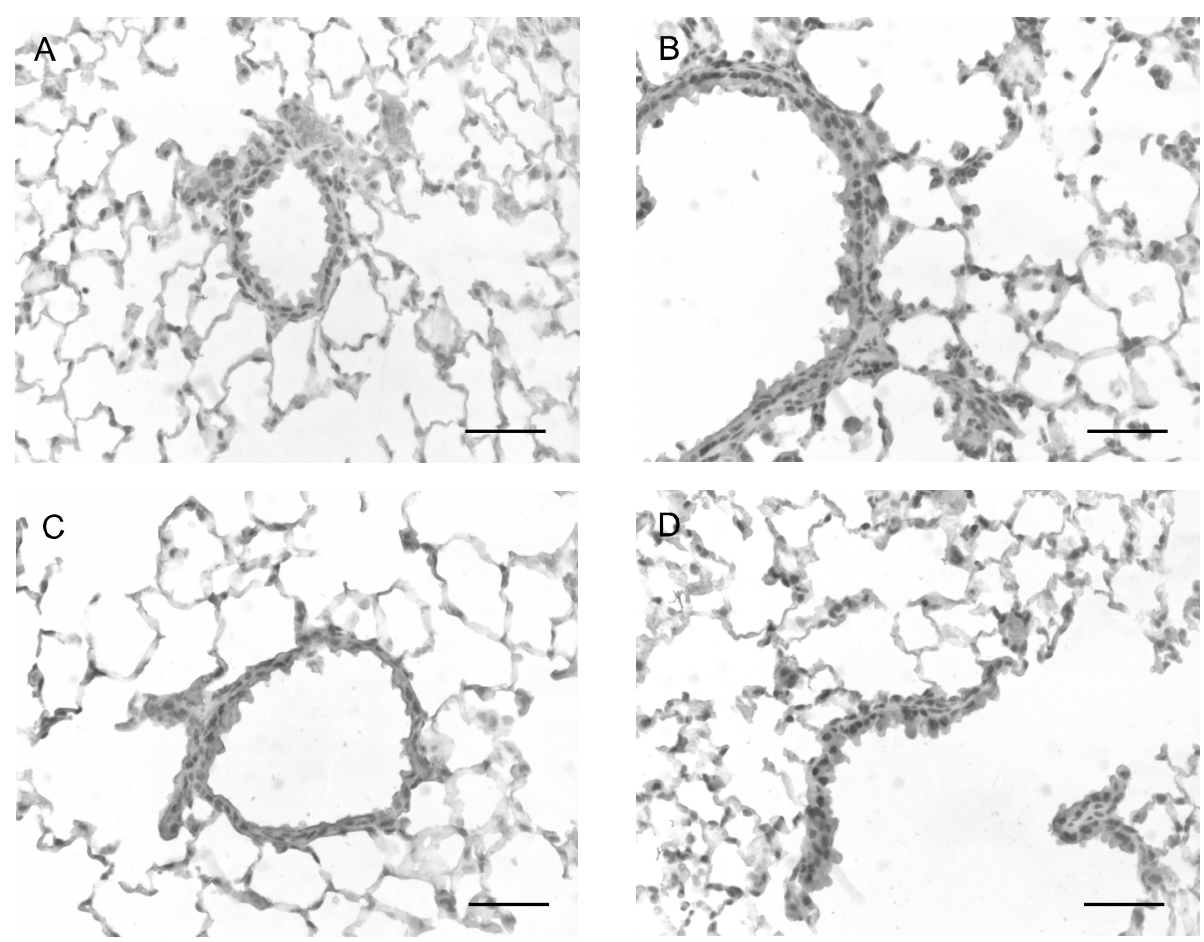

Figure 5: 8-OHdG immunostaining revealed no differences between sham and LPS exposed WT and $\mathrm{MpO}^{-/-}$mice. Paraffin sections of $\mathrm{NaCl}$ (sham) and LPS exposed WT and $\mathrm{Mpo}^{--}$mice were prepared and stained for 8-OHdG. High levels (80-90\%) of DNA adduct formation occurred in lung epithelium of sham mice. LPS exposed WT and $\mathrm{Mpo}^{-/}$demonstrated similar levels of 8-OHdG staining in alveolar and bronchial epithelial cells 72 hours after LPS instillation compared to sham mice. All recruited inflammatory cells, in WT and $\mathrm{Mpo}^{-/-}$mice showed 8-OHdG staining. A, Sham WT. B, LPS WT. C, Sham $\mathrm{Mpo}^{-/}$. D, LPS $\mathrm{Mpo}^{-/}$. Bars, $50 \mu \mathrm{m}$.

Decreased oxidative protein modification in $\mathrm{Mpo}^{-/-}$compared to WT mice Semi-quantitative scoring of immunohistochemical analysis of $\mathrm{NO}_{2} \mathrm{Tyr}$ formation revealed an increase in $\mathrm{NO}_{2} \mathrm{Tyr}$ staining in LPS-treated WT and $\mathrm{Mpo}^{-/}$ animals compared to sham treated mice. $\mathrm{NO}_{2} \mathrm{Tyr}$ formation in LPS-treated $\mathrm{Mpo}^{-\alpha}$ mice showed trend toward a decrease compared to WT mice (Figure $6 \mathrm{C})$. In WT and $\mathrm{Mpo}^{-/}$lungs, $\mathrm{NO}_{2} \mathrm{Tyr}$ formation was specifically localized at sites of neutrophil infiltration and was present in and on all resident lung cells and infiltrated inflammatory cells (Figure 6 A-B). 
A

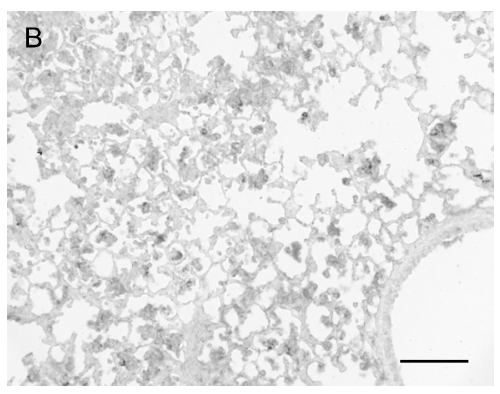

C

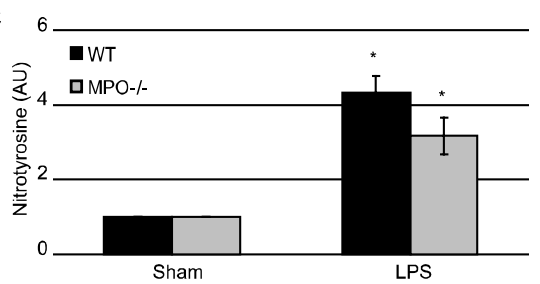

Figure 6: Decreased $\mathrm{NO}_{2} \mathrm{Tyr}$ formation in $\mathrm{Mpo}^{-/}$ mice compared to WT mice after LPS exposure. Paraffin sections of A) $\mathrm{NaCl}$ (sham) and B) LPSexposed WT and $\mathrm{Mpo}^{-/}$mice were stained for $\mathrm{NO}_{2}$ Tyr. $\mathrm{NO}_{2}$ Tyr formation was present at sites in all cells at sites of neutrophil infiltration. C) Semiquantitative analysis of $\mathrm{NO}_{2} \mathrm{Tyr}$ formation. Values are represented as mean \pm SEM. ${ }^{*} p \leq 0.05$ in comparison to respective WT.

\section{$\mathrm{Mpo}^{-/}$mice show normal inflammatory} receptor gene expression patterns

Possible knock-out effects on expression patterns of several receptors known to be important in the development of lung inflammation were investigated by Q-PCR. TIr-4, tnfr-1 $\alpha$, tnfr-1 $\beta, \quad c c r-1$ and $c x c r-2$ mRNA levels were not different in sham treated WT and $\mathrm{Mpo}^{-/-}$mice (Figure 7). In contrast to what one would expect, $c x c r-1$ expression was significantly increased in sham treated $\mathrm{Mpo}^{--}$mice compared to WT mice. 


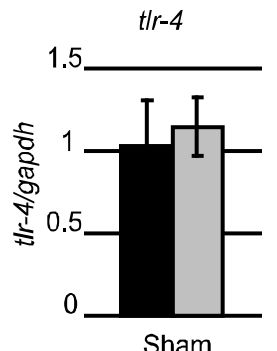

ccr-1

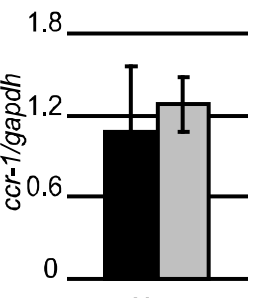

Sham

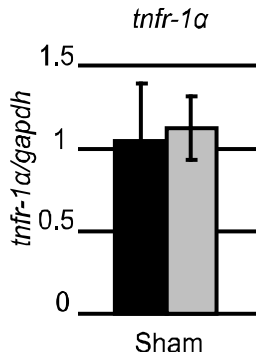

cXcr-1

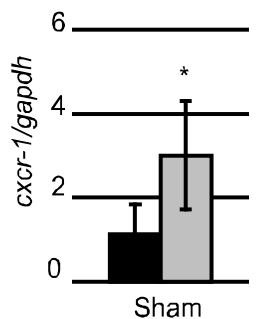

$\operatorname{tnfr}-1 ß$

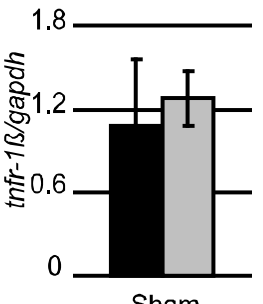

Sham

cxcr-2

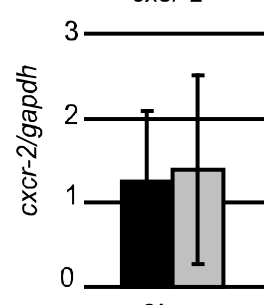

Figure 7: Similar receptor mRNA expression levels in WT and $\mathrm{Mpo}^{-/}$mice. Expression levels of t/r-4 and cytokine and chemokine receptors were measured in whole lung mRNA after $\mathrm{NaCl}$ instillation as described in Materials and Methods. Values are represented as mean \pm SEM. * $p$ $\leq 0.05$ in comparison to respective WT.

Sham

$\mathrm{Mpo}^{-/}$mice show altered patterns of inflammation associated cytokines and chemokines

The induction of cytokines and chemokines was determined on mRNA levels 2 days post exposure and protein levels were determined 3 days post exposure in BALF. Figure 8 demonstrates a significant increase in mRNA expression of neutrophil and macrophage chemotactic proteins il-6, $k c$, mip-1 $\alpha$ and rantes after LPS in WT mice. mRNA expression levels of $k c$ and rantes were significantly reduced in $\mathrm{Mpo}^{-/-}$after LPS as compared to WT mice. Of the investigated cytokines and chemokines tnf- $\alpha, i l-1 \beta, i l-10, m c p-1$ and mip-2 showed a significant increase in mRNA expression after LPS exposure, but knock-out effects were not observed (data not shown). Although mRNA expression levels of $i l-6$ and mip-1a were not reduced in $\mathrm{Mpo}^{-/-}$mice either, Figure 9 shows that protein levels of IL-6 and MIP-1 $\alpha$ were significantly reduced in $\mathrm{Mpo}^{-/-}$mice as compared to WT mice. 

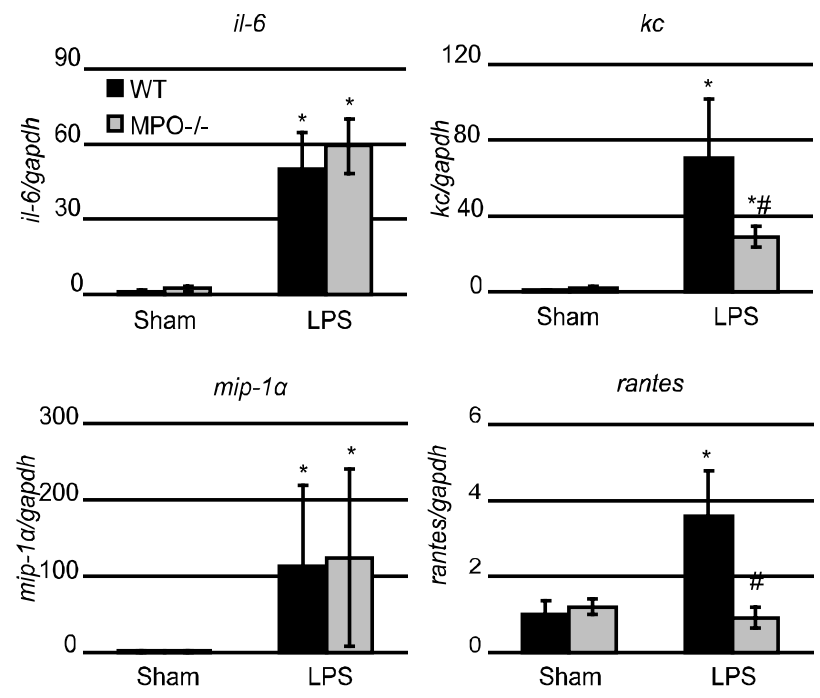

Figure 8: $\mathrm{Mpo}^{-/}$mice show altered mRNA expression levels of various cytokines/chemokines as compared to WT mice after LPS instillation. Cytokine and chemokine expression levels were measured in whole lung mRNA 2 days after LPS exposure as described in Materials and Methods. Values are represented as mean \pm SEM. * $p$ $\leq 0.05$ in comparison to respective sham. \# $p \leq 0.05$ in comparison to LPS exposed WT mice.

IL-13, capable of inhibiting IL-6 and KC, was decreased in $M p o^{-/}$mice in comparison to WT mice, as was the neutrophil and macrophage activity promoting cytokine IFN- $y$. In line with these results, a significant decrease of the blood monocyte chemoattractant, RANTES, was observed in $\mathrm{Mpo}^{-/}$mice after LPS exposure. IL-4 and IL-9 were also significantly decreased in $\mathrm{Mpo}^{-/-}$mice after LPS exposure compared to WT mice. Of the panel of 23 cytokines and chemokines measured in BALF IL-1 $\alpha$, IL-1 $1 \beta$, IL-3, IL-10, IL-12(p40), IL12(p70), IL-17, MIP-1ß, MCP-1, G-CSF, GM-CSF and Eotaxin were all elevated in BALF after LPS exposure in WT and $\mathrm{Mpo}^{-/}$mice (data not shown). IL2 protein levels showed a slight decrease after LPS exposure (data not shown). Protein concentrations of IL-5 and TNF- $\alpha$ in BALF in respons to LPS were not different from control levels at day 3 in WT and $\mathrm{Mpo}^{-/-}$mice (data not shown). 
IL-6
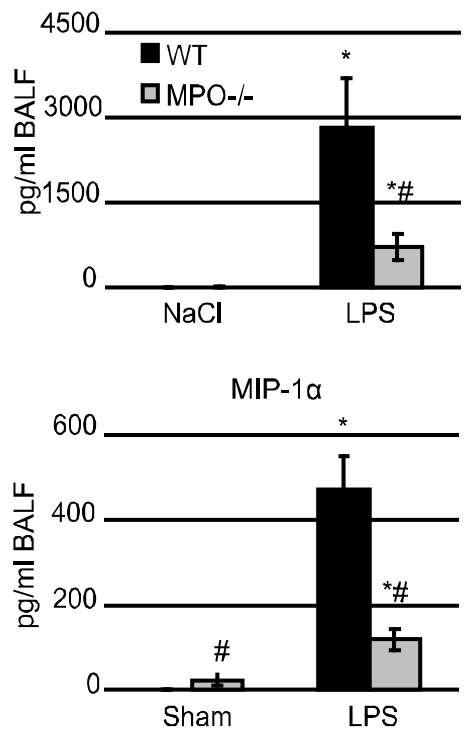

IL-13

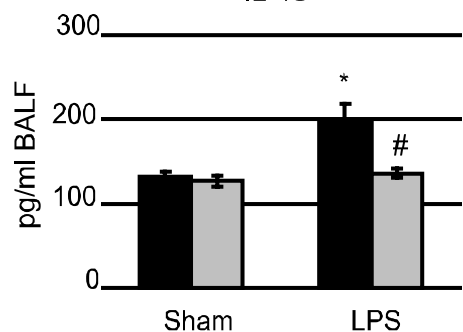

IL-4

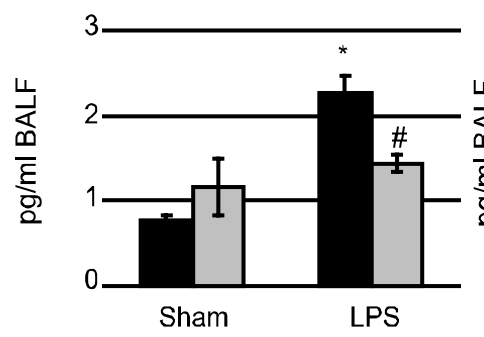

KC

180

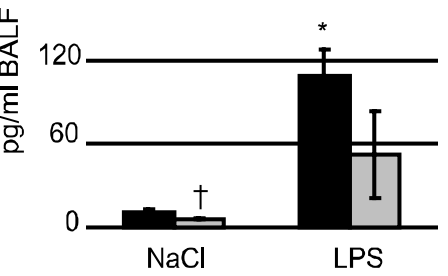

RANTES

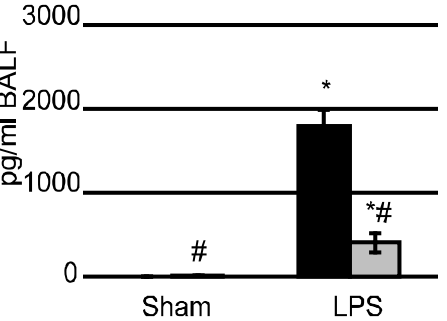

IFN- $\varphi$

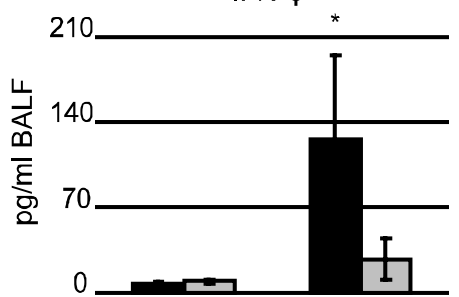

Sham

LPS

IL-9

120

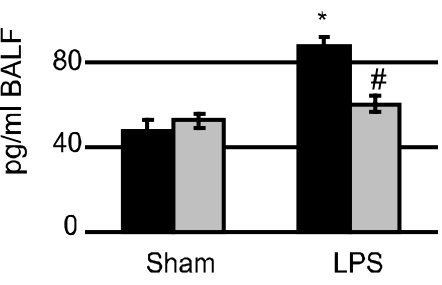

Figure 9: $\mathrm{Mpo}^{-/}$mice demonstrated altered cytokine/chemokines protein levels compared to WT mice after LPS instillation. Cytokine and chemokine protein levels were measured in BALF 3 days after LPS exposure as described in Materials and Methods. Values are represented as mean \pm SEM. * $p \leq 0.05$ in comparison to respective sham. \# p $\leq 0.05$ in comparison to LPS exposed WT mice.

\section{DISCUSSION}

MPO is an important enzyme in innate defence by producing $\mathrm{HOCl}$ and other reactive oxidants (16). This study aimed to investigate the contribution of MPO to LPS induced lung inflammation and subsequent damaging effects on lung 
epithelial cells via the production of reactive oxidants using a knock-out approach. Ideally, after LPS instillation the development of lung neutrophilia would be identical in WT and $\mathrm{Mpo}^{-/}$mice except for the absence of MPO in the knock-out animals. This was however not what we found.

We report here a significant decreased neutrophilia in $\mathrm{Mpo}^{-/-}$mice compared to WT animals that peaks 2 days after LPS exposure. WT mice revealed an inflammatory peak 2-3 days post exposure that returned to control levels 5 days post exposure. This decrease in neutrophil influx in $\mathrm{Mpo}^{-/-}$mice confirms our previous work demonstrating decreased neutrophil levels in BALF of $\mathrm{Mpo}^{-/-}$ compared to WT mice after chrysotile asbestos exposure (11). A similar early peak in neutrophilia, as we report here, has been shown before in $\mathrm{Mpo}^{-/-}$mice in a study on ultraviolet-induced skin inflammation (17). In earlier studies by our group, we reported peak neutrophil influx in Swiss mice 1 day after LPS exposure (18). This suggests a strain-dependent time response to intratracheal LPS instillation.

We furthermore show that LPS instillation results in a dramatic increase in MPO activity in WT mice. Moreover, we demonstrate that MPO is predominantly localized in clusters of infiltrated and activated neutrophils. We demonstrated previously in a mouse model of asbestosis that MPO occurred in distal bronchiolar epithelium at alveolar duct bifurcations, site of asbestos fiber deposition (11). This suggests that distribution of MPO within the lung may be disease model dependent.

Elevated levels of $\mathrm{NO}_{2} \mathrm{Ty}$, an index of protein nitration, are associated with neutrophil influx and have been reported in various lung disorders like COPD $(8,19)$ and idiopathic pulmonary fibrosis $(4)$. In the present study we demonstrate a decrease in $\mathrm{NO}_{2} \mathrm{Tyr}$ formation after LPS exposure in $\mathrm{Mpo}^{-/-}$mice compared to WT animals. This is in line with earlier data demonstrating less nitrotyrosine in $\mathrm{Mpo}^{-/-}$mice in a peritonitis model of acute inflammation (20). A contribution of MPO to protein nitration has also been demonstrated in the lung disease cystic fibrosis (21). Furthermore, MPO dependent nitration mechanisms have been found in the inflammatory condition atherosclerosis (22) and neurodegenerative diseases like multiple sclerosis (23). Other well described mechanisms (6), such as inducible NO synthases (iNOS) may contribute significantly to $\mathrm{NO}_{2}$ Tyr formation which explains why there is still a big increase in $\mathrm{NO}_{2}$ Tyr formation in $\mathrm{Mpo}^{-/-}$mice although the neutrophilic inflammation is dramatically lower in these mice.

Besides effects on protein modification, neutrophil infiltration has also been linked to oxidative stress related DNA damage. We did not find an increase or decrease in the levels of DNA adduct 8-OHdG after LPS instillation in WT or $\mathrm{Mpo}^{-/-}$mice. 8-OHdG has been used extensively to measure DNA damage in models of lung inflammation with various outcomes. Our data are in line with data from an inflammatory model of quartz exposure where no difference was found in 8-OHdG levels in the lungs of sham or quartz exposed rats (24). It has been suggested that $8-\mathrm{OHdG}$ induction would predominantly occur in proliferating cells (25). This could be an explanation for our findings, since we did not find an increase in the proliferation marker Ki-67 (unpublished data) in 
lung cells of LPS exposed WT and $\mathrm{Mpo}^{-/}$mice. A significant increase in ho-1 expression in WT and $\mathrm{Mpo}^{-/-}$mice after LPS exposure was observed suggesting ROS related damage. The dose of LPS used here results in a dramatic lung neutrophilia in WT mice and subsequent oxidative stress. This suggests that compensatory feedback mechanisms like the anti-oxidant marker ho-1 are up-regulated. This dramatic neutrophilia however does not clarify why $\mathrm{Mpo}^{-/-}$ mice show similar patterns of 8-OHdG and ho-1 expression as WT mice. Aratani and colleagues reported data (26) on a study comparing $\mathrm{Mpo}^{-/}$, NADPH-oxidase-/- and double knock-out mice in a model of pulmonary infection that could explain these findings. They reported that $\mathrm{H}_{2} \mathrm{O}_{2}$ used by MPO is solely produced by NADPH-oxidase. It is therefore tempting to speculate that $M p O^{-/}$mice that are incapable of converting $\mathrm{H}_{2} \mathrm{O}_{2}$ to $\mathrm{HOCl}$, build up $\mathrm{H}_{2} \mathrm{O}_{2}$. Increased $\mathrm{H}_{2} \mathrm{O}_{2}$ levels could explain 8-OHdG formation and ho-1 mRNA expression, since $\mathrm{H}_{2} \mathrm{O}_{2}$ is a very potent oxidant like $\mathrm{HOCl}$.

Cytokines and chemokines are key players in the recruitment of neutrophils and macrophages to inflammatory sites. We demonstrate here that the decreased neutrophilia found in $\mathrm{Mpo}^{-/}$mice exposed to intratracheal LPS is not due to differences in inflammatory receptor expression patterns, but due to significantly lower protein levels of the neutrophil attractants KC, IL-6 and MIP$1 \alpha$ in BALF compared to patterns in WT mice. The positive contribution of these inflammatory signaling molecules to the development of lung neutrophilia is in line with the literature. The lowered levels of neutrophil attractants in the lungs of $\mathrm{MpO}^{-/}$mice are in contrast to recent work in a model of lung fungal infection where $\mathrm{Mpo}^{-/-}$mice demonstrated $\mathrm{KC}$ levels comparable to that of WT mice (27). IL-13 has been described to inhibit IL-6 and IL-8 production by human monocytes (28). It is therefore tempting to speculate that decreased protein levels of IL-13 in BALF of $\mathrm{Mpo}^{-/-}$are due to decreased IL-6 and KC, the mouse equivalent of IL-8, levels. After neutrophils become apoptotic, macrophages come in to action to phagocotyze apoptotic cells and cell debris. RANTES has been shown to be a chemoattractant for peripheral blood monocytes. Since neutrophil numbers were significantly lower in $\mathrm{Mpo}^{-/}$mice compared to WT, it is therefore tempting to speculate that as a result of this RANTES production, neutrophils were not increased to the same extent as in WT mice.

Besides from the neutrophil chemo attractants, MPO itself has been described to play a role in the activation of neutrophils. Lau and colleagues (10) have demonstrated that MPO binds to CD11b/CD18 integrins on neutrophils, leading to induction of intracellular signaling cascades and translating into upregulated neutrophil degranulation and CD11b surface expression. CD11b/CD18 is a critical mediator for neutrophil adherence before extravasation. One could therefore speculate that the decreased early neutrophilia is a result of decreased extravasation capacity and that decreased lung epithelial protein damage and chemo attractant production are a consequence of this, leading to earlier clearance of the inflammation.

In summary, our results show that MPO activity is increased after LPS exposure. MPO localizes in clusters of infiltrated and activated neutrophils of LPS 
exposed WT mice. Neutrophil influx in response in $\mathrm{Mpo}^{-/}$mice compared to WT mice is however significantly decreased. Ho-1 expression levels increased after LPS exposure but were similar in WT and $\mathrm{Mpo}^{-/}$mice, as were $8-\mathrm{OHdG}$ levels. $\mathrm{NO}_{2}$ Tyr levels were increased after LPS exposure, but reduced in $\mathrm{Mpo}^{-}$ / compared to WT mice. Lastly, LPS exposed $\mathrm{Mpo}^{-/}$mice demonstrated an altered pattern of inflammatory cytokines and chemokines. Although measures of oxidative damage were unchanged, data suggest that MPO not only plays an important role in the development of lung neutrophilia, but also contributes to $\mathrm{NO}_{2}$ Tyr formation in resident lung cells and altered chemokine and cytokine production that may govern inflammatory responses.

\section{ACKNOWLEDGEMENTS}

The authors would like to thank Betty van der Veen (Department of Pathology and Laboratory Medicine, University Medical Center Groningen, Groningen, the Netherlands), Nadja Drummen (Department of Respiratory Medicine, University Hospital Maastricht, Maastricht, The Netherlands) and Kate Pinnion (Department of Pathology, SAUK, AstraZeneca R\&D Charnwood, Loughborough, Leicestershire, UK) for their excellent technical assistance. 


\section{REFERENCES}

1. Hogg, J. C., F. Chu, S. Utokaparch, R. Woods, W. M. Elliott, L. Buzatu, R. M. Cherniack, R. M. Rogers, F. C. Sciurba, H. O. Coxson, and P. D. Pare. 2004. The nature of smallairway obstruction in chronic obstructive pulmonary disease. N Engl J Med 350:2645.

2. Papi, A., C. M. Bellettato, F. Braccioni, M. Romagnoli, P. Casolari, G. Caramori, L. M. Fabbri, and S. L. Johnston. 2006. Infections and airway inflammation in chronic obstructive pulmonary disease severe exacerbations. Am J Respir Crit Care Med 173:1114.

3. Weiland, J. E., W. B. Davis, J. F. Holter, J. R. Mohammed, P. M. Dorinsky, and J. E. Gadek. 1986. Lung neutrophils in the adult respiratory distress syndrome. Clinical and pathophysiologic significance. Am Rev Respir Dis 133:218.

4. Saleh, D., P. J. Barnes, and A. Giaid. 1997. Increased production of the potent oxidant peroxynitrite in the lungs of patients with idiopathic pulmonary fibrosis. Am J Respir Crit Care Med 155:1763.

5. Cullen, M. R., and W. W. Merrill. 1992. Association between neutrophil concentration in bronchoalveolar lavage fluid and recent losses in diffusing capacity in men formerly exposed to asbestos. Chest 102:682.

6. van der Vliet, A., J. P. Eiserich, M. K. Shigenaga, and C. E. Cross. 1999. Reactive nitrogen species and tyrosine nitration in the respiratory tract: epiphenomena or a pathobiologic mechanism of disease? Am J Respir Crit Care Med 160:1.

7. Gujral, J. S., J. A. Hinson, and H. Jaeschke. 2004. Chlorotyrosine protein adducts are reliable biomarkers of neutrophil-induced cytotoxicity in vivo. Comp Hepatol 3 Suppl 1:S48.

8. Tsoumakidou, M., N. Tzanakis, G. Chrysofakis, and N. M. Siafakas. 2005. Nitrosative stress, heme oxygenase-1 expression and airway inflammation during severe exacerbations of COPD. Chest 127:1911.

9. Knaapen, A. M., N. Gungor, R. P. Schins, P. J. Borm, and F. J. Van Schooten. 2006. Neutrophils and respiratory tract DNA damage and mutagenesis: a review. Mutagenesis 21:225.

10. Lau, D., H. Mollnau, J. P. Eiserich, B. A. Freeman, A. Daiber, U. M. Gehling, J. Brummer, V. Rudolph, T. Munzel, T. Heitzer, T. Meinertz, and S. Baldus. 2005. Myeloperoxidase mediates neutrophil activation by association with CD11b/CD18 integrins. Proc Natl Acad Sci U S A 102:431.

11. Haegens, A., A. van der Vliet, K. J. Butnor, N. Heintz, D. Taatjes, D. Hemenway, P. Vacek, B. A. Freeman, S. L. Hazen, M. L. Brennan, and B. T. Mossman. 2005. Asbestos-induced lung inflammation and epithelial cell proliferation are altered in myeloperoxidase-null mice. Cancer Res 65:9670.

12. Aratani, Y., H. Koyama, S. Nyui, K. Suzuki, F. Kura, and N. Maeda. 1999. Severe impairment in early host defense against Candida albicans in mice deficient in myeloperoxidase. Infect Immun 67:1828.

13. Starcher, B., and I. Williams. 1989. A method for intratracheal instillation of endotoxin into the lungs of mice. Lab Anim 23:234.

14. Sabo-Attwood, T., M. Ramos-Nino, J. Bond, K. J. Butnor, N. Heintz, A. D. Gruber, C. Steele, D. J. Taatjes, P. Vacek, and B. T. Mossman. 2005. Gene expression profiles reveal increased mClca3 (Gob5) expression and mucin production in a murine model of asbestos-induced fibrogenesis. Am J Pathol 167:1243.

15. Guo, R. F., and P. A. Ward. 2007. Role of Oxidants in Lung Injury During Sepsis. Antioxid Redox Signal.

16. Klebanoff, S. J. 1999. Myeloperoxidase. Proc Assoc Am Physicians 111:383.

17. Komatsu, J., H. Koyama, N. Maeda, and Y. Aratani. 2006. Earlier onset of neutrophilmediated inflammation in the ultraviolet-exposed skin of mice deficient in myeloperoxidase and NADPH oxidase. Inflamm Res 55:200.

18. Vernooy, J. H., M. A. Dentener, R. J. van Suylen, W. A. Buurman, and E. F. Wouters. 2001. Intratracheal instillation of lipopolysaccharide in mice induces apoptosis in bronchial epithelial cells: no role for tumor necrosis factor-alpha and infiltrating neutrophils. Am J Respir Cell Mol Biol 24:569. 
19. Ricciardolo, F. L., G. Caramori, K. Ito, A. Capelli, P. Brun, G. Abatangelo, A. Papi, K. F. Chung, I. Adcock, P. J. Barnes, C. F. Donner, A. Rossi, and A. Di Stefano. 2005. Nitrosative stress in the bronchial mucosa of severe chronic obstructive pulmonary disease. J Allergy Clin Immunol 116:1028.

20. Zhang, R., M. L. Brennan, Z. Shen, J. C. MacPherson, D. Schmitt, C. E. Molenda, and S. L. Hazen. 2002. Myeloperoxidase functions as a major enzymatic catalyst for initiation of lipid peroxidation at sites of inflammation. J Biol Chem 277:46116.

21. Van Der Vliet, A., M. N. Nguyen, M. K. Shigenaga, J. P. Eiserich, G. P. Marelich, and C. E. Cross. 2000. Myeloperoxidase and protein oxidation in cystic fibrosis. Am J Physiol Lung Cell Mol Physiol 279:L537.

22. Heinecke, J. W. 1997. Mechanisms of oxidative damage of low density lipoprotein in human atherosclerosis. Curr Opin Lipidol 8:268.

23. Bagasra, O., F. H. Michaels, Y. M. Zheng, L. E. Bobroski, S. V. Spitsin, Z. F. Fu, R. Tawadros, and $\mathrm{H}$. Koprowski. 1995. Activation of the inducible form of nitric oxide synthase in the brains of patients with multiple sclerosis. Proc Natl Acad Sci U S A 92:12041.

24. Albrecht, C., A. M. Knaapen, A. Becker, D. Hohr, P. Haberzettl, F. J. van Schooten, P. J. Borm, and R. P. Schins. 2005. The crucial role of particle surface reactivity in respirable quartz-induced reactive oxygen/nitrogen species formation and APE/Ref-1 induction in rat lung. Respir Res 6:129.

25. Seiler, F., B. Rehn, S. Rehn, M. Hermann, and J. Bruch. 2001. Quartz exposure of the rat lung leads to a linear dose response in inflammation but not in oxidative DNA damage and mutagenicity. Am J Respir Cell Mol Biol 24:492.

26. Aratani, Y., F. Kura, H. Watanabe, H. Akagawa, Y. Takano, K. Suzuki, M. C. Dinauer, N. Maeda, and H. Koyama. 2002. Relative contributions of myeloperoxidase and NADPHoxidase to the early host defense against pulmonary infections with Candida albicans and Aspergillus fumigatus. Med Mycol 40:557.

27. Aratani, Y., F. Kura, H. Watanabe, H. Akagawa, Y. Takano, A. Ishida-Okawara, K. Suzuki, N. Maeda, and H. Koyama. 2006. Contribution of the myeloperoxidase-dependent oxidative system to host defence against Cryptococcus neoformans. $J$ Med Microbiol 55:1291.

28. Zurawski, G., and J. E. de Vries. 1994. Interleukin 13, an interleukin 4-like cytokine that acts on monocytes and B cells, but not on T cells. Immunol Today 15:19. 


\section{MYELOPEROXIDASE ATTENUATES LPS- INDUCED AIRSPACE ENLARGEMENT}

Astrid Haegens, Juanita H.J. Vernooy, Roy H.E. Cloots, Marco C.J.M. Kelders, Nadja E.A. Drummen, Sofia Xanthoulea, Aalt Bast, Heinz Fehrenbach, Matthew E. Poynter, Brooke T. Mossman, Emiel F.M. Wouters

Submitted 
Chapter 5 


\section{ABSTRACT}

Myeloperoxidase (MPO) is a protein stored in neutrophil granula. MPO contributes to the development of inflammation through the enzymatic production of reactive oxygen and nitrogen species as well as independent of its enzymatic activity, by promoting neutrophil extravasation. Persistent neutrophilia is thought to play a key role in the development of lung diseases. The consequence of chronic neutrophilia is a continuous exposure of lung epithelial cells to a variety of proteolytic enzymes, like MPO. Here we describe a study in which wild type (WT) and Mpo knock out $\left({ }^{-/}\right)$mice were repeatedly exposed to LPS to induce chronic lung inflammation and structural changes. This study was conducted to test the hypothesis that MPO contributes to the development of chronic lung inflammation and structural changes. The results demonstrated that chronic LPS exposure leads to increased persistent lung inflammation in WT and $\mathrm{Mpo}^{-/}$mice. Airspace enlargement was increased after chronic LPS exposure and significantly increased in $\mathrm{Mpo}^{-/}$compared to WT mice. This however did not lead to lung function alterations. In addition, the antioxidants, reduced glutathione (GSH) and vitamin $\mathrm{C}$, were increased after chronic LPS exposure and $\mathrm{Mpo}^{-/-}$mice demonstrated a significant increase in GSH/GSSG in comparison to WT mice. Matrix metalloprotease (MMP) mRNA levels in LPS-exposed $\mathrm{Mpo}^{-/-}$mice were significantly elevated compared to sham mice, no differences were found in chemokine and cytokine expression patterns between WT and $\mathrm{Mpo}^{-/}$mice. From this study we can conclude that MPO modulates the antioxidant status of LPS induced lung inflammation and the expression patterns of MMPs. 


\section{INTRODUCTION}

Myeloperoxidase (MPO) is a heme protein and one of the enzymes stored in neutrophil granula. It is a key player in innate defence against bacteria and fungi (1), since enzymatic activity of MPO leads to hypochlorous acid ( $\mathrm{HOCl})$ formation. Chlorination of proteins by $\mathrm{HOCl}$ is a hallmark of MPO related protein modification (2). Other reactive oxygen and nitrogen species (ROS/RNS) formed by MPO such as nitrogen dioxide contribute to an inflammatory state of the lung, via the formation of nitrotyrosine $\left(\mathrm{NO}_{2} \mathrm{Tyr}\right)(3)$. MPO also has been described as a pro-inflammatory factor independent of its catalytic capacity by contributing to neutrophil extravasation (4). We have reported a significant reduction of neutrophil influx in Mpo knock out $\left(^{(-/}\right)$mice as compared to $\mathrm{MpO}^{+/+}$ wild type (WT) mice after inhalation of the inflammatory fiber, chrysotile asbestos (5). This clearly implicates that MPO plays a critical role in the development of lung inflammation.

Persistent neutrophilia is thought to play a key role in the development of lung diseases such as chronic obstructive pulmonary disease (COPD) (6), idiopathic pulmonary fibrosis (7) and cystic fibrosis (8). The consequence of chronic neutrophilia is a continuous exposure of lung epithelial cells to a variety of proteolytic enzymes normally stored in the granula of neutrophils. MPO, one of these proteolytic enzymes, may play a contributing role in the development of chronic inflammation and lung structure alterations.

Here we describe a study in which WT and $\mathrm{Mpo}^{-/}$mice were repeatedly exposed to LPS to induce chronic lung inflammation and structural changes. This study was conducted to test the hypothesis that MPO contributes to the development of chronic lung inflammation and structural changes.

Pulmonary function alterations as a result of structural changes in the lung are associated with increased neutrophil chemo-attractant interleukin (IL)-8 (9). The influx of inflammatory cells is mainly dependent on the release of these chemotactic factors at a site of inflammation. Keratinocyte-derived chemokines (KC) and IL-6 are the major neutrophil attractants, while monocyte chemotactic protein-1 (MCP-1) attracts monocytes and macrophages. Both cell types have been reported to be elevated in sputum of COPD patients (9), we therefore examined the induced lung inflammation and associated chemokines and cytokines.

Currently, there are at least three mechanisms associated with tissue remodeling. Thus we made an attempt to elucidate the contribution of three of the major mechanisms to the airspace enlargement that was found after chronic LPS exposure. The first mechanism involves ROS production. Neutrophils are known to produce ROS, and recent data show that blocking ROS production in mice or administration of antioxidant enzymes to rats protects against bleomycin induced pulmonary fibrosis (10) and respectively asbestosis (11). As a response to ROS, antioxidant enzymes levels are often increased. The antioxidant ratio of reduced glutathione (GSH) to oxidized glutathione (GSSG) is lower in sputum of COPD patients due to increased levels of GSSG (12), indicating increased oxidative stress. Another water soluble antioxidant is vi- 
tamin $\mathrm{C}$ and cross talk between GSH and vitamin $\mathrm{C}$ has been described previously (13). An increase in the antioxidant, heme-oxygenase I, has also been reported during severe exacerbations of COPD (14). Furthermore, oxidative stress has been linked to increased apoptosis (15), a second mechanism of lung remodeling examined here, since increased apoptosis has been found in the alveoli of patients with emphysema $(16,17)$ and in animal models of emphysema (18). Lastly, we explored changes in matrix metalloproteases (MMPs), as they have been reported as a contributing factor in emphysema development (19). It is known that neutrophils directly contribute to MMP production by releasing MMP-8 and MMP-9 $(20,21)$.

\section{MATERIALS AND METHODS}

Animals and treatment 12-wk-old male WT C57BL/6 mice were obtained from Charles River (Maastricht, The Netherlands). $\mathrm{Mpo}^{-/-}$mice were generated by Y. Aratani (22) and bred into the C57BL/6 background. Mice were housed individually in standard laboratory cages and allowed food and water ad libitum throughout the experiments. The studies were carried out under a protocol approved by the Institutional Animal Care Committee of Maastricht University (GGO: IG 04-072).

WT and $\mathrm{Mpo}^{-/}$mice ( $\mathrm{n}=8-12$ per group) were briefly anesthetized with a mix of $75 \mathrm{mg} / \mathrm{kg}$ ketamine (Nimatek, Auv Cuijk, The Netherlands) and $3 \mathrm{mg} / \mathrm{kg}$ xylazine (Sedamun, Auv Cuijk, The Netherlands). Chronic lung inflammation was induced by intratracheal instillation of $10 \mu \mathrm{g}$ LPS (Escherichia coli, serotype O55:B5, Sigma, St.Louis, MO) dissolved in $50 \mu \mathrm{l}$ sterile $0.9 \% \mathrm{NaCl}$ as described previously (23). This procedure was repeated 24 times at intervals of 4 days. Sham mice were instilled 24 times with $50 \mu$ LPS-free sterile $0.9 \%$ $\mathrm{NaCl}$. After intratracheal instillation, the mice were kept in an upright position for 10 minutes to allow the fluid to spread throughout the lungs. Mice were euthanized at two time points, 1 day or 1 week after the last LPS instillation using $115 \mathrm{mg} / \mathrm{kg}$ sodium pentobarbital administered intraperitoneally (Ceva Sante Animale, Maassluis, the Netherlands). These time points were chosen to investigate the combination of acute and chronic inflammation at 1 day after the last exposure and the persistence of chronic inflammation 1 week after the last exposure.

Pulmonary function assessment Mice were anesthetized using $90 \mathrm{mg} / \mathrm{kg}$ sodium pentobarbital administered via intraperitoneal injection. Mice were tracheotomized using an 18-gauge blunted needle and mechanically ventilated (flexivent; SCIREQ, Inc., Montreal, Canada) at a rate of $2.5 \mathrm{~Hz}$, with a tidal volume of $0.2 \mathrm{ml}$ and $3 \mathrm{~cm} \mathrm{H} \mathrm{H}_{2} \mathrm{O}$ positive end-expiratory pressure. After approximately 2 minutes of regular ventilation, two deep sighs to a pressure limit of $25 \mathrm{~cm} \mathrm{H}_{2} \mathrm{O}$ were performed and then two pressure-volume (PV) loops were delivered by stepwise inflation and deflation of the lungs. From the second PV loop, delivered approximately 2 minutes in the protocol, the Quasi-static Elas- 
tance $\left(E_{s t}\right)$ and parameter $K$ of the Salazar-Knowles equation were determined. Mice were then delivered alternating snap shots and 8 second primewaves every minute until another PV loop was delivered at 20 minutes of the protocol. From the snap shot and 8 second primewave delivered at minutes 9 and 10 the following physiological properties were determined: Resistance (R) and Elastance $(E)$, and Newtonian Resistance $\left(R_{N}\right)$, Tissue Damping $(G)$, and Tissue Elastance $(\mathrm{H})$, respectively.

Assesment of airspace enlargement After thoracotomy the left lung was inflated with $10 \%$ zinc-buffered formalin $\left(\mathrm{pH} \mathrm{5.5)}\right.$ at a pressure of $20 \mathrm{~cm} \mathrm{H} \mathrm{H}_{2} \mathrm{O}$ through the trachea and subsequently fixed in $10 \%$ zinc-buffered formalin for 24 hours. Mean chord length was determined on $3 \mu \mathrm{m}$ thick H\&E stained paraffin sections as a measure for airspace enlargement. Each section was systematically scanned by means of a motorized microscope stage at fixed distances along the $x$ - and $y$-axis to obtain a representative set of fields of view. A combined test system consisting of 5 points and 3 lines, points on airspace and intersections with the alveolar epithelium were counted at a final magnification of $853 \mathrm{X}$. The mean chord length (mean free airspace distance) was calculated according to the formula $C m=\frac{2 \bullet \sum P \bullet L p}{\sum I}$ [ $\left.\mu m\right]$, with the length per point $(\mathrm{Lp})$ being $62.9 \mu \mathrm{m}$. Analyses were performed on a personal computerbased Olympus BX 51 light microscope equipped with a Cast-Grid 2.01 system (Olympus, Denmark).

Myeloperoxidase activity assay MPO activity was determined using a Myeloperoxidase Assay Kit (CytoStore, Calgary, Canada) according to manufacturer's protocol. Briefly, approximately $50 \mu \mathrm{g}$ of snap frozen lung from LPS and sham treated animals were homogenized in $1 \mathrm{ml}$ cold sample buffer and centrifuged at $4^{\circ} \mathrm{C}$ for 5 minutes at maximum speed. MPO activity was determined in $20 \mu \mathrm{l}$ supernatant in duplicate using development reagent. Activity was measured over 25 seconds at $450 \mathrm{~nm}$. Development reagent without sample was used as control.

Immunohistochemistry After paraffin embedding, $4 \mu \mathrm{m}$ sections were cut and mounted on slides.

MPO staining Lung sections from sham and LPS-exposed mice were deparaffinized and endogenous peroxidase activity was neutralized with $0.3 \%$ hydrogen peroxide $\left(\mathrm{H}_{2} \mathrm{O}_{2}\right)$ in methanol. Sections were blocked using $20 \%(\mathrm{v} / \mathrm{v})$ normal swine serum in Tris-Buffered Saline (TBS) for $30 \mathrm{~min}$. MPO was detected using a polyclonal rabbit anti-MPO antibody (0398, DAKO, Glostrup, Denmark) followed by a swine anti-rabbit biotin labelled secondary antibody (E0413, DAKO). Labelling was visualised using avidin-biotin peroxidase (K0377, DAKO) and histogreen (Linaris, Wertheim, Germany). Sections were counterstained with hematoxylin and coverslips were applied. Lung sections of $\mathrm{MpO}^{-/-}$ mice revealed no staining. 
Macrophage staining Lung sections from sham and LPS exposed mice were deparaffinized and antigen retrieval was performed by microwave treatment with $10 \mathrm{mM}$ Tris Buffer, $\mathrm{pH} 10$. Endogenous peroxidase activity was neutralized with $0.3 \% \mathrm{H}_{2} \mathrm{O}_{2}$ in methanol. Macrophages were detected using the primary antibody rat anti-mouse MAC-3 (550292, BD Pharmingen, San Jose, CA, USA) followed by a rabbit anti-rat biotin labelled secondary antibody (E0468 DAKO). Staining was visualised using 3-amino-9-ethylcarbazole (AEC). Sections were counterstained with hematoxylin and coverslips were applied.

Inflammation Scoring Inflammation was scored by two individual observers using a blind code for identification of slides and an inflammation scale from 1 to 4 ; with 1 indicating absent inflammation, 2 showing mild macrophage infiltration, 3 indicating moderate macrophage infiltration, and 4 as severe mixed macrophage and neutrophil inflammation.

\section{Assesment of antioxidant status}

GSH/GSSG The GSH/GSSG ratio was determined in whole lung homogenates according to the method described by Baker et al. (24) using the enzymatic DTNB-reductase recycling method. GSH is oxidized by DTNB leading to the formation of GSSG and TNB (5'-thio-2-nitro-benzoic acid). The formation of TNB was measured at $405 \mathrm{~nm}$. GSSG was determined after derivatization of GSH with 2-vinylpyridine.

Vitamin C Vitamin C content of whole lung homogenates was analyzed by an HPLC method with fluorometric detection (25). Vitamin C was oxidized to dehydroascorbic acid and subsequently derivatized with o-phenylenediamine to the fluorescent 3-(1,2-dihydroxyethyl)furo[3,4-b]quinoxaline-1-one, which was detected.

mRNA expression levels of matrix metalloproteases, chemokines and cytokines Total lung RNA was isolated using the RNeasy Mini Kit (Qiagen Inc., CA) according to manufacturer's protocol. Total RNA was reverse transcribed, using the Abgene Kit (Abgene, Epsom, UK) with random decamers and oligo dT primers, and the resulting CDNA was amplified by quantitative polymerase chain reaction (Q-PCR) using the MylQ5 (Biorad, Hercules, CA) for the detection of $k c$, il-6, mcp-1, mip-2, mmp-2, -8, -9 and -12. Each PCR reaction contained $1 \mathrm{X}$ SYBR® Green PCR master mix (Applied Biosystems, Foster City, CA) and $0.3 \mu \mathrm{M}$ each of forward and reverse primer. Following an initial 10 min incubation at $95^{\circ} \mathrm{C}$, thermal cycling was performed using $45 \mathrm{cy}$ cles of $94^{\circ} \mathrm{C}$ for $15 \mathrm{~s}, 60^{\circ} \mathrm{C}$ for $30 \mathrm{~s}$ and $72^{\circ} \mathrm{C}$ for $30 \mathrm{~s}$. Gene expression was quantified using standard curves for the respective cDNA products. All gene expression changes were normalized to hprt-1expression. Table 1 shows the primer sequences used. 
Table I: Primer sequences

\begin{tabular}{|l|c|c|}
\hline GENE & forward primer & reverse primer \\
\hline $\begin{array}{l}\text { kc } \\
\text { NM008176.2 }\end{array}$ & 5'-CACTGCACCCAAACCGAAG-3' & 5'-TCAGGGTCAAGGCAAGCC-3' \\
\hline $\begin{array}{l}\text { il-6 } \\
\text { NM031168 }\end{array}$ & 5'-GTATGAACAACGATGATGCACTTG-3' & 5'-GAAGACCAGAGGAAATTTTCAATAGG-3' \\
\hline $\begin{array}{l}m c p-1 \\
\text { NM011333 }\end{array}$ & 5'-GCTGGAGAGCTACAAGAGGATCA-3' & 5'-CAGACCTCTCTCTTGAGCTTGGT-3' \\
\hline $\begin{array}{l}\text { mip-2 } \\
\text { NM009140.2 }\end{array}$ & 5'-GCCCCCAGGACCCCA-3' & 5'-CTTTTTTGACCGCCCTTGAGA-3' \\
\hline $\begin{array}{l}\text { mmp-2 } \\
\text { NM008610.2 }\end{array}$ & 5'-CGATGTCGCCCCTAAAACAG-3' & 5'-CTTGAGGGTATCTTTCAGCACAAA-3' \\
\hline $\begin{array}{l}\text { mmp-8 } \\
\text { NM008611.3 }\end{array}$ & 5'-CCCAGTACCTGAACACCTGGAA-3' & 5'-TTAAGCTTCTCTGCAACCATCGT -3' \\
\hline $\begin{array}{l}\text { mmp-9 } \\
\text { NM013599.2 }\end{array}$ & 5'-TCTTCCCCAAAGACCTGAAAAC-3' & 5'-GCCCGGGTGTAACCATAGC-3' \\
\hline $\begin{array}{l}\text { mmp-12 } \\
\text { NM008605.3 }\end{array}$ & 5'-TGAGGCAGAAACGTGGACTAAA-3' & 5'-ATTGACTTTGGATTATTGGAATGCT-3' \\
\hline $\begin{array}{l}\text { hprt-1 } \\
\text { NM013556 }\end{array}$ & 5'-AGCTACTGTAATGATCAGTCAACG-3' & 5'-AGAGGTCCTTTTCACCAGCA-3' \\
\hline
\end{tabular}

Assesment of apoptosis After paraffin embedding, $4 \mu \mathrm{m}$ sections were cut and mounted on slides. Lung sections from sham and LPS-exposed mice were deparaffinized and antigen retrieval with sodium citrate $(10 \mathrm{mM}, \mathrm{pH} 6.0)$ was performed by microwave treatment. Endogenous peroxidase activity was neutralized with $3 \%$ hydrogen peroxide $\left(\mathrm{H}_{2} \mathrm{O}_{2}\right)$ in phosphate-buffered saline (PBS). Sections were blocked using $5 \%(\mathrm{v} / \mathrm{v})$ normal goat serum in PBS for $30 \mathrm{~min}$. Active Caspase-3 was detected using a polyclonal rabbit anti-cleaved caspase-3 antibody (9661, Cell Signaling Technology, MA) followed by a goat anti-rabbit biotin labelled secondary antibody (E0413, DAKO). Labeling was visualised using avidin-biotin peroxidase (K0377, DAKO) and DAB (K3468, DAKO). Sections were counterstained with hematoxylin and coverslips were applied.

Statistical Analysis Data were reported as mean \pm SEM. Data were analyzed using Mann-Whitney $U$ test. Values of $p \leq 0.05$ between groups were considered significant.

\section{RESULTS}

Increased MPO activity in WT mice occurs directly after chronic LPS exposure

To determine MPO activity during chronic inflammation and to determine $\mathrm{Mpo}^{-}$ /- status, total MPO activity was determined in lung tissue of WT and $\mathrm{Mpo}^{-/}$ mice 1 day and 1 week after the last LPS exposure. Figure $1 \mathrm{~A}$ shows an increase in MPO activity 1 day after the last LPS exposure in WT animals. MPO activity decreased to control levels 1 week after the last exposure. $\mathrm{Mpo}^{-/-}$mice do not demonstrate MPO activity. 
To localize MPO in the lungs of WT animals and to confirm the absence of $\mathrm{MPO}$ activity in $\mathrm{Mpo}^{-/-}$mice, sections were stained for MPO. Figure $1 \mathrm{C}$ demonstrates that WT animals show MPO staining (arrows) 1 day after the final LPS instillation in neutrophil clusters in close proximity to the large airways. Sham(Figure 1B) and LPS- exposed WT mice 1 week after instillation (Figure 1D) show neither accumulation of neutrophils in the airways nor MPO staining. Sham and LPS treated $\mathrm{Mpo}^{-/}$mice (Figure $1 \mathrm{E}, \mathrm{F}$ and $\mathrm{G}$ ) were negative for MPO staining, as expected.

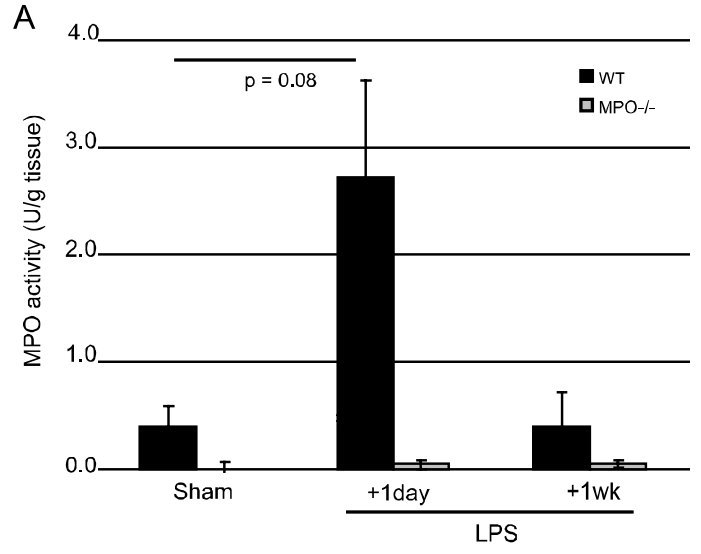

Figure 1A: Increased MPO activity in whole lung homogenates of LPS exposed WT mice. A) MPO activity was increased 1 day after the last LPS instillation and returned back to baseline levels 1 week post exposure. Absence of $\mathrm{MPO}$ activity in $\mathrm{Mpo}^{-/-}$mice confirms their knock-out status. Values are represented as mean \pm SEM. * $p \leq 0.05$ in comparison to respective sham. \# $p$ $\leq 0.05$ in comparison to LPS-exposed WT mice.

\section{Increased lung inflammation after chronic LPS exposure in WT and Mpo- mice}

Histopathology on MAC-3 stained lung sections revealed that lung inflammation in WT C57BL/6 mice was similar to that of Swiss mice chronically exposed to LPS (26), previously described by our group. Figure 2 shows that $\mathrm{Mpo}^{-/}$ mice demonstrate inflammation levels equal to C57BL/6 WT mice. Elevated neutrophil and macrophage numbers were observed 1 day after the last exposure. Neutrophil numbers were back to sham levels 1 week later, macrophage numbers were however still elevated 1 week after the last exposure compared to sham treated mice. 


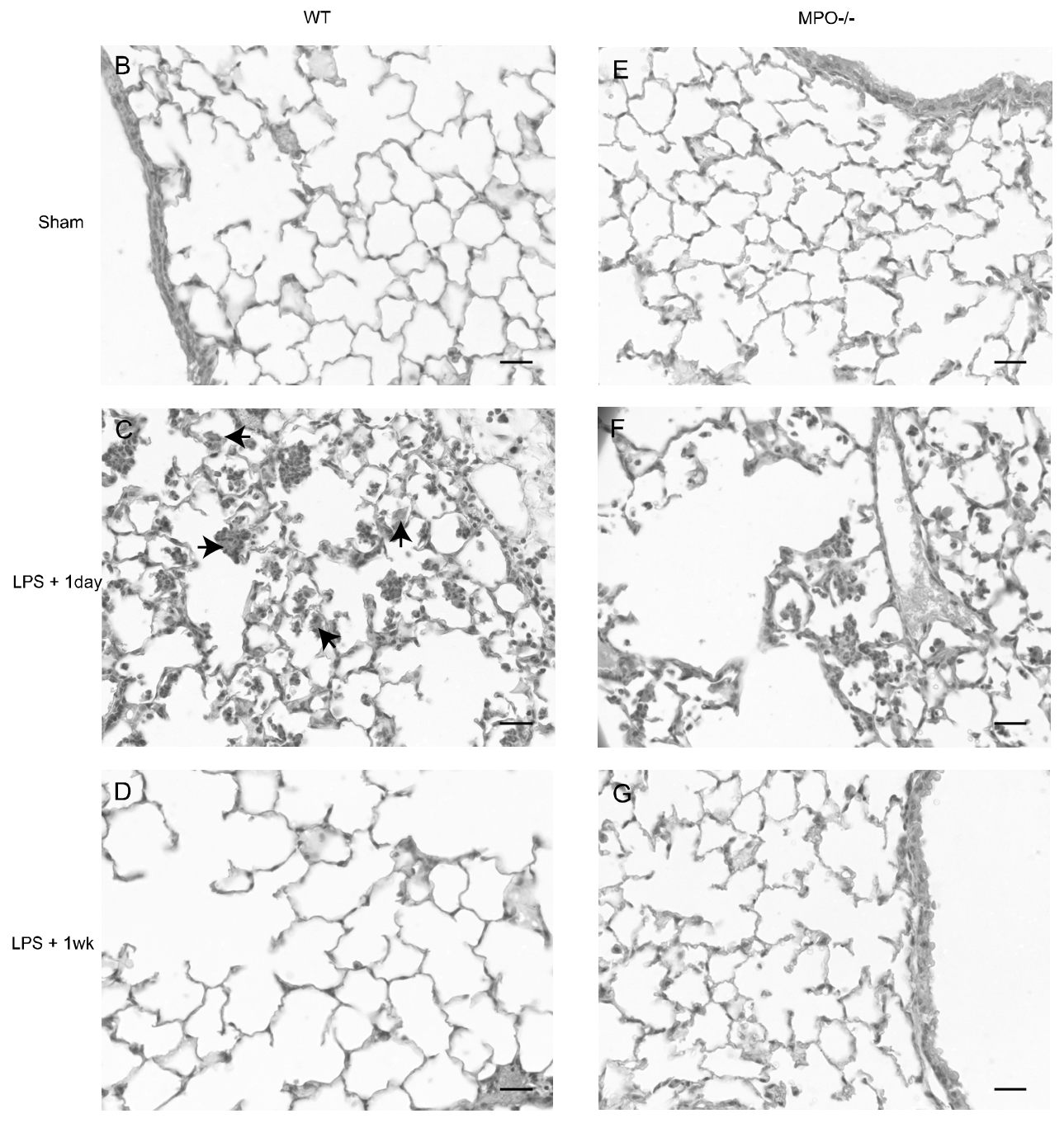

Figure 1B-G: Chronic LPS exposure increased MPO levels in WT mice localized in clusters of infiltrated neutrophils. Paraffin sections of Sham and LPS exposed WT and $\mathrm{Mpo}^{-/}$mice were stained for MPO. Mpo- mice lack MPO staining. B, Sham WT. C, LPS exposed WT +1 day. C, LPS exposed WT +1 week. E, Sham $\mathrm{Mpo}^{-/-}$. F, LPS exposed $\mathrm{Mpo}^{-/}+1$ day. G, LPS exposed $\mathrm{Mpo}^{-/}+1$ week. Bars $=25 \mu \mathrm{m}$. 


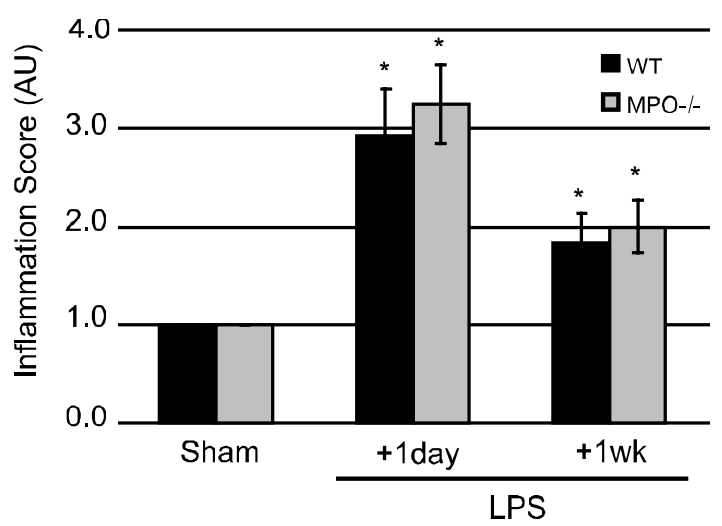

Figure 2: Grading of lung inflammation 1 day and 1 week after the last LPS exposure. Values are represented as mean \pm SEM. * $p \leq 0.05$ in comparison to respective sham.

Chronic LPS exposure results in airspace enlargement in WT and Mpo-mice that does not translate to lung function alterations

Emphysematous changes of the alveolar lung tissue are found in patient with chronic lung inflammation (16). Morphological analysis of lung sections from sham and LPS-exposed WT and $\mathrm{Mpo}^{--}$mice was performed, to investigate airspace enlargement in the lungs of these animals. Figure $3 \mathrm{~A}$ demonstrates a significant increase in mean chord length $(\mathrm{Cm})$, a measure of airspace enlargement, in LPS exposed WT and $\mathrm{Mpo}^{-/}$mice. LPS exposed $\mathrm{Mpo}^{-/-}$mice showed a significant increase in Cm compared to LPS treated WT animals.

A

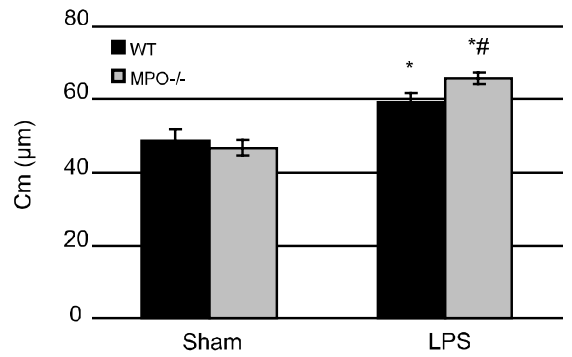

B 15

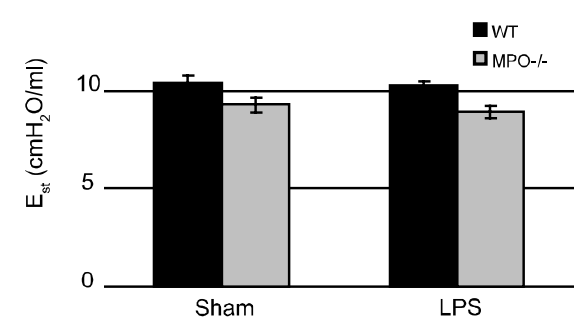

Figure 3: Increased airspace enlargement in chronic LPS exposed $\mathrm{Mpo}^{-/}$mice compared to WT animals does not result in alterations in lung function parameters. A) Quantification of mean linear chord length in paraffin sections of sham and LPS exposed WT and $\mathrm{Mpo}^{-/}$mice 1 week after the last exposure demonstrated airspace enlargement in LPS exposed WT mice. $\mathrm{Mpo}^{-/-}$mice show significantly more enlargement compared to WT mice. B) Lung function measurements prior to sacrifice reveal no difference in quasi-static Elastance $\left(E_{s t}\right)$ in LPS exposed WT and $\mathrm{Mpo}^{-/-}$mice compared to sham treated animals. Values are represented as mean \pm SEM. ${ }^{*} p \leq 0.05$ in comparison to respective sham. \# $p \leq 0.05$ in comparison to LPS exposed WT mice.

To investigate whether these morphological changes translate into lung functional alterations, lung function measurements were performed. Figure 3B shows that the quasi-static elastance $\left(\mathrm{E}_{\mathrm{st}}\right)$, a measure of the static elastic recoil pressure of the lungs at a given lung volume, is not changed in LPS exposed mice in comparison to sham animals. Respiratory system resistance 
$(R)$, a measure of the level of contriction in the lungs, was not changed in LPSexposed mice compared to sham animals (data not shown). The elastance, a measure for the elastic rigidity of the lungs, and the newtonian resistance, a measure for the resistance of the central airways, were unchanged in LPS exposed mice (data not shown).

\section{$\mathrm{Mpo}^{-/-}$mice demonstrate a significantly increased GSH/GSSG ratio and} lower vitamin C levels compared to WT mice after chronic LPS exposure

Oxidative stress is thought to be a key contributor to airway remodeling (10). Therefore, we determined the antioxidant status of lungs repeatedly exposed to LPS by measuring the GSH/GSSG ratio and the total vitamin C content. Figure 4A shows that $\mathrm{Mpo}^{-/}$mice have a significantly higher basal GSH/GSSG ratio compared to WT mice. LPS induced an increase in the GSH/GSSG ratio 1 day after the last LPS exposure in WT and $\mathrm{Mpo}^{-/-}$mice. This increase was further enhanced in $\mathrm{Mpo}^{-/}$mice and was still present 1 week later. WT mice did not show an increase 1 week after LPS treatment. Figure 4B demonstrates an increase in total vitamin C content after repeated LPS exposure in WT animals. This increase was present in $\mathrm{Mpo}^{-/}$mice as well, but demonstrated a trend towards a decrease compared to LPS treated WT mice.

A

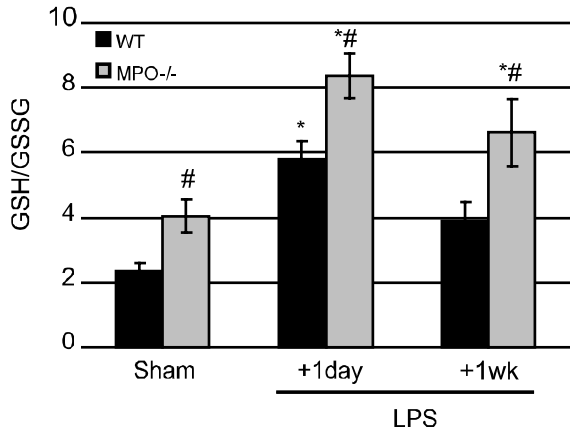

$\mathrm{B}$

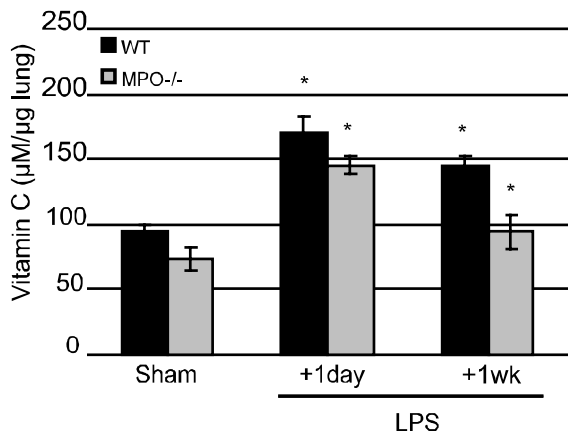

Figure 4: Chronic LPS exposure results in increased anti-oxidant levels in $\mathrm{Mpo}^{-/}$and WT mice. A) Sham levels of GSH/GSSG were higher in $\mathrm{Mpo}^{-/-}$mice compared to WT animals. This GSH/GSSG ratio was increased after chronic LPS exposure in WT and $\mathrm{Mpo}^{-/}$mice compared to their respective sham groups and persisted longer in $\mathrm{Mpo}^{-/}$compared to WT mice. B) Total vitamin C content increased after chronic LPS exposure in WT and $M \mathrm{Mo}^{-/-}$ mice. Vitamin $C$ levels showed however a trends towards a decrease in $\mathrm{Mpo}^{-/}$mice in comparison to WT animals. * $p \leq 0.05$ in comparison to respective sham. \# $p \leq 0.05$ in comparison to LPS exposed WT mice.

\section{Alveolar cell apoptosis is not present after chronic LPS exposure in WT and $\mathrm{Mpo}^{-/-}$mice}

Apoptosis has been described to be increased in patients with emphysema $(16,17)$. Immuno-histochemical staining of cleaved caspase-3, a crucial step in the process of cell apoptosis, was performed to investigate the contribution of apoptosis in this model of airspace enlargement. Analyses of stained sec- 
tions revealed that chronic LPS exposure in WT and $\mathrm{Mpo}^{-/}$mice did not cause apoptosis in resident lung cells or infiltrated inflammatory cells at the two time points examined (data not shown).

\section{$M_{p o}^{-/}$mice show increased mmp-2, -8 and -12 expression compared to WT mice after chronic LPS exposure}

MMPs are known to contribute to tissue destruction and the development of emphysema (19). Q-PCR was performed to investigate the expression patterns of $m m p-2,8,9$ and 12 in the lungs of WT and $\mathrm{Mpo}^{-/}$mice after chronic LPS exposure. MMP-8 and -9 are released by neutrophils. MMP-2 can be released from epithelial (27) cells and alveolar macrophages (28). MMP-12 is released by macrophages (29).

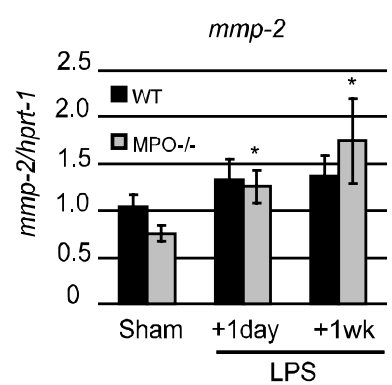

$m m p-9$

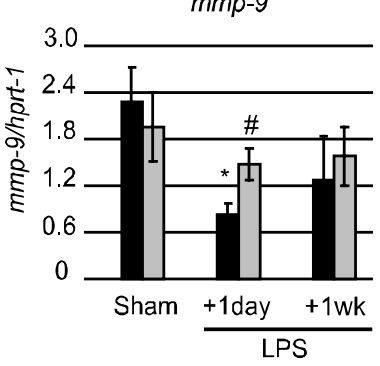

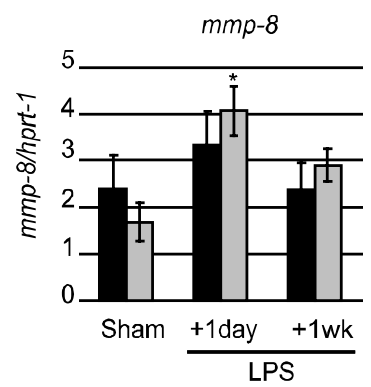

$m m p-12$

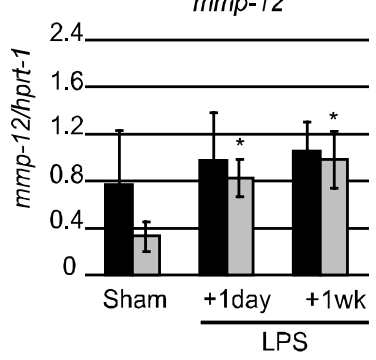

Figure 5: Q-PCR revealed increased levels of $m m p-2,-8$ and -12 after chronic LPS exposure in $\mathrm{Mpo}^{-/}$mice. Mmp-2, -8 and 12 expression levels were elevated 1 day after the last LPS exposure. Mmp-2 and -12 increased even further 1 week after the last exposure. Mmp-9 expression decreased 1 day after LPS exposure in WT mice, but not in $\mathrm{Mpo}^{-/}$animals. Values are represented as mean \pm SEM. * $p \leq 0.05$ in comparison to respective sham. \# $p \leq 0.05$ in comparison to LPS exposed WT mice.

Figure 5 demonstrates that $m m p-2$ was up-regulated 1 day after the last LPS exposure in $\mathrm{Mpo}^{-/-}$mice and was even further up-regulated 1 week after the last exposure. Mmp-8 expression showed a trend of up-regulation in WT mice and was significantly up-regulated in $\mathrm{Mpo}^{-/-}$mice 1 day post exposure. $\mathrm{Mmp}-8$ expression levels were near those of the sham 1 week after the last exposure in WT and $\mathrm{Mpo}^{-/}$mice. $\mathrm{Mmp}-9$ expression exhibited a trend towards a decrease in WT and $\mathrm{Mpo}^{-/}$mice 1 day post exposure, but $\mathrm{Mpo}^{-/-}$mice had raised mmp-9 expression levels in comparison to LPS-exposed WT mice 1 day after LPS treatment. Mmp-12 expression was increased in $\mathrm{Mpo}^{-/}$mice 1 day after LPS exposure and was still elevated 1 week after the last exposure. Mmp-12 expression in WT animals was not changed by chronic LPS exposure. 
Similar cytokine and chemokines mRNA expression patterns after chronic LPS exposure in WT and $\mathrm{Mpo}^{-/-}$mice

Cytokine and chemokines play a crucial role in the development of inflammation. In $\mathrm{Mpo}^{-/-}$mice we have already reported on altered expression levels during acute inflammation associated with inhalation of asbestos (5). Here we investigate the expression patterns of the neutrophil-associated chemo attractants $k c$, il-6, mip-2 and macrophage chemoattractant $m c p-1$ in a model of chronic LPS exposure.
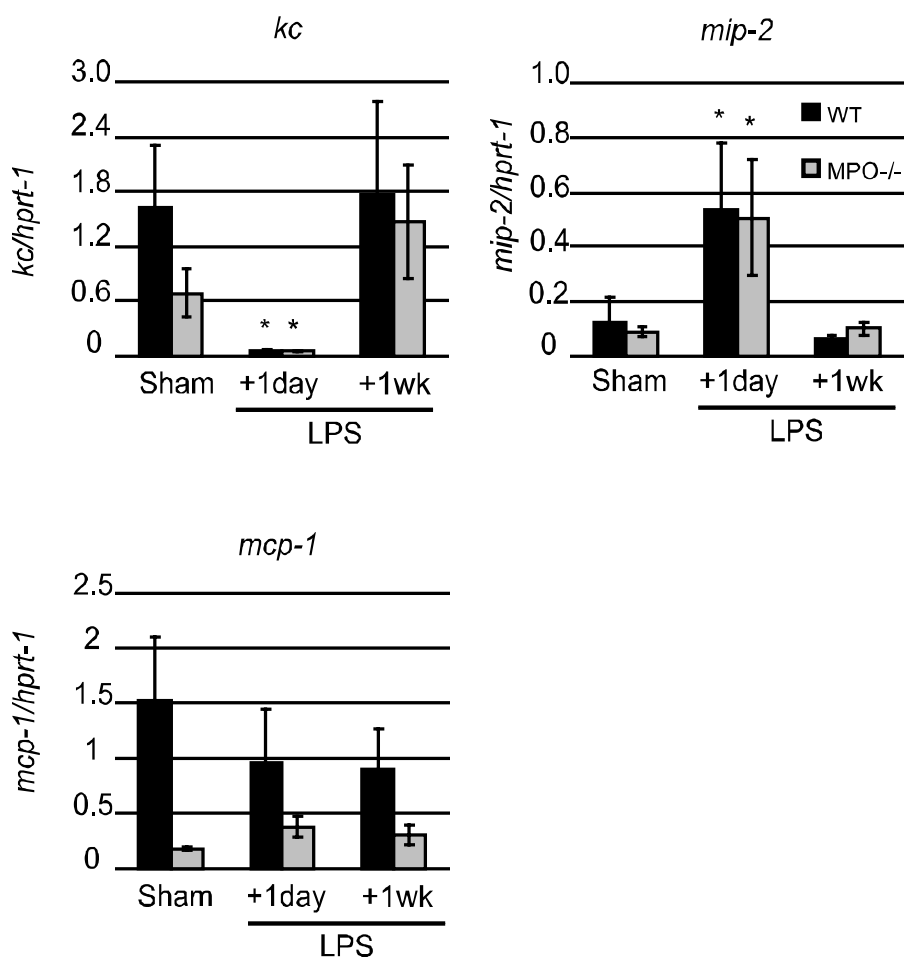

Figure 6: Chronic LPS exposure leads to similar cytokine and chemokine mRNA expression patterns in $\mathrm{Mpo}^{-/}$and WT mice. Kc, mip-2 and mcp1 expression was analyzed by Q-PCR and normalized against hprt-1 expression. Kc expression decreased significantly 1 day after the last LPS exposure in WT and $\mathrm{Mpo}^{-/-}$mice, but returned back to sham levels 1 week later. Mip-2 on the contrary increased significantly 1 day after the last exposure and returned to sham levels 1 week later. No differences were found in mcp-1 expression. Values are represented as mean \pm SEM. * $\mathrm{p} \leq 0.05$ in comparison to respective sham. \# $p$ $\leq 0.05$ in comparison to LPS exposed WT mice.

Figure 6 shows that mRNA expression of $k c$ decrease significantly 1 day after the last LPS exposure. Interestingly, this is in contrast to mip-2, which increases significantly directly after the last LPS exposure. Both chemoattractants return to sham expression levels 1 week later. There were no differences found between WT and $M p o^{--}$mice. Mcp-1 expression levels did not demonstrate differences between the sham and LPS exposed mice, nor were there any significant transgenic effects. II-6 expression levels were not detectable in lung in this model of chronic lung inflammation. 


\section{DISCUSSION}

MPO is an important enzyme in innate defence through the enzyme-catalyzed production of $\mathrm{HOCl}$ and other reactive oxidants (1). This study aimed to investigate the contribution of MPO to the development of chronic lung inflammation and emphysematous changes in a model of LPS-induced chronic lung inflammation.

Here we show that lung inflammation after chronic LPS exposure is similar in C57BL/6 WT mice and Swiss WT mice as previously reported (26). $\mathrm{Mpo}^{-/-}$mice demonstrated the same lung inflammation after chronic LPS exposure as C57BL/6 WT mice. In line with this finding were mRNA expression levels of the chemokines $k c, m i p-2$ and $m c p-1$. The results of the study presented here confirm our earlier published data in a model of chrysotile asbestos-induced chronic inflammation (5), where we did not find chronic inflammatory differences between WT C57BL/6 and $\mathrm{Mpo}^{-/-}$mice. In this publication we demonstrate that, although acute inflammation is attenuated, the chronic lung inflammation in $\mathrm{Mpo}^{--}$mice is comparable with that of WT C57BL/6 mice.

Although we did not find differences in inflammatory cell profiles or levels of lung inflammation, there was a small but significant increase in airspace enlargement in LPS treated $\mathrm{Mpo}^{-/}$mice in comparison to LPS treated WT mice. Therefore, we attempted to elucidate the mechanisms contributing to these structural changes after chronic LPS exposure.

The first mechanism investigated was oxidative stress due to an altered antioxidant status of chronic LPS-exposed lungs. Our results demonstrate an increased GSH/GSSG ratio due to increased GSH levels. This ratio is still elevated in $\mathrm{Mpo}^{-/-}$mice 1 week after the last exposure. GSH levels have been reported to show a two-fold induction in chronic smokers compared to nonsmokers (30), most likely due to upregulation of $y$-glutamylcysteine synthetase ( $Y$-GCS). This enzyme is the rate limiting factor in GSH synthesis. It is likely that chronic lung inflammation in mice leads to an elevated $y$-GCS level as well. Why the increase in GSH/GSSG ratio is prolonged in $\mathrm{Mpo}^{-/-}$mice compared to WT animals, requires further investigation. We report here for the first time that vitamin $\mathrm{C}$, unlike $\mathrm{GSH}$ a non thiol anti-oxidant, is increased after chronic LPS exposure compared to sham mice. Vitamin $C$ is increased in BALF of smokers compared to non-smokers (31). Similarly, alveolar macrophages from smokers have both increased levels of ascorbic acid and augmented uptake of ascorbate $(31,32)$. These data are in line with our own presented herein In contrast to GSH levels, vitamin C levels in $\mathrm{Mpo}^{-/-}$mice demonstrate a trend towards a decrease compared to LPS treated WT animals. It has been shown before that ROS are more reactive towards some antioxidants than towards others. For example, the main targets for $\mathrm{HOCl}$ seem to be thiol-containing $\mathrm{GSH}$, as well as, methionine and cysteine residues in proteins (33). But GSH can also be oxidized by $\mathrm{H}_{2} \mathrm{O}_{2}$ to form GSSG. We were not able to determine whether or not this reaction occurs in our model. We did not find an absolute increase in GSSG levels, but this may be due to increased activation of glutathione reductase which would result in increased reduction of 
GSSG. A second explanation why we did not find an increase in GSSG levels is the possibility of GSH to reacts with another structure containing a sulfide group, leading to mixed disulfides.

Interestingly, our data indicating increased airspace enlargement in $\mathrm{Mpo}^{-/-}$ mice compared to WT mice, are opposite of what would be expected with regard to the current knowledge of $\alpha_{1}$-antiprotease inhibition by $\mathrm{HOCl}$. $\mathrm{Mpo}^{-/-}$ mice, not able to produce $\mathrm{HOCl}$, would be expected to have increased $\alpha_{1}$ antiprotease activation, resulting in decreased elastase activity. This would lead to a decrease in airspace enlargement, since $\alpha_{1}$-antiprotease oxidation by $\mathrm{HOCl}$ results in inhibition of $\alpha_{1}$-antiprotease and therefore an increase elastase activity. Increased elastin breakdown results in alveolar wall destruction and mucus hypersecretion (34). The fact that our results are opposite, suggest that this mechanism does not contribute to airspace enlargement in this model of chronic lung inflammation.

The second mechanism known to contribute to airspace enlargement in patients with emphysema $(16,17)$ and in animal models of emphysema $(18)$ is apoptosis. Intracellular caspase-3 has to be cleaved for a cell to undergo apoptosis $(35,36)$. Furthermore, oxidative stress has been linked to increased apoptosis (15). In our model of LPS-induced chronic lung inflammation, where we did observe airspace enlargement, we did not find cells that were positive for cleaved caspase-3. This indicates that apoptosis does not seem to play a role in our model of chronic lung inflammation and airspace enlargement induced by repeated LPS exposure. This is in contrast to a recently published study in which a significant increase in apoptotic cells was found after 3 weeks of LPS exposure (37). The discrepancy between the studies may be explained by the susceptibility of the mouse strain used. We used C57BL/6 mice while the study of Lee et al. used AKR/J mice.

The third mechanism investigated to explain the significant increase in airspace enlargement in LPS-exposed $\mathrm{Mpo}^{-/}$in comparison to LPS treated WT mice was the expression of MMPs, since they have been reported as a contributing factor to emphysema development (19). It is known that neutrophils, the predominant inflammatory cell type recruited to the lung in response to LPS exposure, directly contribute to MMP production by releasing MMP-8 and MMP-9 (20, 21). MMP-8 and MMP-9 are released from activated neutrophils and described to be of importance in chronic inflammatory lung disease. MMP8 and MMP-9 activity have been reported by our group to be increased and correlate with neutrophil numbers in sputum of COPD patients (38). In line with these findings are the data presented here on $m m p-8$ expression. Mmp-8 expression was found to be increased directly after LPS exposure with a significant elevation in lungs of $\mathrm{Mpo}^{-/-}$mice. In contrast to the results in humans in our previous study (38), data presented here show decreased $m m p-9$ levels in lungs of mice at 1 day after LPS exposure that returned to sham levels 1 week after LPS treatment. The discrepancy between these studies may not only be explained by the fact that the study presented here is a mouse study but also by the fact that the human study has a mixed patient group of smoker and exsmokers. This means that for some patients the time interval between the 
inflammatory stimulus and the time of tissue sampling was over 6 months. The time interval between inflammatory stimulus and analysis in our mouse model was the same for all mice, 1 day (or 1 week) after LPS exposure. Here we describe for the first time a significant increase in $\mathrm{mmp}-2$ expression in lung in $\mathrm{Mpo}^{-/}$mice after chronic LPS exposure. WT mice demonstrated a trend towards an increase after LPS treatment. These data are in line with a recently published article reporting that MMP-2 expression in mild/moderate and severe COPD patients to be increased compared to smokers and non-smokers (39).

During the development of chronic inflammation, the role of macrophages becomes increasingly important. We have recently reported a significant increase in alveolar macrophages after chronic LPS exposure in Swiss mice (26). Here we demonstrate the novel finding that, although overall macrophage infiltration is not different in $\mathrm{Mpo}^{-/}$mice compared to WT animals, the expression of $\mathrm{mmp}-12$ increases significantly after chronic LPS exposure in $\mathrm{Mpo}^{-/}$ mice. This increase is even more pronounced 1 week after the last exposure. WT animals showed a slight trend toward an increase after LPS treatment. These data are in line with two recently published studies that demonstrate an increase in MMP-12 in tissue, BALF (40) and induced sputum (41) of COPD patients. It is interesting to find a trend towards increased expression of $\mathrm{mmp}$ 2, -8 and -9 in $\mathrm{Mpo}^{-/}$compared to WT mice, although inflammatory cell infiltration is similar. This may be due to the fact that none of the investigated MMPs are solely expressed by neutrophils and macrophages. Resident noninflammatory cells capable of producing MMPs may be triggered differently in WT and $\mathrm{Mpo}^{-/}$mice. As for MMP-12, there is even some evidence that it can also be produced by bronchial epithelial cells (42).

Although we did find significant airspace enlargement after chronic LPS treatment in WT and $\mathrm{Mpo}^{-/}$mice, this did not translate into measurable lung function alterations. This is in line with a paper reporting on the lack of correlation between structural emphysema and lung compliance in two mouse strains tested in a model of cigarette smoke induced emphysema (43).

In summary, our results show that chronic LPS exposure leads to increased lung inflammation in WT and $\mathrm{Mpo}^{-/-}$mice 1 day after the last exposure. This inflammation is still elevated 1 week later. Airspace enlargement is increased after chronic LPS exposure and significantly increased in $\mathrm{Mpo}^{-/}$compared to WT mice. This however does not lead to lung function alterations. As a result of oxidative stress, GSH/GSSG and vitamin C are increased after chronic LPS exposure. $\mathrm{MpO}^{-/}$mice demonstrate a significant increase in GSH/GSSG in comparison to WT mice. Mmp-2, -8 and -12 mRNA expression levels in LPSexposed $\mathrm{Mpo}^{-/}$mice were significantly elevated compared to sham mice. Lastly, $k c$ mRNA expression was significantly decreased while mip-2 was significantly increased directly after LPS exposure. Expression levels of $m c p-1$ were unchanged. There were no differences found in chemokine and cytokine expression patterns between WT and $\mathrm{Mpo}^{-/}$mice. From this study we can conclude that neutrophils and MPO are not a key factor in the development of chronic lung inflammation. MPO however seems to have an effect on the anti- 
oxidant status of LPS induced lung inflammation and the expression patterns of some MMPs.

\section{ACKNOWLEDGEMENTS}

The authors would like to thank Marie-José Drittij, Mark Fischer (Department of Pharmacology and Toxicology, University Hospital Maastricht, The Netherlands) and Robert Jan van Suylen (Department of Pathology, University Hospital Maastricht, The Netherlands) for their excellent assistance. 


\section{REFERENCES}

1. Klebanoff, S. J. 1999. Myeloperoxidase. Proc Assoc Am Physicians 111:383.

2. Gujral, J. S., J. A. Hinson, and H. Jaeschke. 2004. Chlorotyrosine protein adducts are reliable biomarkers of neutrophil-induced cytotoxicity in vivo. Comp Hepatol 3 Suppl 1:S48.

3. Van Der Vliet, A., M. N. Nguyen, M. K. Shigenaga, J. P. Eiserich, G. P. Marelich, and C. E. Cross. 2000. Myeloperoxidase and protein oxidation in cystic fibrosis. Am J Physiol Lung Cell Mol Physiol 279:L537.

4. Lau, D., H. Mollnau, J. P. Eiserich, B. A. Freeman, A. Daiber, U. M. Gehling, J. Brummer, V. Rudolph, T. Munzel, T. Heitzer, T. Meinertz, and S. Baldus. 2005. Myeloperoxidase mediates neutrophil activation by association with $C D 11 b / C D 18$ integrins. Proc Natl Acad Sci U S A 102:431.

5. Haegens, A., A. van der Vliet, K. J. Butnor, N. Heintz, D. Taatjes, D. Hemenway, P. Vacek, B. A. Freeman, S. L. Hazen, M. L. Brennan, and B. T. Mossman. 2005. Asbestos-induced lung inflammation and epithelial cell proliferation are altered in myeloperoxidase-null mice. Cancer Res 65:9670.

6. Hogg, J. C., F. Chu, S. Utokaparch, R. Woods, W. M. Elliott, L. Buzatu, R. M. Cherniack, R. M. Rogers, F. C. Sciurba, H. O. Coxson, and P. D. Pare. 2004. The nature of smallairway obstruction in chronic obstructive pulmonary disease. N Engl J Med 350:2645.

7. Saleh, D., P. J. Barnes, and A. Giaid. 1997. Increased production of the potent oxidant peroxynitrite in the lungs of patients with idiopathic pulmonary fibrosis. Am J Respir Crit Care Med 155:1763.

8. van der Vliet, A., J. P. Eiserich, M. K. Shigenaga, and C. E. Cross. 1999. Reactive nitrogen species and tyrosine nitration in the respiratory tract: epiphenomena or a pathobiologic mechanism of disease? Am J Respir Crit Care Med 160:1.

9. Vernooy, J. H., M. Kucukaycan, J. A. Jacobs, N. H. Chavannes, W. A. Buurman, M. A. Dentener, and E. F. Wouters. 2002. Local and systemic inflammation in patients with chronic obstructive pulmonary disease: soluble tumor necrosis factor receptors are increased in sputum. Am J Respir Crit Care Med 166:1218.

10. Manoury, B., S. Nenan, O. Leclerc, I. Guenon, E. Boichot, J. M. Planquois, C. P. Bertrand, and V. Lagente. 2005. The absence of reactive oxygen species production protects mice against bleomycin-induced pulmonary fibrosis. Respir Res 6:11.

11. Mossman, B. T., J. P. Marsh, A. Sesko, S. Hill, M. A. Shatos, J. Doherty, J. Petruska, K. B. Adler, D. Hemenway, R. Mickey, and et al. 1990. Inhibition of lung injury, inflammation, and interstitial pulmonary fibrosis by polyethylene glycol-conjugated catalase in a rapid inhalation model of asbestosis. Am Rev Respir Dis 141:1266.

12. Beeh, K. M., J. Beier, N. Koppenhoefer, and R. Buhl. 2004. Increased glutathione disulfide and nitrosothiols in sputum supernatant of patients with stable COPD. Chest 126:1116.

13. Martensson, J., J. Han, O. W. Griffith, and A. Meister. 1993. Glutathione ester delays the onset of scurvy in ascorbate-deficient guinea pigs. Proc Natl Acad Sci U S A 90:317.

14. Tsoumakidou, M., N. Tzanakis, G. Chrysofakis, and N. M. Siafakas. 2005. Nitrosative stress, heme oxygenase-1 expression and airway inflammation during severe exacerbations of COPD. Chest 127:1911.

15. Tuder, R. M., L. Zhen, C. Y. Cho, L. Taraseviciene-Stewart, Y. Kasahara, D. Salvemini, N. F. Voelkel, and S. C. Flores. 2003. Oxidative stress and apoptosis interact and cause emphysema due to vascular endothelial growth factor receptor blockade. Am J Respir Cell Mol Biol 29:88.

16. Yokohori, N., K. Aoshiba, and A. Nagai. 2004. Increased levels of cell death and proliferation in alveolar wall cells in patients with pulmonary emphysema. Chest 125:626.

17. Calabrese, F., C. Giacometti, B. Beghe, F. Rea, M. Loy, R. Zuin, G. Marulli, S. Baraldo, M. Saetta, and M. Valente. 2005. Marked alveolar apoptosis/proliferation imbalance in end-stage emphysema. Respir Res 6:14. 
18. Bartalesi, B., E. Cavarra, S. Fineschi, M. Lucattelli, B. Lunghi, P. A. Martorana, and G. Lungarella. 2005. Different lung responses to cigarette smoke in two strains of mice sensitive to oxidants. Eur Respir J 25:15.

19. Imai, K., S. S. Dalal, E. S. Chen, R. Downey, L. L. Schulman, M. Ginsburg, and J. D'Armiento. 2001. Human collagenase (matrix metalloproteinase-1) expression in the lungs of patients with emphysema. Am J Respir Crit Care Med 163:786.

20. Cataldo, D., C. Munaut, A. Noel, F. Frankenne, P. Bartsch, J. M. Foidart, and R. Louis. 2001. Matrix metalloproteinases and TIMP-1 production by peripheral blood granulocytes from COPD patients and asthmatics. Allergy 56:145.

21. Atkinson, J. J., and R. M. Senior. 2003. Matrix metalloproteinase-9 in lung remodeling. Am J Respir Cell Mol Biol 28:12.

22. Aratani, Y., H. Koyama, S. Nyui, K. Suzuki, F. Kura, and N. Maeda. 1999. Severe impairment in early host defense against Candida albicans in mice deficient in myeloperoxidase. Infect Immun 67:1828.

23. Starcher, B., and I. Williams. 1989. A method for intratracheal instillation of endotoxin into the lungs of mice. Lab Anim 23:234.

24. Baker, M. A., G. J. Cerniglia, and A. Zaman. 1990. Microtiter plate assay for the measurement of glutathione and glutathione disulfide in large numbers of biological samples. Anal Biochem 190:360.

25. Speek, A. J., J. Schrijver, and W. H. Schreurs. 1984. Fluorometric determination of total vitamin $\mathrm{C}$ in whole blood by high-performance liquid chromatography with pre-column derivatization. J Chromatogr 305:53.

26. Vernooy, J. H., M. A. Dentener, R. J. van Suylen, W. A. Buurman, and E. F. Wouters. 2002. Long-term intratracheal lipopolysaccharide exposure in mice results in chronic lung inflammation and persistent pathology. Am J Respir Cell Mol Biol 26:152.

27. Araya, J., M. Maruyama, K. Sassa, T. Fujita, R. Hayashi, S. Matsui, T. Kashii, N. Yamashita, E. Sugiyama, and M. Kobayashi. 2001. Ionizing radiation enhances matrix metalloproteinase-2 production in human lung epithelial cells. Am J Physiol Lung Cell Mol Physiol 280:L30.

28. John, M., U. Oltmanns, I. Fietze, C. Witt, and K. Jung. 2002. Increased production of matrix metalloproteinase-2 in alveolar macrophages and regulation by interleukin-10 in patients with acute pulmonary sarcoidosis. Exp Lung Res 28:55.

29. Gueders, M. M., J. M. Foidart, A. Noel, and D. D. Cataldo. 2006. Matrix metalloproteinases (MMPs) and tissue inhibitors of MMPs in the respiratory tract: potential implications in asthma and other lung diseases. Eur J Pharmacol 533:133.

30. Morrison, D., I. Rahman, S. Lannan, and W. MacNee. 1999. Epithelial permeability, inflammation, and oxidant stress in the air spaces of smokers. Am J Respir Crit Care Med 159:473.

31. Bui, M. H., A. Sauty, F. Collet, and P. Leuenberger. 1992. Dietary vitamin C intake and concentrations in the body fluids and cells of male smokers and nonsmokers. J Nutr $122: 312$

32. McGowan, S. E., C. M. Parenti, J. R. Hoidal, and D. E. Niewoehner. 1984. Ascorbic acid content and accumulation by alveolar macrophages from cigarette smokers and nonsmokers. J Lab Clin Med 104:127.

33. Pullar, J. M., C. C. Winterbourn, and M. C. Vissers. 1999. Loss of GSH and thiol enzymes in endothelial cells exposed to sublethal concentrations of hypochlorous acid. Am J Physiol 277:H1505.

34. Barnes, P. J. 1999. Novel approaches and targets for treatment of chronic obstructive pulmonary disease. Am J Respir Crit Care Med 160:S72.

35. Fernandes-Alnemri, T., G. Litwack, and E. S. Alnemri. 1994. CPP32, a novel human apoptotic protein with homology to Caenorhabditis elegans cell death protein Ced-3 and mammalian interleukin-1 beta-converting enzyme. J Biol Chem 269:30761.

36. Nicholson, D. W., A. Ali, N. A. Thornberry, J. P. Vaillancourt, C. K. Ding, M. Gallant, Y. Gareau, P. R. Griffin, M. Labelle, Y. A. Lazebnik, and et al. 1995. Identification and inhibition of the ICE/CED-3 protease necessary for mammalian apoptosis. Nature 376:37. 
37. Lee, K. M., R. A. Renne, S. J. Harbo, M. L. Clark, R. E. Johnson, and K. M. Gideon. 2007. 3-week inhalation exposure to cigarette smoke and/or lipopolysaccharide in AKR/J mice. Inhal Toxicol 19:23.

38. Vernooy, J. H., J. H. Lindeman, J. A. Jacobs, R. Hanemaaijer, and E. F. Wouters. 2004. Increased activity of matrix metalloproteinase-8 and matrix metalloproteinase- 9 in induced sputum from patients with COPD. Chest 126:1802.

39. Baraldo, S., E. Bazzan, M. Elena Zanin, G. Turato, S. Garbisa, P. Maestrelli, A. Papi, M. Miniati, L. Fabbri, R. Zuin, and M. Saetta. 2007. Matrix Metalloproteinase-2 protein in lung periphery is related to COPD progression. Chest.

40. Molet, S., C. Belleguic, H. Lena, N. Germain, C. P. Bertrand, S. D. Shapiro, J. M. Planquois, P. Delaval, and V. Lagente. 2005. Increase in macrophage elastase (MMP-12) in lungs from patients with chronic obstructive pulmonary disease. Inflamm Res 54:31.

41. Demedts, I. K., A. Morel-Montero, S. Lebecque, Y. Pacheco, D. Cataldo, G. F. Joos, R. A. Pauwels, and G. G. Brusselle. 2006. Elevated MMP-12 protein levels in induced sputum from patients with COPD. Thorax 61:196.

42. Lavigne, M. C., P. Thakker, J. Gunn, A. Wong, J. S. Miyashiro, A. M. Wasserman, S. Q. Wei, J. W. Pelker, M. Kobayashi, and M. J. Eppihimer. 2004. Human bronchial epithelial cells express and secrete MMP-12. Biochem Biophys Res Commun 324:534.

43. Foronjy, R. F., B. A. Mercer, M. W. Maxfield, C. A. Powell, J. D'Armiento, and Y. Okada. 2005. Structural emphysema does not correlate with lung compliance: lessons from the mouse smoking model. Exp Lung Res 31:547. 



\section{AIRWAY EPITHELIAL NF-KB ACTIVATION MODULATES ASBESTOS-INDUCED INFLAMMATION AND MUCIN PRODUCTION IN VIVO}

Astrid Haegens, Trisha F. Barrett, Joanna Gell, Arti Shukla, Maximilian MacPherson, Pamela Vacek, Matthew E. Poynter, Kelly J. Butnor, Yvonne M. Janssen-Heininger, Chad Steele, and Brooke T. Mossman

Journal of Immunology

Vol 178, page 1800-1808, 2007 


\section{ABSTRACT}

To investigate the role of bronchiolar epithelial NF-KB activity in the development of inflammation and fibrogenesis in a murine model of asbestos inhalation, we used transgenic mice expressing an IKBa mutant (IKBasr) resistant to phosphorylation-induced degradation and targeted to bronchiolar epithelium using the CC10 promoter. Sham and chrysotile asbestos-exposed CC10IKBasr transgenic $\left(\mathrm{Tg}^{+}\right)$and $\mathrm{Tg}$ - mice were examined for altered epithelial cell proliferation and differentiation, cytokine profiles, lung inflammation and fibrogenesis at 3,9 and 40 days. KC, IL- 6 and IL-1 $\beta$ were increased $(p \leq 0.05)$ in bronchoalveolar lavage fluid (BALF) from asbestos-exposed mice, but to a lesser extent $(p \leq 0.05)$ in Tg+ vs. Tg- mice. Asbestos also caused increases in IL-4, MIP-1 $\beta$ and MCP-1 in BALF that were more elevated $(p \leq 0.05)$ in Tg+ mice at 9 days. Differential cell counts revealed eosinophils in BALF that increased $(p \leq 0.05)$ in $\mathrm{Tg}+$ mice at 9 days, a time point corresponding with significantly increased numbers of bronchiolar epithelial cells staining positively for mucus production. At all time points, asbestos caused increased numbers of distal bronchiolar epithelial cells and peribronchiolar cells incorporating the proliferation marker, Ki-67. However, bronchiolar epithelial cell and interstitial cell labeling was diminished at 40 days $(p \leq 0.05)$ in $\mathrm{Tg}+\mathrm{vs}$. Tg- mice. Our findings demonstrate that airway epithelial NF-KB activity plays a role in orchestrating the inflammatory response as well as cell proliferation in response to asbestos. 


\section{INTRODUCTION}

Asbestos is a family of naturally occurring mineral fibers associated with the development of lung cancers, mesotheliomas, and fibroproliferative diseases, i.e., pleural and diffuse interstitial fibrosis or asbestosis $(1,2)$. Asbestosassociated lung repair has been compared to models of wound healing wherein early injury to epithelial cells by inhaled fibers leads to compensatory hyperplasia. The mechanisms of asbestos-related diseases are still unclear, but rodent inhalation models have revealed that bronchiolar and alveolar type II (ATII) epithelial cells, that when transformed give rise to bronchiolar and peripheral carcinomas, undergo early injury and proliferation and are linked to the initiation of inflammation and fibroproliferation (3-5).

Recently, the airway epithelium has been recognized as a critical regulator of the innate immune system. For example, examination of bronchial biopsies and isolated airway epithelial cells in culture has revealed that many inflammatory cascades become activated in lung epithelium after various stresses or infection (6). These intracellular signaling cascades promote inflammatory responses that aid in the elimination of infectious agents and/or contribute to the development of respiratory disease.

Of the many signaling cascades activated in airway epithelium in response to stimulation, NF- KB has been implicated as one of the most important in regulation of inflammation. NF-KB is a ubiquitous transcription factor that can be activated by cytokines, reactive oxygen species (ROS), growth factors, bacteria and viruses, ultraviolet irradiation, airborne particulate matter (PM) and inorganic minerals such as asbestos or silica (6-10). NF-KB activity is tightly controlled by the inhibitory protein, IKBa, that is normally present in the cytosol complexed to NF-kB dimers, thereby preventing the nuclear localization of NF$\mathrm{KB}$ and ensuring low basal transcriptional activity. Upon stimulation, IKBa becomes phosphorylated at serines 32 and 36 by the activity of the IKB kinase (IKK) complex, then ubiquinated, and degraded through the $26 \mathrm{~S}$ proteasome pathway. This exposes the nuclear localization sequence of NF-KB, allowing its retention in the nucleus, thus facilitating DNA binding and the transcriptional up-regulation of genes downstream of the $\mathrm{KB}$ motif. The regulation and degradation of NF-kB are topics of contemporary interest, as many NF-kB inducible genes encode inflammatory chemokines and cytokines, adhesion molecules, growth factors, enzymes and transcription factors (7). For example, interleukin6 (IL-6) (11), and interleukin-8 (IL-8) (12)/macrophage inflammatory protein 2 (MIP-2) (13), two putative mediators of inflammation and fibrogenesis in lung, have NF-KB binding sequences in their promoter regions that are critical to their transcriptional activation. NF-KB is also linked to increased cell survival and may govern proliferative responses after stress (14).

We have shown previously that asbestos fibers cause activation of the NF-KB signaling pathway in tracheal epithelial cells in vitro (8) and in lung epithelium after inhalation of asbestos by rats (15). In vivo, striking increases in nuclear translocation of p65 (Rel A), the subunit causing transcriptional activation of $\mathrm{NF}-\mathrm{KB}$, occur in distal bronchiolar and alveolar epithelial cells after brief expo- 
sures to asbestos fibers (15). Thus, the induction of NF-KB in airway epithelium by asbestos may be a critical event promoting asbestos-associated epithelial cell alterations, inflammation and fibrogenesis. To test this hypothesis, we created a transgenic mouse expressing an IKBa mutant (also referred to as an IKBa super repressor) resistant to phosphorylation-induced degradation and under transcriptional control of the CC10 promoter to inhibit NF-kB selectively in airway epithelial cells. The CC10-IKBasr mice, as previously characterized $(14,16)$, were then bred into the C57BL/6 background and evaluated in a murine inhalation model of chrysotile asbestos-induced fibrogenesis at time points of peak epithelial cell proliferation, inflammation and fibrogenesis, i.e. 3,9 and 40 days, respectively $(4,5)$. Based upon results with CC10-IKBasr mice after intranasal instillation of LPS (16) and in the ovalbumin (OVA) sensitization and challenge model (14), we hypothesized that acute inflammation in response to asbestos would be curtailed. However, our results show that inhalation of chrysotile asbestos causes lung recruitment of eosinophils that are proportionally greater in $\mathrm{Tg}+$ mice at 9 days and minimal recruitment of neutrophils. Data also reveal candidate cytokines and chemokines that may govern altered immune cell profiles and increased mucus production by bronchiolar epithelial cells in $\mathrm{Tg}+$ mice, in contrast to patterns found in the OVA model (14). In addition, we hypothesized, based upon a compendium of data in tumor cells after exposure to chemotherapeutic drugs, that NF-kB might be a survival factor promoting epithelial cell mitogenesis after injury by asbestos. We demonstrate that asbestos-induced bronchiolar epithelial and interstitial cell proliferation is diminished at 40 days in CC10-IkBasr mice, suggesting that NF-KB may be a survival factor in normal epithelial cells that modulate mitogenesis of adjacent fibroblasts after epithelial cell injury by asbestos fibers.

\section{MATERIALS AND METHODS}

CC10-IKBasr mice These mice were originally characterized by Poynter et al. $(14,16)$ and bred 6-8 times into the C57BL/6 background. Eight to 12 week old mice were housed and allowed to acclimate for 1 week in a HEPA-filtered clean air environment under controlled conditions of temperature, humidity, and light and provided food and water ad libitum before the initiation of inhalation exposures. Before starting the experiments, the presence or absence of the transgene was determined using Southern Blot analysis on tail DNA isolated using a DNA Extraction Kit (Strategene Cloning Systems, CA), according to the manufacturer's protocol. Ten $\mu \mathrm{g}$ whole tail DNA was immobilized on a nitrocellulose membrane and hybridized with a ${ }^{32} \mathrm{P}$-labeled $\mathrm{hGH}$-probe. The signal was visualized by exposing the hybridized membrane to X-OMAT AR film (Kodak Scientific Imaging, Rochester, NY) at $-80^{\circ} \mathrm{C}$ overnight. Mice were housed in the University of Vermont Animal Inhalation Facility during experiments. All studies were approved by the University of Vermont Institutional Animal Care and Use Committee. 
Inhalation protocol CC10-IKBasr transgene-positive $(\mathrm{Tg}+)$ mice and transgene-negative ( $\mathrm{Tg}$-) littermates [ $\mathrm{N}=5$ per each of 4 groups $(\mathrm{Tg}+$ sham, $\mathrm{Tg}+$ asbestos, Tg- sham, Tg- asbestos) per time point] were exposed to either ambient air (sham) or National Institute of Environmental Health Sciences (NIEHS) reference samples of chrysotile asbestos for 6 hours per day, 5 days a week for a total of 3,9 or 40 days in duplicate experiments. These time points were selected based upon previous work showing that they represented peak times of epithelial cell proliferation, inflammation and fibrogenesis, respectively, in lungs of chrysotile asbestos-exposed C57BL/6 mice $(4,5,17)$. The chemical and physical characteristics of NIEHS chrysotile asbestos have been previously described (18), and fibers were endotoxin-free as determined by the Limulus Amebocyte Lysate gel clot assay (Endosage, Charles River Labs, Wilmington, MA). Asbestos fibers were aerosolized using a modified Timbrell generator to generate a target concentration of $7-10 \mathrm{mg} / \mathrm{m}^{3}$ air, as previously described (19). Aerosol characteristics and concentrations were measured daily using a Sierra cascade impactor.

Mice were euthanized via intraperitoneal injection of sodium pentobarbital and lungs were lavaged as described below. The lungs were then perfused and inflated under pressure with phosphate-buffered saline (PBS). The left lobes were tied off, excised, fixed in $4 \%$ paraformaldehyde, and embedded in paraffin for histology and immunocytochemistry, as previously described $(4,5)$. The right lobes were excised and frozen at $-80^{\circ} \mathrm{C}$ for isolation of protein or RNA.

Nuclear translocation of Rel A (p65) in distal bronchiolar epithelium To determine whether nuclear translocation of Rel A occurred at initial sites of asbestos deposition and to verify that this did not occur in asbestos-exposed $\mathrm{Tg}+$ mice, $\mathrm{Tg}+$ and $\mathrm{Tg}$ - sham and asbestos-exposed mouse lungs were instilled with PBS for 5 min at a pressure of $25 \mathrm{~cm} \mathrm{H}_{2} \mathrm{O}$, placed into Tissue-Tek OCT Compound (Sakura Finetek, Inc., Torrance, CA), and frozen sections prepared. Slides were fixed for 5 minutes in 3\% paraformaldehyde in PBS, washed and permeabilized for 20 min with $1 \%$ Triton X-100 in PBS, and blocked with $10 \%$ goat serum in PBS for $1 \mathrm{hr}$. Slides were then incubated at room temperature with Ab for Rel A (10 ug/ml, SC-372, Santa Cruz Biotechnology, Santa Cruz, CA) in 1\% BSA/PBS for $3 \mathrm{~h}$. Following $3 X$ PBS washes, slides were incubated for 30 min with goat anti-rabbit Alexa 647-labeled secondary Ab (Molecular Probes, Eugene, OR) in PBS and counterstained with a 1:1000 dilution of SYTOX Green (Molecular Probes) in PBS to label nuclei. Slides were then washed and coverslipped, and distal bronchioles (defined as those with a $<800$ micron perimeter at $400 \mathrm{X}$ magnification) were scanned using a Bio-Rad MRC 1024 confocal scanning laser microscope.

Bronchoalveolar lavage (BAL) and differential cell counts Following euthanasia, tracheas of mice were cannulated with polyethylene tubing. Lungs were then lavaged with sterile calcium and magnesium free PBS in a total volume of $1 \mathrm{ml}$. Total cells in BAL fluid (BALF) were enumerated, and $2 \times 10^{4}$ cells were centrifuged onto glass slides at $600 \mathrm{rpm}$. Cytospins were stained 
using the Hema3 kit (Biochemical Sciences, Inc. Swedesboro, NJ), and differential cell counts were performed on 500 cells/mouse (4).

Bio-Plex analysis of BALF cytokines and chemokines To quantify cytokine and chemokine levels in BALF, a multiplex suspension protein array was performed using the Bio-Plex Protein Array System and a Mouse Cytokine 22plex Panel (Bio-Rad, Hercules, CA) as described previously (5). This method of analysis is based on Luminex ${ }^{\mathrm{TM}}$ technology and simultaneously measures IL-1 $\alpha$, IL-1 $\beta$, IL-2, IL-4, IL-5, IL-6, IL-9, IL-10, IL-12(p40), IL-12(p70), IL-13, IL17, TNF- $\alpha$, RANTES, MIP-1 $\alpha$, MIP-1 $\beta$, MCP-1, KC, G-CSF, GM-CSF, IFN- $\gamma$ and Eotaxin protein. Briefly, anti-cytokine/chemokine antibody conjugated beads were added to individual wells of a 96-well filter plate and adhered using vacuum filtration. After washing, $50 \mu \mathrm{l}$ of pre-diluted standards (range between $32,000 \mathrm{pg} / \mathrm{ml}$ and $1.95 \mathrm{pg} / \mathrm{ml}$ ) or BALF ( $\mathrm{N}=5$ samples/group) were added, and the filter plate shaken at $300 \mathrm{rpm}$ for $30 \mathrm{~min}$ at room temperature. Thereafter, the filter plate was washed, and $25 \mu$ of pre-diluted multiplex biotin-conjugated detection antibody was added for $30 \mathrm{~min}$. After washing, $50 \mu \mathrm{l}$ of pre-diluted streptavidin-conjugated phycoerythrin was added for $10 \mathrm{~min}$ followed by an additional wash and the addition of $125 \mu$ of Bio-Plex assay buffer to each well. The filter plate was analyzed using the Bio-Plex Protein Array System, and concentrations of each cytokine and chemokine were determined using Bio-Plex Manager Version 3.0 software.

Histopathology to evaluate inflammation and fibrosis Paraffin sections at 3 and 9 days were stained with Hematoxylin and Eosin (H\&E) and at 40 days by the Masson's trichrome technique to detect collagen. Sections were evaluated by a board-certified pathologist (KJB) using a blind coding system. Inflammation was scored on a scale from 1 through $4(1=$ no inflammation, $2=$ mild inflammation that was rarely peribronchiolar and consisted of primarily lymphocytes, $3=$ moderate inflammation with peribronchiolar neutrophils, eosinophils, lymphocytes and abundant macrophages, and $4=$ severe inflammation). At 40 days, fibrosis was evaluated on a $1-4$ scale $(1=$ no fibrosis; $2=$ focal fibrosis; 3 = moderate fibrosis; and 4 = severe fibrosis).

Ki-67 immunoperoxidase technique Ki-67 is a marker of cycling cells undergoing proliferation $(17,20)$. Lung sections were deparaffinized in xylene, rehydrated through graded ethanols and equilibrated in PBS (17). Antigen retrieval was then performed using a 1:10 dilution in PBS of 10X DAKO Target Retrieval Solution (DAKO, Carpinteria, CA) in a $95^{\circ} \mathrm{C}$ water bath for 40 min followed by 20 min cooling to room temperature. Sections were then treated with DAKO Peroxidase Block for $30 \mathrm{~min}$ followed by a $5 \mathrm{~min}$ wash in Tris Buffered Saline (TBS) before incubation in DAKO Serum Free Protein Block for $30 \mathrm{~min}$. Sections were then immersed in $50 \mu \mathrm{l}$ of a 1:25 dilution of monoclonal rat antimouse Ki-67 primary antibody (DAKO), a 1:600 dilution of biotinylated anti-rat IgG secondary antibody (Vector, Burlingame, CA), a 1:25 dilution of rat whole serum (Zymed, San Francisco, CA) and 1\% bovine serum albumin in PBS at 
room temperature for 30 min before blocking of excess secondary antibody with normal rat serum for $1.5 \mathrm{~h}$. Negative controls were incubated in PBS without primary antibody, and all sections were incubated overnight at $4^{\circ} \mathrm{C}$ in a humidified chamber. Sections were washed $3 X$ in TBS, treated for 30 min with Horseradish Peroxidase Streptavidin (Vector), and incubated in 3,3'diaminobenzidine (DAB) (DAKO) for $3 \mathrm{~min}$. Sections were then rinsed in $\mathrm{dd}_{2} \mathrm{O}$, counterstained for $30 \mathrm{sec}$ in hematoxylin, dehydrated through increasing dilutions of ethanol, and washed in xylene $2 X$ for 15 min before coverslips were mounted in Histomount (Zymed). Ki-67 positive cells were quantitated in 3 compartments: 1) the distal bronchiolar epithelium/alveolar duct epithelium; 2) the peribronchiolar compartment of these same bronchioles; and 3) the lung interstitium excluding vessels and bronchioles. Distal bronchioles were restricted to those with less than an $800 \mu \mathrm{m}$ perimeter as viewed at 400X magnification. Ki-67 positively stained cells in all compartments presented with distinct brown vs. purple nuclei, and the total number of Ki-67 positive and negative nuclei from all bronchioles on a lung section and their peribronchiolar region were quantitated to obtain an average of the $\%$ of positively stained cells per animal. For the interstitial compartment, an image of the interstitium of the lung was viewed at $400 \mathrm{X}$ with a grid superimposed. For each image, the $\%$ of $\mathrm{Ki}-67$ positive cells in 5 boxes, excluding blood vessels, red blood cells, and bronchioles was determined to achieve an average (Means \pm SEM) per animal. Means and SEMs were then calculated for all animals in each experimental group.

Alcian blue staining We have recently reported that inhalation of chrysotile asbestos induces increased mucin production in bronchiolar epithelium as confirmed by both Alcian blue and Alcian blue/PAS staining, which peaks at 9 days (5). To determine the percentage of mucus producing cells, lung sections from 3 and 9 day mice were deparaffinized, rehydrated, equilibrated in PBS and stained with Alcian blue (5). Lung sections were then graded by a board certified pathologist (KJB) using a blind coding system for the severity of mucous metaplasia after evaluation of $>10$ distal bronchioles (defined in size as $<800$ microns in perimeter) per mouse. The numbers of Alcian blue positive epithelial cells were scored in individual bronchioles using a 1 to 4 scale for severity $(1=$ no positive cells, $2=1-25 \%$ positive cells, $3=26-50 \%$ positive cells, $4=51-100 \%$ positive cells). The extent of mucin production was expressed as the percentage of bronchioles exhibiting Alcian blue positive epithelial cells.

RNA isolation and ribonuclease protection assays (RPA) Total RNA was extracted from lavaged frozen lungs using TRIzol Reagent (Invitrogen Life Technologies, CA) followed by a cleaning procedure using a RNeasy Mini Kit (Qiagen Inc. CA). Gene expression was assessed qualitatively and quantitatively using the Multi-Probe RNAse Protection Assay (RPA) system (Riboquant $^{\mathrm{TM}}$ Pharmingen, San Jose, CA) (21). The murine cytokine template set mCK- $5 \mathrm{c}$ was used on RNA from 9 day animals (the time of peak inflammation) 
employing radiolabeled antisense RNA probes for Itn, rantes, mip- $\alpha$, mip- $1 \beta$, mip-2, ip-10, mcp-1, tca-3, eotaxin, 132 and gapdh. A fibrosis template was custom made by Riboquant ${ }^{\mathrm{TM}}$ Pharmingen and used on RNA from 40 day exposed animals with probes for il- $1 \beta$, collagen 1,2 and 10 , tgf- $\beta 1$, il-6, tenascin, I32 and gapdh. In vitro transcription was carried out by incubation of $1 \mu \mathrm{l}$

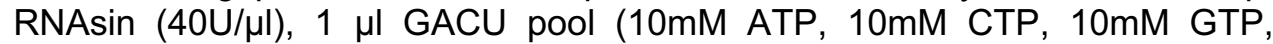
$10 \mathrm{mM}$ UTP), $2 \mu \mathrm{I}$ DTT (100mM), $4 \mu \mathrm{l}$ transcription buffer, $1 \mu \mathrm{l}$ RPA template, $10 \mu \mathrm{l}\left[\alpha^{32} \mathrm{P}\right]$ UTP and $1 \mu \mathrm{l}$ T7 RNA polymerase $(20 \mathrm{U} / \mu \mathrm{l})$. The mixture was incubated at $37^{\circ} \mathrm{C}$ for $60 \mathrm{~min}$ and then treated with Dnase I at $37^{\circ} \mathrm{C}$ for $30 \mathrm{~min}$. The mixture was extracted with a combination of phenol and chloroform, and the RNA precipitated with ethanol at $-80^{\circ} \mathrm{C}$ and collected by centrifugation at $4^{\circ} \mathrm{C}$. The RNA was resuspended in $50 \mu$ hybridization buffer and diluted to $3 \times 10^{5} \mathrm{cpm} / \mu \mathrm{l}$, for a total of $2 \mu \mathrm{l}$ per reaction. The lung RNA samples $(5 \mu \mathrm{g}$ from each mouse) were dried in a vacuum evaporator and resuspended in $8 \mu$ l hybridization buffer. The RNA was denatured at $95^{\circ} \mathrm{C}$ for 3 min and then annealed to the probe overnight at $56^{\circ} \mathrm{C}$. RNase digestion was carried out at $30^{\circ} \mathrm{C}$ for $45 \mathrm{~min}$ to remove all the single-stranded RNA. The protected RNA duplexes were purified by phenol/chloroform extraction and ethanol precipitation at $-80^{\circ} \mathrm{C}$ and collected by centrifugation at $4^{\circ} \mathrm{C}$. The pelleted RNA was resuspended in $8 \mu \mathrm{l} \mathrm{gel} \mathrm{loading} \mathrm{buffer,} \mathrm{incubated} \mathrm{at} 95^{\circ} \mathrm{C}$ for $3 \mathrm{~min}$, and put on ice until separation on a $5 \%$ polyacrylamide/ $8 \mathrm{M}$ urea gel. Each specific hybridized product migrates according to its size, thereby allowing identification of individual bands that were assigned to specific mRNA products. After gels were dried, autoradiograms were developed and quantitated using a Bio-Rad phosphorimager (Bio-Rad, Hercules, CA). Results were normalized to expression of the housekeeping gene, $/ 32$.

Statistical analyses Analysis of variance using the Student-Newman-Keul's procedure for adjustment of multiple pair-wise comparisons was performed to identify significant differences between groups at each time point. Analyses of statistical differences in the Alcian blue staining data and differential cell counts were performed using the non-parametric Kruskal-Wallis test. $p$ values $\leq 0.05$ were considered statistically significant.

\section{RESULTS}

Our strategy was to first determine if abrogation of NF-KB signaling in bronchial epithelial cells affected epithelial cell and fibrogenic responses to asbestos. We then examined cytokine and inflammatory cell profiles in BALF in sham and asbestos-exposed $\mathrm{Tg}+$ and $\mathrm{Tg}$ - mice comparatively. Since chrysotile asbestos fibers preferentially deposit after inhalation in the distal bronchioles and alveolar duct regions, we focused specifically on these lung areas in our histopathologic and other analyses. 
Distal bronchioles of CC10-IKBasr Tg+ mice do not show nuclear translocation of $\operatorname{Rel} A$ (p65) in response to asbestos

As shown in Figure 1A, distal bronchiolar epithelium from sham Tg- mice showed little nuclear localization of the NF-kB subunit, Rel A. At 9 days after asbestos inhalation (Figure 1C), marked nuclear translocation of Rel A was observed in some, but not all distal bronchioles, presumably reflecting those bronchioles in which maximum impingement and interaction of fibers with epithelial cells occurred. Sham $\mathrm{Tg}+$ mice also showed little nuclear localization of Rel A (Figure 1B) and no nuclear translocation in response to asbestos (Figure 1D).
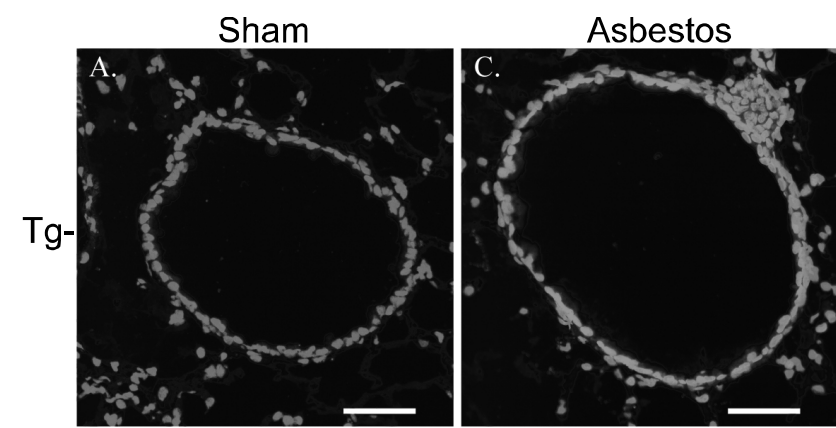

Figure 1: Immunolocalization of the NF-kB subunit, Rel A (p65) shows that asbestos exposure (9 days) causes increased nuclear translocation in distal bronchiolar epithelium of $\mathrm{Tg}-$, but not $\mathrm{Tg}+$ mice. Frozen lung sections were prepared and stained with an antibody directed against Rel A followed by incubation with an
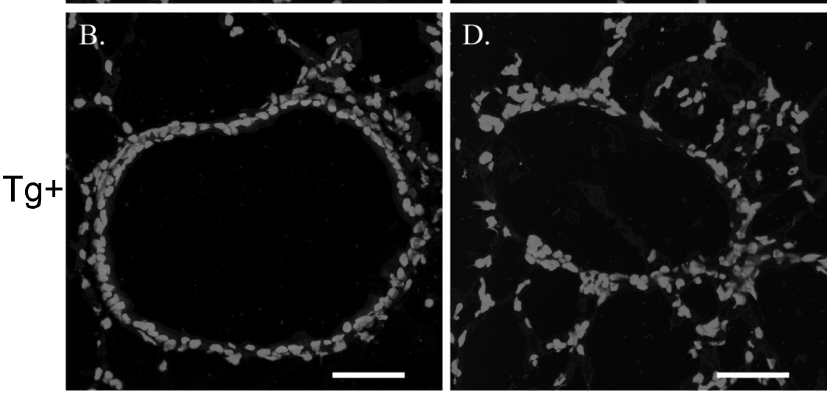
Alexa 647-conjugated secondary antibody (blue). A nuclear counter stain (SYTOX Green) was used to evaluate nuclear localization of Rel A. Overlapping signals (turquoise) indicate nuclear co-localization of Rel A. A, Sham Tg- lung. B, Sham $\mathrm{Tg}+$ lung. C, Asbestosexposed $\mathrm{Tg}$ - mouse lung. D, Asbestos exposed $\mathrm{Tg}+$ mouse lung. Bars $=50 \mu \mathrm{m}$.

\section{Distal bronchioles of CC10-IKBasr Tg+ mice exhibit decreases in chronic epithelial cell proliferation in response to asbestos}

We have shown recently that the peak time point of epithelial cell proliferation, as measured by nuclear Ki-67 immunoreactivity, occurs 3 days after exposure of C57BL/6 wild type mice to chrysotile asbestos (5). In studies here, we also measured cell proliferation in other distal lung compartments at 3, 9, and 40 days post inhalation of asbestos to determine if they were altered by inhibition of NF-KB in bronchiolar epithelium. Bronchiolar epithelial cell proliferation was increased in asbestos-exposed $\mathrm{Tg}$ - and $\mathrm{Tg}+$ mouse lungs at all time points; however, significantly fewer distal bronchiolar epithelial cells in $\mathrm{Tg}+$ mice incorporated Ki-67 at 40 days (Figure 2A). Proliferation in the peribronchiolar regions of these bronchioles was also elevated in response to asbestos at all time points (Figure 2B). Ki-67 labeling in the lung interstitium was not elevated 
in response to asbestos at 3 or 9 days, but at 40 days there was significantly less proliferation in $\mathrm{Tg}+$ mice overall $(\mathrm{Tg}+\mathrm{vs}$. Tg- averaged over both sham and asbestos-exposed mice) (Figure 2C). No changes in any other endpoint examined (see below) were observed between sham $\mathrm{Tg}+$ and sham $\mathrm{Tg}$ mouse at any time point.

A. Bronchiolar

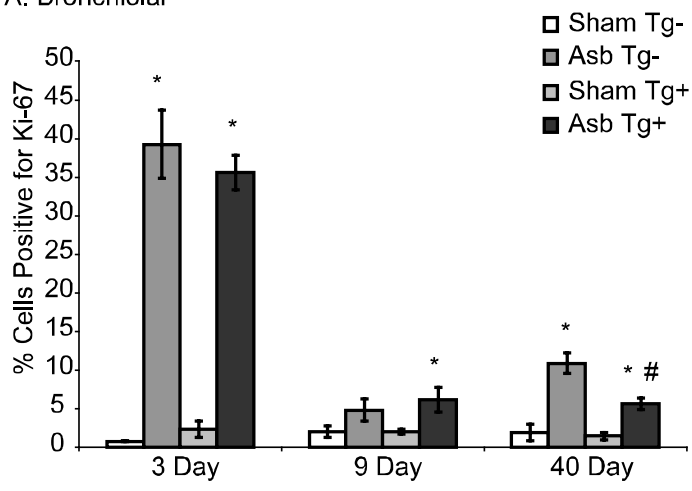

B. Peribronchiolar

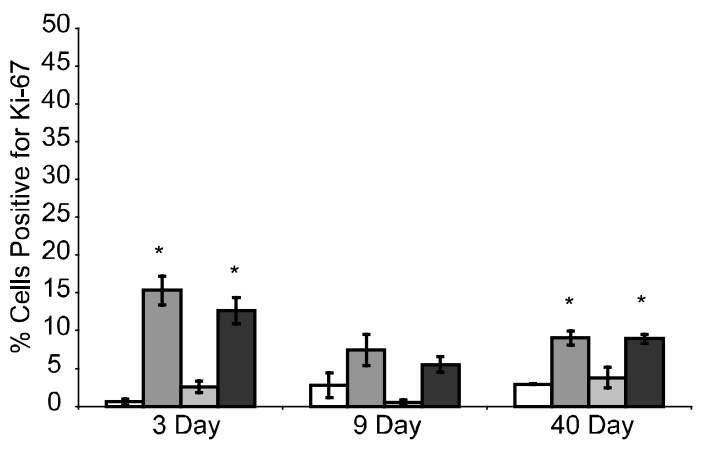

C. Interstitial

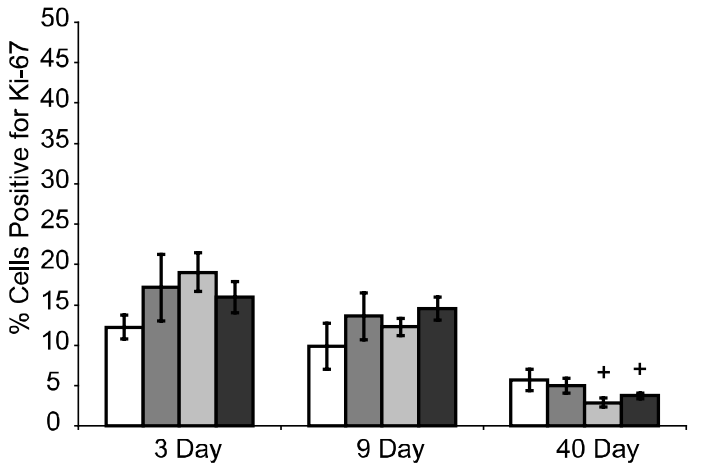

Figure 2: Ki-67 immunoperoxidase staining reveals that proliferation of distal bronchiolar epithelial cells is decreased in CC10-IkBasr (Tg+) mice after 40 days of asbestos exposure. A) Bronchiolar epithelial cell incorporation of $\mathrm{Ki}-67$ over time. B) Incorporation of Ki-67 by peribronchiolar cells. C, Interstitial cell incorporation of Ki-67. Values are graphed as Mean \pm SEM. * $p \leq 0.05$ in comparison to respective sham group at same time point. \# $p \leq 0.05$ in comparison to asbestos $\mathrm{Tg}$ - mice at same time point. $+=$ significant overall difference between $\mathrm{Tg}+$ and $\mathrm{Tg}$ - mice at same time point averaged over sham and asbestos-exposed treatment groups.

Mucin production in asbestosexposed CC10-IKBasr (Tg+) mice is increased in comparison to $\mathrm{Tg}$ - mice

We have recently reported that mucus accumulates in the bronchiolar epithelium of chrysotile asbestos-exposed C57BL/6 mice with a peak response at 9 days. Grading of Alcian blue-stained lung sections showed that $\mathrm{Tg}+$ mice exhibited more mucinpositive bronchiolar epithelial cells at 9 days compared to Tgmice (Figure 3, Table I). In addition, the percentage of bronchioles exhibiting mucus production was increased at the earlier 3 day time point in asbestos-exposed $\mathrm{Tg}+$ mice. 
Table I:

Mucus production in bronchiolar epithelium (Alcian blue staining)

\begin{tabular}{|c|c|c|c|c|}
\hline Group & Sham Tg- & Asbestos Tg- & Sham Tg+ & Asbestos Tg+ \\
\hline Severity $^{\mathrm{b}}$ & & & & \\
\hline 3 Day & $1.0 \pm 0$ & $2.0 \pm 0.3$ & $1.0 \pm 0.3$ & $2.0 \pm 0.3$ \\
\hline 9 Day & $1.0 \pm 0$ & $3.0 \pm 0.0^{\mathrm{d}}$ & $1.3 \pm 0.3$ & $3.75 \pm 0.3^{\mathrm{de}}$ \\
\hline Extent $^{\mathrm{c}}$ & & & & \\
\hline 3 Day & $42 \pm 14$ & $63 \pm 16$ & $15 \pm 12$ & $88 \pm 7^{\mathrm{d}}$ \\
\hline 9 Day & $34 \pm 10$ & $25 \pm 18$ & $48 \pm 18$ & $63 \pm 7$ \\
\hline
\end{tabular}

a Values represent means \pm SEM ( $n=5$ mice/group).

${ }^{\mathrm{b}}$ Severity was graded on a 1-4 score as described in Materials and Methods.

${ }^{\mathrm{c}}$ Extent was scored as the percentage of bronchioles exhibiting Alcian blue-positive epithelial cells.

${ }^{\mathrm{d}} p \leq 0.05$ compared with respective sham group.

${ }^{\mathrm{e}} p \leq 0.05$ compared with asbestos-exposed $\mathrm{Tg}$ - group.

Sham

\section{A.}

Tg-

\section{A.}

-

$\mathrm{Tg}+$
Asbestos

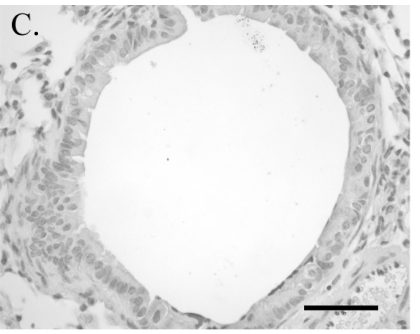

D.

Figure 3: Mucin production in asbestos-exposed CC10IkBasr $\left(\mathrm{Tg}^{+}\right)$mice is increased in comparison to Tg- mice. Alcian blue staining demonstrates mucus production by distal bronchiolar epithelial cells in lungs at 9 days. A, Sham exposed Tg- lung. B, Sham exposed $\mathrm{Tg}+$ lung. C Asbestos exposed Tg- lung. $D$, Asbestos-exposed $\mathrm{Tg}+$ lung.

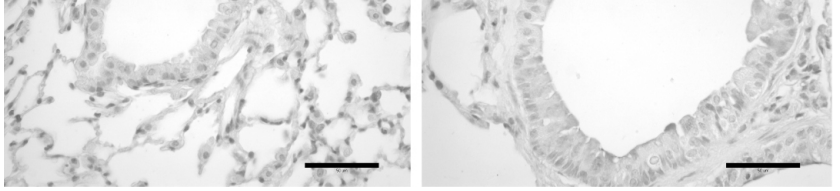

CC10-IKBasr mice show altered patterns of asbestos-associated inflammation compared to $\mathrm{Tg}$ - mice

Although we have reported increased numbers of polymorphonuclear cells in the lungs and BALF of C57BL/6 mice inhaling chrysotile asbestos (17), we have not characterized the individual cell types in BALF comparatively over time.

Here we show in comparison to sham mice with a BALF population consisting of alveolar macrophages that both asbestos-exposed $\mathrm{Tg}+$ and $\mathrm{Tg}$-mice exhibit increased total cell numbers in BALF with increased proportions of eosinophils and neutrophils at 3 days and elevated numbers of eosinophils, neutrophils 
and lymphocytes at 9 days (Figure 4). At 40 days, total cell numbers in BALF are largely diminished, but small numbers of lymphocytes are observed and increased in $\mathrm{Tg}+$ mice. In comparison to asbestos-exposed Tg- mice, CC10IkBasr Tg+ mice inhaling asbestos also demonstrated significantly more eosinophilia in BALF at 9 days.

\section{A. 3 Day}
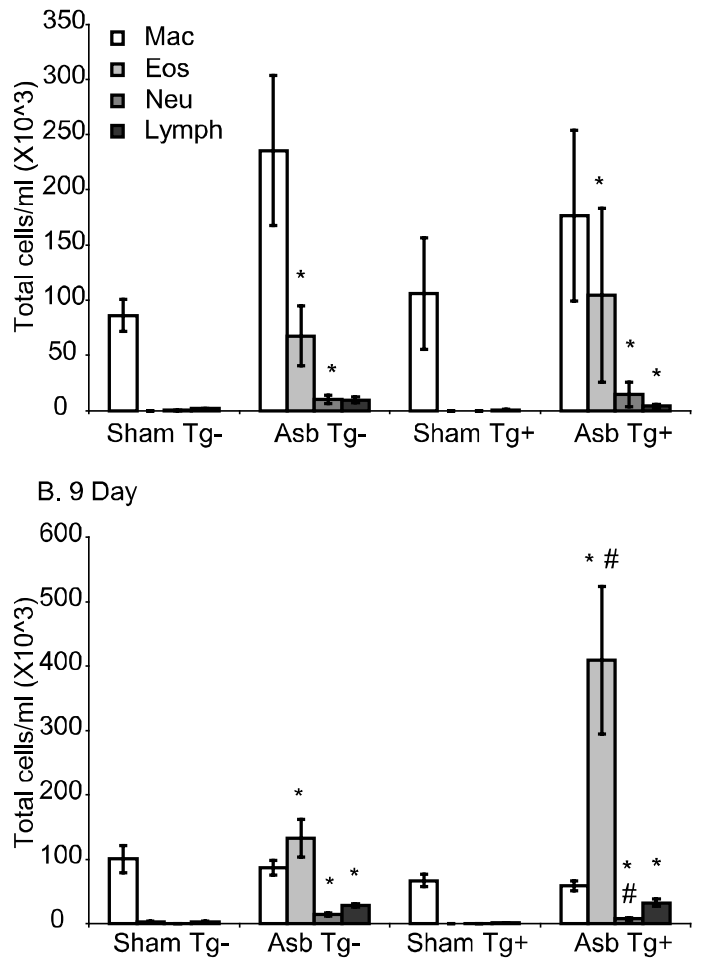

C. 40 Day

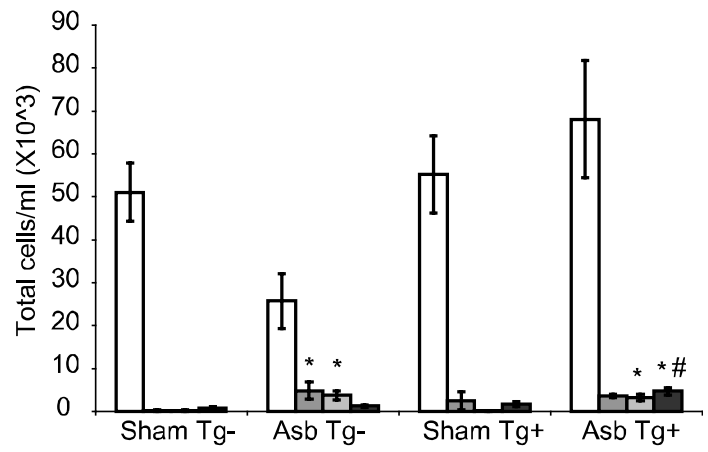

Figure 4: CC10-IkBasr mice show altered patterns of asbestos-associated inflammation as compared to Tg- mice. Differential cell counts in BALF. A, 3 day. B, 9 day. C, 40 day sham- and asbestos-exposed groups. Values are graphed as mean \pm SEM. ${ }^{*} p \leq 0.05$ in comparison to respective sham group at same time point. \# $p \leq 0.05$ in comparison to asbestos Tg- mice at same time point.

As shown in Figure 5, lung sections from sham $\mathrm{Tg}$ - and $\mathrm{Tg}+$ mice exhibited no inflammation, but lungs from asbestos-exposed animals at 3 and 9 days showed mild to moderate peribronchiolar inflammation with no apparent transgene effects (Table II). After 40 days of exposure to asbestos, staining of collagen with the Masson's trichrome technique showed the development of focal peribronchiolar fibrosis that was not seen in the lungs of sham animals (Table II, Figure 5B). 
Table II: Scoring of Immune Cell Infiltration and Fibrosis in Lung Tissue

\begin{tabular}{|c|c|c|c|c|}
\hline Group & Sham Tg- & Asbestos Tg- & Sham Tg+ & Asbestos Tg+ \\
\hline Immune Cell Infiltration $^{a}$ & & & & \\
\hline 3 Day & $1.3 \pm 0.3$ & $2.75 \pm 0.3^{*}$ & $1.0 \pm 0.0$ & $3.0 \pm 0.0^{*}$ \\
\hline 9 Day & $1.5 \pm 0.5$ & $3.0 \pm 0.0^{*}$ & $1.0 \pm 0.0$ & $3.5 \pm 0.3^{*}$ \\
\hline 40 Day & $1.25 \pm 0.3$ & $2.75 \pm 0.3^{*}$ & $1.0 \pm 0.0$ & $2.75 \pm 0.3^{*}$ \\
\hline & & & & \\
\hline Fibrosis (40 Day) $)^{b}$ & $1.0 \pm 0.0$ & $2.3 \pm 0.3^{*}$ & $1.0 \pm 0.0$ & $2.0 \pm 0.0^{*}$ \\
\hline
\end{tabular}

${ }^{a}$ Evaluated on H\&E stained sections using a 1-4 scoring system where $1=$ no infiltration, 2 $=$ mild infiltration, $3=$ moderate infiltration, $4=$ severe infiltration

${ }^{b}$ Evaluated on lung sections stained with the Masson's trichrome method to detect collagen where $1=$ no fibrosis, 2 = focal fibrosis, $3=$ moderate fibrosis, $4=$ severe fibrosis

${ }^{*}=p \leq 0.05$ compared to respective sham group
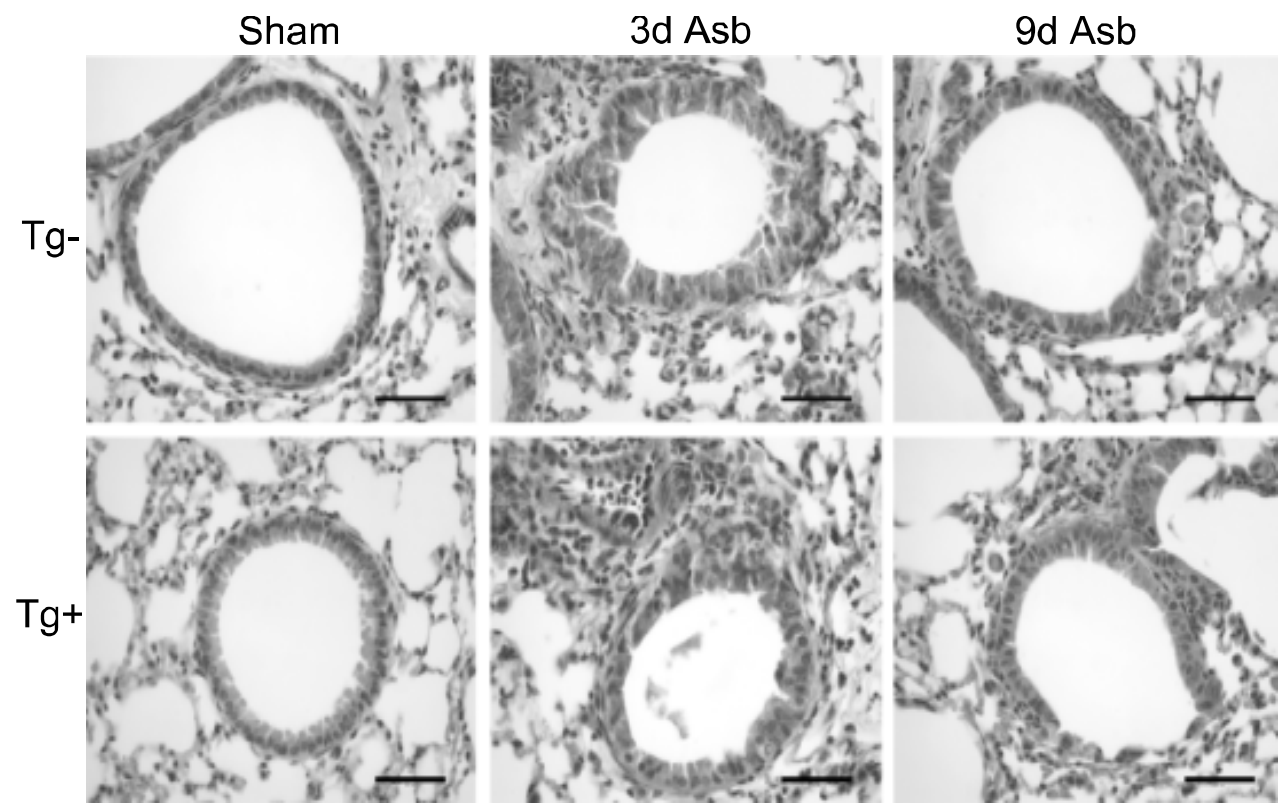

Figure 5A: Both Tg- and Tg+ mice show mild to moderate inflammation and focal peribronchiolar fibrosis after asbestos inhalation. Histopathology on mouse lungs at 3, 9 and 40 days. H\&E staining. 


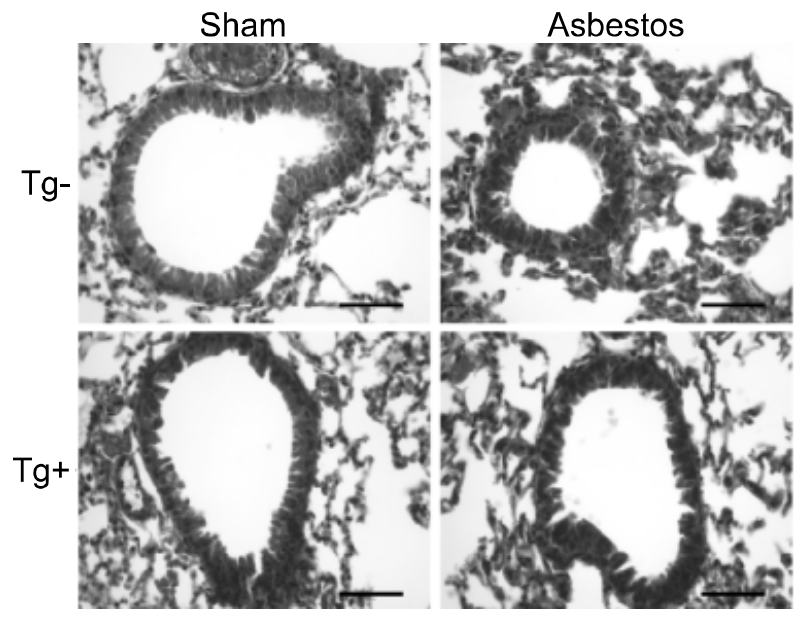

Figure 5B: Both $\mathrm{Tg}-$ and $\mathrm{Tg}+$ mice show mild to moderate inflammation and focal peribronchiolar fibrosis after asbestos inhalation. Masson's trichrome staining for collagen.

Because the development of fibrosis was minimal in chrysotile asbestosexposed mice as has been reported previously $(4,5,17)$ and unlikely to reveal transgene differences, we screened lung homogenates from 40 day mice using a custom-made RPA template for genes linked to fibrogenesis (Figure $6 A)$.Significant increases in tgf- $\beta 1$, collagen 1 and tenascin mRNA levels were seen in asbestos-exposed lungs. Tgf- $\beta 1$ gene expression was reduced ( $p$ $\leq 0.05$ ) in $\mathrm{Tg}+\mathrm{vs}$. $\mathrm{Tg}$ - mice, and tenascin gene expression was increased only in asbestos-exposed Tg- mice in comparison to sham mice. Increased gene expression of eotaxin and mip-1a were observed in asbestos-exposed mouse lungs at 9 days (Figure 6B). Other genes analyzed on RPAs did not demonstrate asbestos-induced changes in expression, and results were not graphed. 

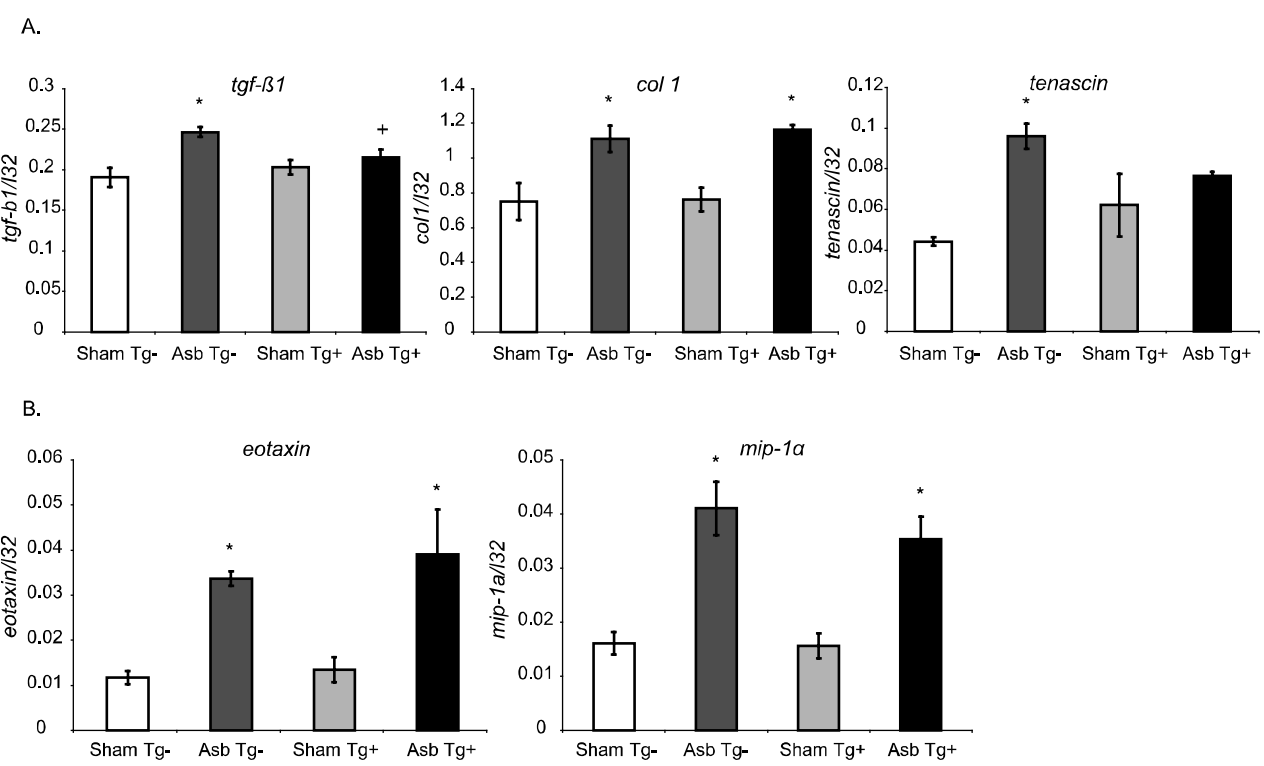

Figure 6: Ribonuclease protection assay showing the difference in pattern of profibrotic gene expression in $\mathrm{Tg}$ - and $\mathrm{Tg}+$ mice after asbestos inhalation. Ribonuclease protection assays on lavaged lungs at $40(\mathrm{~A})$ and 9 (B) days. Values are graphed as mean \pm SEM. ${ }^{*} p \leq 0.05$ in comparison to respective sham group at same time point; $+p \leq 0.05$ in comparison to asbestos $\mathrm{Tg}$ - mice at same time point.

\section{CC10-IKBasr Tg+ mice show altered cytokine and chemokine levels in response to asbestos}

A number of cytokines were induced by asbestos and significantly diminished or increased selectively in Tg+ vs. Tg- mice (Figure 7). Levels of KC, a potent neutrophil chemoattractant, were significantly higher in BALF after inhalation of asbestos by $\mathrm{Tg}$ - but not $\mathrm{Tg}+$ mice at all time points. IL-10 was induced by asbestos at 9 days in Tg- mice, but no asbestos-induced induction of IL-10 was observed in Tg+ mice. Additionally, IL-1 $\beta$ and IL-6 levels were higher in asbestos-exposed Tg- vs. $\mathrm{Tg}+$ mice at 40 days ( $\leq 00.05$ ). In contrast, asbestosassociated increase in IL-4, MIP-1 $\beta$ and MCP-1 were significantly higher in the BALF of 9 day asbestos-exposed Tg+ vs. Tg- mice. These data suggest that several asbestos-induced cytokines and chemokines not produced exclusively by bronchiolar epithelial cells are modulated by suppression of NF-kB in the bronchiolar epithelium. Levels of IL-13, IL-5, RANTES, G-CSF, and GMCSF were significantly increased in asbestos-exposed mice at one or more time points but consistent transgene effects were not observed (data not shown). Of the panel of 22 cytokines/chemokines measured in BALF, eotaxin, MIP-1 $\alpha$ and TNF- $\alpha$ levels were low or highly variable, showing no differences between groups at any time point. Levels of IL-12 (p70), IL-17, IFN- $y$, IL-1 $\alpha$, IL2 , IL-3 and IL-9 were detected in BALF, but levels were not significantly different in sham vs. asbestos-exposed mice (data not shown). 
Table III: Summary of effects found in asbestos-exposed CC10-IKBasr Tg+ vs Tg- mice

\begin{tabular}{|c|c|c|c|c|c|}
\hline Days & $\begin{array}{c}\text { Cytokine } \\
\text { production }\end{array}$ & $\begin{array}{c}\text { Differential } \\
\text { Cell Counts }\end{array}$ & $\begin{array}{c}\text { Mucin Pro- } \\
\text { duction }\end{array}$ & $\begin{array}{c}\text { Cell prolif- } \\
\text { eration }\end{array}$ & $\begin{array}{c}\text { Lung gene } \\
\text { expression }\end{array}$ \\
\hline 3 Days & \begin{tabular}{c}
$<\mathrm{KC},>\mathrm{IL}-4$ \\
\hline $\mathrm{MCP}-1$, \\
$>\mathrm{MIP}-1 \beta$, \\
No $>\mathrm{IL}-10^{\mathrm{c}}$
\end{tabular} & $\mathrm{ND}^{\mathrm{a}}$ & $\mathrm{ND}$ & $\mathrm{ND}$ & $\mathrm{NE}^{\mathrm{b}}$ \\
\hline 40 Days & $\begin{array}{c}<\mathrm{KC},<\mathrm{LL}-6, \\
<\mathrm{LL}-1 \beta\end{array}$ & $>$ Lymphophils & Increased & $\mathrm{ND}$ & $\mathrm{NE}$ \\
\hline
\end{tabular}

${ }^{\text {a }} \mathrm{ND}$, No difference compared with Tg- mice.

${ }^{\mathrm{b}} \mathrm{NE}$, Not evaluated.

${ }^{\mathrm{c}}$ No increase in IL-10 in contrast to Tg- mice.
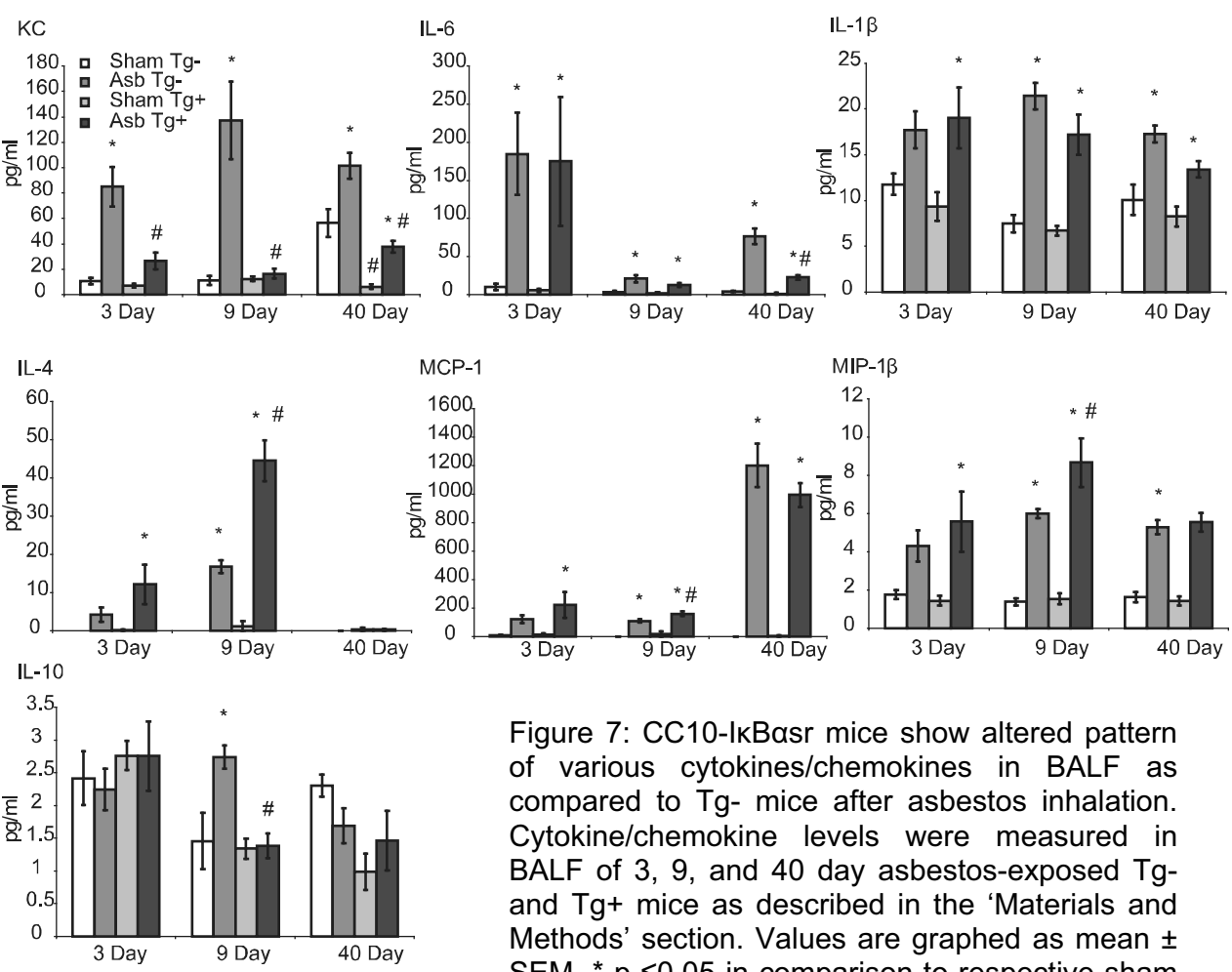

Figure 7: CC10-IkBasr mice show altered pattern of various cytokines/chemokines in BALF as compared to Tg- mice after asbestos inhalation. Cytokine/chemokine levels were measured in BALF of 3,9 , and 40 day asbestos-exposed Tgand $\mathrm{Tg}+$ mice as described in the 'Materials and Methods' section. Values are graphed as mean \pm SEM. * $p \leq 0.05$ in comparison to respective sham group at same time point. \# $p \leq 0.05$ in comparison to asbestos $\mathrm{Tg}$ - mice at same time point. 


\section{DISCUSSION}

We have shown previously that asbestos fibers cause activation of the NF-KB signaling pathway in airway epithelial cells $(8,15)$. Here we reveal that NF-KB activation in epithelial cells of the lung modulates their differentiation and chronic proliferation by asbestos as well as chemokines and cytokines produced by both epithelial and non-epithelial cells. Cell signaling in epithelial cells is integral to recruitment of inflammatory cell types and chemokine/cytokine expression, as has been shown recently in by others (22) and in our previous work using the CC10-IKBasr mouse in lipopolysaccharide and allergen-induced models of airway inflammation $(14,16)$. However, there are distinct differences between the LPS, OVA, and asbestos inhalation models and endpoints examined in these studies. In the LPS model (16), a single bolus of LPS was intranasally instilled into mice, and an acute time study (30 min to $24 \mathrm{hr}$ ) revealed increased neutrophil influx into BALF and lungs of LPSexposed $\mathrm{Tg}$ - vs. $\mathrm{Tg}+$ mice that was maximal at $4 \mathrm{hrs}$. ELISA on BALF revealed increased MIP-2 and TNF- $\alpha$ protein in these mice, and RPAs on lung mip-2 mRNA levels at this time point also showed selective increases by LPS in Tg-animals. In contrast, in the OVA sensitization and challenge model (14) all analyses were performed at $48 \mathrm{hr}$ after a third daily administration of OVA challenge. These acute studies documented: 1) total and differential cell counts in BALF and lung histopathology, both reflecting increased eosinophilia in Tg- mice; 2) Eotaxin-1, IL-4, IL-5, IL-13 and IFN-y by ELISA in BALF, some of which were reduced in $\mathrm{Tg}+\mathrm{vs}$. Tg- mice, and 3) lung mRNA levels of chemokines (rantes, ip-10, mcp-1, eotaxin-1 and cc/20) that were increased in OVA-challenged Tg- vs. Tg+ mice. Although expression of Gob5 by semiquantitative PCR and PAS staining appeared less in lungs of OVA-challenged $\mathrm{Tg}+$ mice, data were not examined statistically. Moreover, pulmonary function data did not reveal transgene effects.

Here we performed a subchronic kinetic study (3, 9, 40 days) with CC10IkBasr ( $\mathrm{Tg}+)$ and $\mathrm{Tg}$ - mice using physiological administration of inhaled asbestos fibers at airborne concentrations equivalent to historical occupational exposures $(1,2)$. We characterized novel patterns in differential cell counts in BALF by asbestos over time and profiled cytokines in BALF using a robust Bio-Plex analysis. Because asbestos fibers are inhaled over time, and the majority is cleared from the lungs, it was unsurprising that the magnitude of inflammation and cytokine expression in this model was less robust than that seen with LPS (16) or the OVA model (14).

Asbestos causes initial injury to epithelial (23) and mesothelial cells (15) in vitro that is followed by compensatory proliferation. Data in Figure 1 using incorporation of $\mathrm{Ki}-67$ as a marker of proliferation correlate with earlier studies in rat and murine asbestos inhalation model using labeling with 5bromodeoxyuridine (BrdU) (24) or proliferating cell nuclear antigen (PCNA) (25). Studies show a robust increase in acute epithelial proliferation in response to asbestos that is followed by less dramatic mitogenesis over time. Data here reveal that inhibition of NF-KB in distal bronchiolar epithelial cells 
suppresses chronic proliferation (40 days), but not acute mitogenesis, in response to asbestos. Our results are consistent with studies implicating NF-kB as a survival factor after cell injury by chemotherapeutic agents and oxidant stress (26). We have shown that other survival pathways such as extracellular signal-regulated kinases (ERK1/2 and ERK5) are important mediators of early epithelial cell proliferation by asbestos (27) and it is likely that cross-talk between the ERK/Activator Protein-1 and NF-KB signaling pathways occurs in our model. Our recent studies also reveal increased expression of Cyclin D1 in the distal bronchiolar epithelium of mice inhaling chrysotile asbestos at 9 days (17). Cyclin D1 and its partner, cyclin-dependent kinase 4 (CDK4), are critical in promoting the $\mathrm{G} 1$ to $\mathrm{S}$ phase progression via phosphorylation of the retinoblastoma protein, and expression of Cyclin D1 is regulated by NF-kB in a myoblast model of proliferation and growth (28). Lack of NF-kB-regulated Cyclin D1 expression in bronchiolar epithelial cells from $\mathrm{Tg}+$ mice might explain decreased epithelial cell mitogenesis in response to asbestos at later time points (40 days). We also noted decreased overall trends in interstitial cell proliferation in $\mathrm{Tg}+$ mice at 40 days, which reflected less $\mathrm{Ki}-67$ labeling in thickened interstitial areas containing fibroblasts. These data support the concept that the extent of bronchiolar epithelial cell mitogenesis or survival correlates with fibroblast proliferation that is intrinsic to fibrogenesis. In this regard, a compendium of studies document epithelial cell modulation of fibroblast growth by cytokine production and other mechanisms (29, 30). Although focal peribronchiolar and interstitial fibrosis was noted in asbestos-exposed $\mathrm{Tg}+$ and Tg- mice (Table II), longer times of exposure will be required to demonstrate possible transgene differences.

We recently reported that chrysotile asbestos caused increased expression of Gob5 and mucin production peaking at 9 days in our inhalation model (5). Later, mucin production is diminished, presumably because fibers move peripherally within the lung over time and fiber dose to the epithelium diminishes. Novel findings here (Table I) show that suppression of NF-KB in epithelial cells increases the severity and extent of mucin production at 9 days- moreover, increased numbers of mucin-positive epithelial cells are seen at 3 days only in asbestos-exposed $\mathrm{Tg}+$ mice. Increased mucin production might have many functional ramifications in this model such as increased clearance of fibers and epithelial protection from fiber injury. Moreover, several cytokines linked to mucus metaplasia, such as IL-13 (31) and IL-4 (32) were elevated in BALF from mice exposed to chrysotile asbestos, and dramatic increases in IL-4 were seen in $\mathrm{Tg}+$ mice at 9 days, the time point of greatest mucin production. Although the increased eosinophilia and mucin production at 9 days may be linked to IL-4, future inhalation experiments using anti-IL-4 antibodies or IL-4 null mice will be necessary to establish a cause and effect relationship. However, it should also be noted that mucin production by CC10-IKBasr (Tg+) vs. Tg- mice in the OVA model appeared decreased, possibly reflecting less IL-13 in BALF in the absence of changes in IL-4 in $\mathrm{Tg}+$ mice (14). These results suggest different mechanisms of regulation of mucin production in these models. 
We also reveal here significant increases in eosinophils in the BALF of mice exposed to chrysotile asbestos that are strikingly increased in CC10-IKBasr Tg+ mice at 9 days (Figure 4). At this time point, neutrophils in BALF (albeit small in numbers) were significantly lower in $\mathrm{Tg}+$ mice in comparison to $\mathrm{Tg}$ mice. The interplay and balance between neutrophils and eosinophils may dictate the extent of inflammation as well as its general resolution by 40 days in the asbestos model. Levels of IL-5, a chemokine linked to eosinophilporesis, and eosinophil recruitment and survival, was increased in both Tg- and Tg+ mice at 3 days. Although lung mRNA levels of eotaxin were increased in asbestos exposed $\mathrm{Tg}$ - and $\mathrm{Tg}+$ mouse lungs at 40 days, no increases in eotaxin, an NF-kB dependent chemokine that is important for eosinophil recruitment to the lungs and is expressed by airway epithelial cells (33) were detected in the BALF of asbestos-exposed mice. In the OVA model, Eotaxin-1 and IL-5 were both decreased in BALF of OVA-exposed $\mathrm{Tg}+$ mice, corresponding with less eosinophilia in BALF (14). A novel observation here is that, KC levels associated with neutrophil recruitment were strikingly decreased in asbestosexposed CC10-IKBasr Tg+ mice at all time points.

Several proinflammatory cytokines and chemokines such as IL-1 $\beta$, MIP-1 $\beta$, MCP-1 and IL-6 implicated as putative mediators of inflammation and fibrogenic responses to asbestos (34), were elevated in BALF from mice exposed to asbestos, and exhibited transgene differences in expression at later time points. Although we were unable to demonstrate transgene differences in the focal fibrosis occurring in our model, decreased levels of IL- 6 and IL- $1 \beta$ in BALF from asbestos exposed $\mathrm{Tg}+$ mice at 40 days correlated with decreases in tgf- $\beta 1$ and tenascin gene expression, indicators of fibrogenesis and lung remodeling.

Airway epithelial NF-kB activation has been implicated in the initiation and perpetuation of lung inflammatory responses and is, therefore, regarded as a potential target of therapies for a number of diseases. NF-kB in the airway epithelium has been studied experimentally using adenoviral vectors to induce (35) or inhibit (36) its activity, and has also been inhibited using genetic approaches $(14,16,37)$. These studies demonstrate the capacity of airway epithelial NF-kB to modulate neutrophilic and eosinophilic inflammatory responses to endotoxin and allergens. The data presented herein demonstrate that airway epithelial NF-kB modulates the expression of neutrophilic chemokines. Although airway epithelial NF-KB has been shown to modulate the recruitment of eosinophils in the OVA (14) and LPS (16) models, asbestosinduced eotaxin mRNA levels in lung were similar in both $\mathrm{Tg}+$ and $\mathrm{Tg}$ - mice, and levels of eotaxin protein in BALF were comparable. However, the intriguing observation that increased eosinophilia and mucin production both occur at 9 days suggest that they may be linked to IL-4 expresssion.

In summary, we show in Table II, the different responses to asbestos in $\mathrm{Tg}+$ vs. Tg- mice. These results suggest that NF-kB activity in the bronchiolar epithelium is not only important in modulation of airway epithelial proliferation and differentiation, but also is involved in the regulation of cytokine production and recruitment of inflammatory cells to the lung. Our studies lend further support 
to the hypothesis that epithelial cells have an impact on innate and possibly adaptive responses to asbestos.

\section{ACKNOWLEDGEMENTS}

We thank Dr. David Hemenway and Justin Robbins, Votey Inhalation Facility, University of Vermont, for performing inhalation experiments. Stacie Beuschel provided valuable technical assistance. We also thank Professor Emiel Wouters for his support and guidance. 


\section{REFERENCES}

1. Mossman, B. T., and J. B. Gee. 1989. Asbestos-related diseases. In N. Engl. J. Med., Vol. 320, p. 1721.

2. Mossman, B. T., J. Bignon, M. Corn, A. Seaton, and J. B. Gee. 1990. Asbestos: scientific developments and implications for public policy. In Science, Vol. 247, p. 294.

3. Brody, A. R., and L. H. Overby. 1989. Incorporation of tritiated thymidine by epithelial and interstitial cells in bronchiolar-alveolar regions of asbestos-exposed rats. In Am. J. Pathol., Vol. 134, p. 133.

4. Robledo, R. F., S. A. Buder-Hoffmann, A. B. Cummins, E. S. Walsh, D. J. Taatjes, and B. T. Mossman. 2000. Increased phosphorylated extracellular signal-regulated kinase immunoreactivity associated with proliferative and morphologic lung alterations after chrysotile asbestos inhalation in mice. In Am. J. Pathol., Vol. 156, p. 1307.

5. Sabo-Attwood, T., M. Ramos-Nino, J. Bond, K. J. Butnor, N. Heintz, A. D. Gruber, C. Steele, D. J. Taatjes, P. Vacek, and B. T. Mossman. 2005. Gene Expression Profiles Reveal Increased mClca3 (Gob5) Expression and Mucin Production in a Murine Model of Asbestos-Induced Fibrogenesis. In Am. J. Pathol., Vol. 167, p. 1243.

6. Christman, J. W., R. T. Sadikot, and T. S. Blackwell. 2000. The role of nuclear factorkappa B in pulmonary diseases. In Chest, Vol. 117, p. 1482.

7. Ghosh, S., M. J. May, and E. B. Kopp. 1998. NF-kappa B and Rel proteins: evolutionarily conserved mediators of immune responses. In Annu. Rev. Immunol., Vol. 16, p. 225.

8. Janssen, Y. M., A. Barchowsky, M. Treadwell, K. E. Driscoll, and B. T. Mossman. 1995. Asbestos induces nuclear factor kappa B (NF-kappa B) DNA-binding activity and NFkappa B-dependent gene expression in tracheal epithelial cells. In Proc. Natl. Acad. Sci. USA, Vol. 92, p. 8458.

9. Janssen, Y. M., K. E. Driscoll, B. Howard, T. R. Quinlan, M. Treadwell, A. Barchowsky, and B. T. Mossman. 1997. Asbestos causes translocation of p65 protein and increases NF-kappa B DNA binding activity in rat lung epithelial and pleural mesothelial cells. In Am. J. Pathol., Vol. 151, p. 389.

10. Janssen-Heininger, Y. M., M. E. Poynter, and P. A. Baeuerle. 2000. Recent advances towards understanding redox mechanisms in the activation of nuclear factor kappaB. In Free. Radic. Biol. Med., Vol. 28, p. 1317.

11. Sanceau, J., T. Kaisho, T. Hirano, and J. Wietzerbin. 1995. Triggering of the human interleukin- 6 gene by interferon-gamma and tumor necrosis factor-alpha in monocytic cells involves cooperation between interferon regulatory factor-1, NF kappa B, and Sp1 transcription factors. In J. Biol. Chem., Vol. 270, p. 27920.

12. Harant, H., R. de Martin, P. J. Andrew, E. Foglar, C. Dittrich, and I. J. Lindley. 1996. Synergistic activation of interleukin- 8 gene transcription by all-trans-retinoic acid and tumor necrosis factor-alpha involves the transcription factor NF-kappaB. In J. Biol. Chem., Vol. 271, p. 26954.

13. Driscoll, K. E., D. G. Hassenbein, B. W. Howard, R. J. Isfort, D. Cody, M. H. Tindal, M. Suchanek, and J. M. Carter. 1995. Cloning, expression, and functional characterization of rat MIP-2: a neutrophil chemoattractant and epithelial cell mitogen. In J. Leukoc. Biol., Vol. 58, p. 359.

14. Poynter, M. E., R. Cloots, T. van Woerkom, K. J. Butnor, P. Vacek, D. J. Taatjes, C. G. Irvin, and Y. M. Janssen-Heininger. 2004. NF-kappa B activation in airways modulates allergic inflammation but not hyperresponsiveness. In J. Immunol., Vol. 173, p. 7003.

15. Goldberg, J. L., C. L. Zanella, Y. M. Janssen, C. R. Timblin, L. A. Jimenez, P. Vacek, D. J. Taatjes, and B. T. Mossman. 1997. Novel cell imaging techniques show induction of apoptosis and proliferation in mesothelial cells by asbestos. In Am. J. Respir. Cell Mol. Biol., Vol. 17, p. 265.

16. Poynter, M. E., C. G. Irvin, and Y. M. Janssen-Heininger. 2003. A prominent role for airway epithelial NF-kappa B activation in lipopolysaccharide-induced airway inflammation. In J. Immunol., Vol. 170, p. 6257.

17. Haegens, A., A. van der Vliet, K. J. Butnor, N. Heintz, D. Taatjes, D. Hemenway, P. Vacek, B. A. Freeman, S. L. Hazen, M. L. Brennan, and B. T. Mossman. 2005. Asbes- 
tos-induced lung inflammation and epithelial cell proliferation are altered in myeloperoxidase-null mice. In Cancer Res., Vol. 65, p. 9670.

18. Campbell, W. C. H., and A. Wylie. 1980. U.S. Bureau of Mines Report of Investigations, No. 8452.

19. Hemenway, D. R., and S. M. MacAskill. 1982. Design, development and test results of a horizontal flow inhalation toxicology facility. In Am. Ind. Hyg. Assoc. J., Vol. 43, p. 874.

20. Scholzen, T., and J. Gerdes. 2000. The Ki-67 protein: from the known and the unknown. In J. Cell Physiol., Vol. 182, p. 311.

21. Shukla, A., C. Timblin, K. BeruBe, T. Gordon, W. McKinney, K. Driscoll, P. Vacek, and B. T. Mossman. 2000. Inhaled particulate matter causes expression of nuclear factor (NF)-kappaB-related genes and oxidant-dependent NF-kappaB activation in vitro. In Am. J. Respir. Cell Mol. Biol., Vol. 23, p. 182.

22. Polito, A. J., and D. Proud. 1998. Epithelia cells as regulators of airway inflammation. In J. Allergy. Clin. Immunol., Vol. 102, p. 714.

23. Buder-Hoffmann, S., C. Palmer, P. Vacek, D. Taatjes, and B. Mossman. 2001. Different accumulation of activated extracellular signal-regulated kinases (ERK 1/2) and role in cell-cycle alterations by epidermal growth factor, hydrogen peroxide, or asbestos in pulmonary epithelial cells. In Am. J. Respir. Cell Mol. Biol., Vol. 24, p. 405.

24. BeruBe, K. A., T. R. Quinlan, G. Moulton, D. Hemenway, P. O'Shaughnessy, P. Vacek, and B. T. Mossman. 1996. Comparative proliferative and histopathologic changes in rat lungs after inhalation of chrysotile or crocidolite asbestos. In Toxicol. Appl. Pharmacol., Vol. 137, p. 67.

25. Manning, C. B., A. B. Cummins, M. W. Jung, I. Berlanger, C. R. Timblin, C. Palmer, D. J. Taatjes, D. Hemenway, P. Vacek, and B. T. Mossman. 2002. A mutant epidermal growth factor receptor targeted to lung epithelium inhibits asbestos-induced proliferation and proto-oncogene expression. In Cancer Res., Vol. 62, p. 4169.

26. Orlowski, R. Z., and A. S. Baldwin, Jr. 2002. NF-kappaB as a therapeutic target in cancer. In Trends Mol. Med., Vol. 8, p. 385.

27. Scapoli, L., M. E. Ramos-Nino, M. Martinelli, and B. T. Mossman. 2004. Src-dependent ERK5 and Src/EGFR-dependent ERK1/2 activation is required for cell proliferation by asbestos. In Oncogene, Vol. 23, p. 805.

28. Guttridge, D. C., C. Albanese, J. Y. Reuther, R. G. Pestell, and A. S. Baldwin, Jr. 1999. NF-kappaB controls cell growth and differentiation through transcriptional regulation of cyclin D1. In Mol. Cell Biol., Vol. 19, p. 5785.

29. Portnoy, J., T. Pan, C. A. Dinarello, J. M. Shannon, J. Y. Westcott, L. Zhang, and R. J. Mason. 2006. Alveolar type II cells inhibit fibroblast proliferation: role of IL-1alpha. In Am. J. Physiol. Lung Cell Mol. Physiol., Vol. 290, p. L307.

30. Selman, M., and A. Pardo. 2004. Idiopathic pulmonary fibrosis: misunderstandings between epithelial cells and fibroblasts? In Sarcoidosis Vasc. Diffuse Lung Dis., Vol. 21, p. 165.

31. Kibe, A., H. Inoue, S. Fukuyama, K. Machida, K. Matsumoto, H. Koto, T. Ikegami, H. Aizawa, and N. Hara. 2003. Differential regulation by glucocorticoid of interleukin-13induced eosinophilia, hyperresponsiveness, and goblet cell hyperplasia in mouse airways. In Am. J. Respir. Crit. Care Med., Vol. 167, p. 50.

32. Dabbagh, K., K. Takeyama, H. M. Lee, I. F. Ueki, J. A. Lausier, and J. A. Nadel. 1999. IL-4 induces mucin gene expression and goblet cell metaplasia in vitro and in vivo. In $\mathrm{J}$. Immunol., Vol. 162, p. 6233.

33. Takizawa, H., S. Abe, H. Okazaki, T. Kohyama, I. Sugawara, Y. Saito, T. Ohtoshi, S. Kawasaki, M. Desaki, K. Nakahara, K. Yamamoto, K. Matsushima, M. Tanaka, M. Sagai, and S. Kudoh. 2003. Diesel exhaust particles upregulate eotaxin gene expression in human bronchial epithelial cells via nuclear factor-kappa B-dependent pathway. In Am. J. Physiol. Lung Cell Mol. Physiol., Vol. 284, p. L1055.

34. Mossman, B. T., and A. Churg. 1998. Mechanisms in the pathogenesis of asbestosis and silicosis. In Am. J. Respir. Crit. Care Med., Vol. 157, p. 1666. 
35. Sadikot, R. T., W. Han, M. B. Everhart, O. Zoia, R. S. Peebles, E. D. Jansen, F. E. Yull, J. W. Christman, and T. S. Blackwell. 2003. Selective I kappa B kinase expression in airway epithelium generates neutrophilic lung inflammation. In J. Immunol., Vol. 170, p. 1091.

36. Sadikot, R. T., H. Zeng, M. Joo, M. B. Everhart, T. P. Sherrill, B. Li, D. S. Cheng, F. E. Yull, J. W. Christman, and T. S. Blackwell. 2006. Targeted immunomodulation of the NFkappaB pathway in airway epithelium impacts host defense against Pseudomonas aeruginosa. In J. Immunol., Vol. 176, p. 4923.

37. Broide, D. H., T. Lawrence, T. Doherty, J. Y. Cho, M. Miller, K. McElwain, S. McElwain, and M. Karin. 2005. Allergen-induced peribronchial fibrosis and mucus production mediated by IkappaB kinase beta-dependent genes in airway epithelium. In Proc. Natl. Acad. Sci. USA, Vol. 102, p. 17723. 


\section{GENERAL DISCUSSION}




\section{GENERAL DISCUSSION}

Neutrophilic inflammation a is a key contributor to development of lung disorders such as COPD (1), acute respiratory distress syndrome (2), idiopathic pulmonary fibrosis (3), asbestosis (4) and cystic fibrosis (5). Levels of neutrophils in BALF correlate significantly with decline in $\mathrm{FEV}_{1}$ in long term asbestos workers (6). A similar correlation has been found in COPD patients. Neutrophil numbers and sputum levels of IL-8, the main neutrophil chemoattractant, from COPD patients correlate strongly with airflow limitation $(7,8)$. Markers of neutrophil-related damage, caused by ROS and RNS formation during neutrophilia, have been described in these diseases. $\mathrm{NO}_{2} \mathrm{Tyr}$ positive cells have been reported to be increased in sputum samples of COPD patients (9). General oxidative stress, measured indirectly by increased $\mathrm{HO}-1$ levels, was also found in these patients (9). CITyr protein adducts, a specific marker for $\mathrm{HOCl}$ related oxidative damage due to MPO enzymatic activity, have been found in the airways of patients with cystic fibrosis (10). Neutrophilrelated oxidative stress can also lead to DNA damage such as oxidation, nitration, methylation or deamination of DNA. These mechanisms have been elegantly described in a review by Knaapen and colleagues (11).

The overall aim of this work was to investigate the consequences in lung epithelial cells of infiltrating neutrophils on the molecular, protein and whole cell level. There was a specific focus on the contributing effects on these parameters of the neutrophilic enzyme, MPO. In order to test the hypotheses of the separate studies, an in vitro approach was combined with several in vivo approaches as a proof of concept. $\mathrm{Mpo}^{-/}$mice were tested in models of acute and chronic chrysotile asbestos- or LPS-induced inflammation. Ideally, WT and $\mathrm{MpO}^{-/-}$mice would have developed lung neutrophilia in an identical fashion and to the same extent. This way the exact contribution of MPO to epithelial cell damage could have been determined.

\section{Acute lung inflammation}

The results show that knocking out the mpo gene causes an attenuated acute inflammatory response in both acute models tested (chapters 3 and 4 ). The decreased levels of neutrophil chemoattractants, found in the acute LPS model, could be an explanation for the decreased neutrophilia at day 2 and 3 of inflammation. The initial situation is however identical in WT and $\mathrm{Mpo}^{-/-}$ mice, since the inflammatory receptors related to the development of neutrophilia are expressed in a similar fashion. It is therefore tempting to speculate that the reason for a decline in neutrophil influx must be sought in the extravasation of neutrophils during the developmental phase of inflammation. Lau and colleagues (12) have recently found that MPO is involved in CD11b/CD18 expression, crucial integrins during neutrophil extravasation. The lack of MPO could therefore result in a decreased capability of neutrophils to enter a site of inflammation. This would lead to a decreased stimulation of resident cells in this model, resulting in less stimulation of epithelial cells and resident macro- 
phages. Decreased stimulation of epithelial cells results in a lowered chemokine and cytokine production. In line with the results described in chapters $\mathbf{3}$ and $\mathbf{4}$ are data described in (13). In these studies decreased neutrophil influx was shown in a renal model of ischemia and reperfusion, resulting in reduced renal failure in $\mathrm{Mpo}^{-/-}$mice. Unfortunately, no attempt was made to elucidate the mechanisms leading to decreased neutrophilia in these studies.

\section{Chronic lung inflammation}

The long term results of MPO deficiency in chronic inflammation were investigated in chapter $\mathbf{3}$ and chapter $\mathbf{5}$. In the past, attempts have been made to link acute inflammation to the development of chronic inflammation. In the studies described here, it is demonstrated that this link is not straight forward. Repeated asbestos and LPS exposure eventually lead to similar patterns of inflammation in WT and $\mathrm{Mpo}^{-/-}$mice, although the differences between WT and $\mathrm{MpO}^{-/-}$mice in acute responses, meaning the attenuated neutrophil inflammation and cytokine and chemokine levels, are striking. This means that neutrophils and MPO in particular are not a key factor in the development of chronic inflammation. Future research will need to focus on the possible additional mechanisms contributing to the chronic character of several inflammatory lung diseases.

\section{Tissue remodeling}

Another link often made is the one between chronic inflammation and tissue remodeling. Epithelial cell proliferation, although attenuated during acute inflammation, was equally high in WT and $\mathrm{Mpo}^{-/-}$mice after 30 days of asbestos exposure. Structural changes after chronic LPS exposure, measured by airspace enlargement, was increased in WT and $\mathrm{Mpo}^{--}$mice and mathematically significant increased in $\mathrm{Mpo}^{-/}$mice compared to WT animals. The difference in airspace enlargement between WT and $\mathrm{Mpo}^{-/-}$mice was, however, very small and whether these differences are relevant is the question.

If progress is to be made in the treatment of inflammatory lung diseases associated with tissue remodeling, further efforts will be needed to understand the regulation and possible link between the mechanisms causing inflammation and those leading to structural changes.

\section{Oxidative stress}

A possible contributing factor to chronic inflammation and tissue remodeling is oxidative stress. Although acute lung inflammation is attenuated in $\mathrm{Mpo}^{-/}$mice, oxidative stress levels were similar in WT and $\mathrm{MpO}^{-/}$mice. This was measured indirectly by mRNA expression of the antioxidant ho-1. Aratani and colleagues reported data (14) on a study comparing $\mathrm{Mpo}^{-/}$, NADPH-oxidase-/- and double knock-out mice in a model of pulmonary infection that could explain these findings. They reported that $\mathrm{H}_{2} \mathrm{O}_{2}$ used by MPO is solely produced by NADPHoxidase. It is therefore likely that $\mathrm{MpO}^{-/-}$mice that are incapable of converting $\mathrm{H}_{2} \mathrm{O}_{2}$ to $\mathrm{HOCl}$ build up $\mathrm{H}_{2} \mathrm{O}_{2}$. This leads to similar levels of oxidative stress, only from a different oxidative source. As described in the introduction of this 
thesis, the majority of oxidants produced by neutrophils originate from NADPH-oxidase.

The idea that oxidative stress is a contributing factor to tissue remodeling is not only supported by data presented in chapter $\mathbf{5}$, but also by a paper describing protection against bleomycin-induced pulmonary fibrosis in $\mathrm{p} 47^{\text {phox }}-{ }_{-}-$ mice. These mice are deficient in ROS production via the NADPH-oxidase pathway (15). In line with all the findings in models of lung diseases, a recently published review on osteoarthritis (16), an inflammatory disorder of the joints, made an attempt to highlight the uncoupling effect of ROS on structural changes and inflammation. It was suggested that antioxidant therapy could be helpful to treat the structural changes in this disease.

\section{Epithelial cell responses during neutrophilia}

The in vitro studies (chapter 2) were used to determine epithelial cell responses to MPO under basal and inflammatory conditions. Results showed that MPO exposure leads to increased oxidative stress and transient DNA damage. Further results indicated that epithelial cell responses during neutrophilia depend on the primary trigger initiating the inflammation. This was demonstrated by the decreased IL-8 production with PMA as primary trigger. These findings fit with the results of the in vivo studies described in chapters 3 and 4. Both asbestos and LPS exposed mice develop neutrophilic lung inflammation, but only bronchiolar epithelial cells from asbestos exposed mice demonstrate a proliferative profile. Proliferation was even further increased in asbestos-exposed $\mathrm{Mpo}^{-/-}$mice compared to asbestos-exposed WT mice. This supports the idea that the primary trigger, inducing neutrophilia, plays an important role in the epithelial cell responses during neutrophilia. Other mouse studies using CC10-IKBasr mice that are incapable of Rel A translocation, and thus NF-KB transcriptional activity in bronchiolar epithelial cells supports this idea as well. In a study where CC10-IKBasr and WT mice were exposed to LPS as described by Poynter et al. (17), CC10-IkBasr mice demonstrated a decreased lung neutrophilia accompanied by decreased MIP-2 production. These same mice exposed to chrysotile asbestos (chapter 6), normally leading to mixed neutrophilia and eosinophilia, demonstrate an altered inflammatory cell and cytokine/chemokine profile. This profile is characterized by a dramatic eosinophilic inflammation that is accompanied by decreased BALF levels of KC and increased levels of IL-4.

\section{Closing remarks}

A better understanding of processes leading to lung neutrophilia and the subsequent responses of lung epithelial cells is needed to identify therapeutic targets in neutrophilic lung diseases. It would be of interest to explore the possibility of enzymatic inhibition of MPO, while keeping MPO intact as signaling molecule. This would mean that MPO will still contribute to neutrophil extravasation via for instance CD11b/CD18 signaling. The damaging effects of MPO related to its enzymatic activity, as described in this thesis, would however not occur. This theory is very appealing, since it is known that MPO deficiency in 
humans does not lead to increased risk of infections because of compensatory mechanisms taking over in the fight against infections (18).

For this moment, it is important to remember that underlying pathogenic processes in the lung diseases where neutrophilia plays a role in are very different. Inside in these pathogenic processes will have to come from in vitro and in vivo models in combination with neutrophilia causing pathogenic substances. This research approach will contribute to a better understanding of the different human lung diseases and thereby help to identify suitable therapeutic targets for each disease. 


\section{REFERENCES}

1. Hogg, J. C., F. Chu, S. Utokaparch, R. Woods, W. M. Elliott, L. Buzatu, R. M. Cherniack, R. M. Rogers, F. C. Sciurba, H. O. Coxson, and P. D. Pare. 2004. The nature of smallairway obstruction in chronic obstructive pulmonary disease. N Engl J Med 350:2645.

2. Weiland, J. E., W. B. Davis, J. F. Holter, J. R. Mohammed, P. M. Dorinsky, and J. E. Gadek. 1986. Lung neutrophils in the adult respiratory distress syndrome. Clinical and pathophysiologic significance. Am Rev Respir Dis 133:218.

3. Saleh, D., P. J. Barnes, and A. Giaid. 1997. Increased production of the potent oxidant peroxynitrite in the lungs of patients with idiopathic pulmonary fibrosis. Am J Respir Crit Care Med 155:1763.

4. Cullen, M. R., and W. W. Merrill. 1992. Association between neutrophil concentration in bronchoalveolar lavage fluid and recent losses in diffusing capacity in men formerly exposed to asbestos. Chest 102:682.

5. van der Vliet, A., J. P. Eiserich, M. K. Shigenaga, and C. E. Cross. 1999. Reactive nitrogen species and tyrosine nitration in the respiratory tract: epiphenomena or a pathobiologic mechanism of disease? Am J Respir Crit Care Med 160:1.

6. Rom, W. N. 1992. Accelerated loss of lung function and alveolitis in a longitudinal study of non-smoking individuals with occupational exposure to asbestos. Am J Ind Med 21:835.

7. Vernooy, J. H., M. Kucukaycan, J. A. Jacobs, N. H. Chavannes, W. A. Buurman, M. A. Dentener, and E. F. Wouters. 2002. Local and systemic inflammation in patients with chronic obstructive pulmonary disease: soluble tumor necrosis factor receptors are increased in sputum. Am J Respir Crit Care Med 166:1218.

8. Keatings, V. M., P. D. Collins, D. M. Scott, and P. J. Barnes. 1996. Differences in interleukin-8 and tumor necrosis factor-alpha in induced sputum from patients with chronic obstructive pulmonary disease or asthma. Am J Respir Crit Care Med 153:530.

9. Tsoumakidou, M., N. Tzanakis, G. Chrysofakis, and N. M. Siafakas. 2005. Nitrosative stress, heme oxygenase-1 expression and airway inflammation during severe exacerbations of COPD. Chest 127:1911.

10. Kettle, A. J., T. Chan, I. Osberg, R. Senthilmohan, A. L. Chapman, T. J. Mocatta, and J. S. Wagener. 2004. Myeloperoxidase and protein oxidation in the airways of young children with cystic fibrosis. Am J Respir Crit Care Med 170:1317.

11. Knaapen, A. M., N. Gungor, R. P. Schins, P. J. Borm, and F. J. Van Schooten. 2006. Neutrophils and respiratory tract DNA damage and mutagenesis: a review. Mutagenesis 21:225.

12. Lau, D., H. Mollnau, J. P. Eiserich, B. A. Freeman, A. Daiber, U. M. Gehling, J. Brummer, V. Rudolph, T. Munzel, T. Heitzer, T. Meinertz, and S. Baldus. 2005. Myeloperoxidase mediates neutrophil activation by association with CD11b/CD18 integrins. Proc Natl Acad Sci U S A 102:431.

13. Matthijsen, R. A., D. Huugen, N. T. Hoebers, B. de Vries, C. J. Peutz-Kootstra, Y. Aratani, M. R. Daha, J. W. Tervaert, W. A. Buurman, and P. Heeringa. 2007. Myeloperoxidase is critically involved in the induction of organ damage after renal ischemia reperfusion. Am J Pathol 171:1743.

14. Aratani, Y., F. Kura, H. Watanabe, H. Akagawa, Y. Takano, K. Suzuki, M. C. Dinauer, N. Maeda, and H. Koyama. 2002. Relative contributions of myeloperoxidase and NADPHoxidase to the early host defense against pulmonary infections with Candida albicans and Aspergillus fumigatus. Med Mycol 40:557.

15. Manoury, B., S. Nenan, O. Leclerc, I. Guenon, E. Boichot, J. M. Planquois, C. P. Bertrand, and V. Lagente. 2005. The absence of reactive oxygen species production protects mice against bleomycin-induced pulmonary fibrosis. Respir Res 6:11.

16. Henrotin, Y. E., P. Bruckner, and J. P. Pujol. 2003. The role of reactive oxygen species in homeostasis and degradation of cartilage. Osteoarthritis Cartilage 11:747. 
17. Poynter, M. E., C. G. Irvin, and Y. M. Janssen-Heininger. 2003. A prominent role for airway epithelial NF-kappa B activation in lipopolysaccharide-induced airway inflammation. J Immunol 170:6257.

18. Stendahl, O., B. I. Coble, C. Dahlgren, J. Hed, and L. Molin. 1984. Myeloperoxidase modulates the phagocytic activity of polymorphonuclear neutrophil leukocytes. Studies with cells from a myeloperoxidase-deficient patient. J Clin Invest 73:366. 
SUMMARY 
Chapter 8 


\section{SUMMARY}

Neutrophils are highly specialized members of the innate immune system and are often the first immune cells to arrive at a site of infection. Their primary function is phagocytosis and destruction of micro-organisms and foreign material. Several lung diseases, like COPD, asbestosis, ARDS, cystic fibrosis and idiopathic pulmonary fibrosis have to cope with neutrophilia. It is important that the consequences of neutrophilia, and MPO exposure specifically, for lung epithelial cells and responses by epithelial cells to neutrophil exposure are investigated. Neutrophilia is a key contributor to a variety of lung diseases and is therefore of significant clinical relevance. The overall aim of this work was to address the response of lung epithelial cells to infiltrating neutrophils on molecular, protein and whole cell level. There was furthermore a specific focus on the contributing effects of the neutrophilic enzyme MPO. An in vitro model and several mouse models of acute and chronic lung inflammation together with knock-out and transgenic approaches were used to address the above mentioned aims. The results of the conducted studies are summarized below.

\section{Myeloperoxidase modulates lung epithelial responses to pro- inflammatory agents}

In this study we focused on the responses of bronchial and alveolar epithelial cells to MPO exposure, with or without pre-exposure to a pro-inflammatory agent. The endpoints determined were 1) the up-take of MPO by lung epithelial cells, 2) DNA strand breakage by MPO, 3) oxidative stress responses and 4) the production of chemo-attractants. Furthermore we explored involvement of NF-KB and AP-1 signaling. Analysis of MPO stimulated cells showed MPO up-take by bronchial and alveolar epithelial cells. DNA strand breakage was increased by MPO, but this was a temporary effect. Furthermore, MPO exposure resulted in increased oxidative stress levels indirectly measured by the upregulation of ho-1, which was further increased when cells were primed with a pro-inflammatory stimulus. Interestingly, MPO can inhibit IL-8 production by bronchial but not alveolar epithelium, indicating a possible negative feedback loop. Although IL-8 production involves NF-KB and/or AP-1 signaling, neither of these transcription factors were up- or down regulated after MPO exposure.

\section{Asbestos-induced lung inflammation and epithelial cell proliferation are altered in myeloperoxidase null mice}

This animal study aimed to unravel the contributing effects of MPO on the development of lung inflammation and epithelial cell changes in a murine model of chrysotile asbestos-induced lung inflammation. The endpoints measured in this study were 1) localization of MPO in resident lung cells during inflammation, 2) general levels of cell injury, 3) levels of inflammation and inflammatory cell profile and 4) epithelial cell proliferation. Chrysotile asbestos exposure resulted in MPO localization in bronchiolar epithelial cells of inflamed lungs. BALF analysis revealed increased total protein levels and LDH activity in WT and $\mathrm{Mpo}^{-/-}$mice after asbestos exposure. BALF cell content revealed a 
decreased inflammatory response in $\mathrm{Mpo}^{-/}$compared to WT mice after asbestos exposure. Lastly, asbestos exposed $\mathrm{Mpo}^{-/}$mice demonstrated increased bronchiolar epithelial cell proliferation compared to WT mice, addressed by Ki67 and cyclin D1.

\section{Myeloperoxidase deficiency attenuates LPS-induced acute lung inflam- mation and subsequent epithelial injury}

In this study we used a model of LPS-induced acute lung inflammation to test the hypothesis that MPO contributes to the development of lung neutrophilia and the subsequent oxidative stress and damage by LPS to cellular and molecular structures in the lung. To test this hypothesis the following parameters were evaluated 1) MPO activity and localization during acute lung inflammation, 2) neutrophil influx, 3) oxidative stress levels, 4) DNA damage, 5) nitrotyrosine formation, 6 ) basal cytokine and chemokine receptor expression levels and 7) cytokine and chemokine expression and production levels. A single intratracheal dose of LPS resulted in a dramatic increase in MPO activity in WT mice that was absent in $\mathrm{Mpo}^{-/}$mice. MPO is primarily localized in clusters of infiltrated neutrophils. $\mathrm{Mpo}^{-/-}$mice demonstrated a significant decrease in neutrophil influx compared to WT mice, although the levels of ho-1 and 8$\mathrm{OHdG}$ were similar in WT and $\mathrm{Mpo}^{-/}$mice. The formation of nitrotyrosine protein adducts after LPS exposure was decreased in $\mathrm{Mpo}^{-/}$animals compared to WT mice. Basal expression levels of all cytokine and chemokine receptors were similar in WT and $\mathrm{Mpo}^{-/-}$mice, except for $\mathrm{cxcr}-1$. Interestingly, cytokine and chemokine expression and production levels were altered in $\mathrm{Mpo}^{-/-}$mice compared to WT animals.

\section{MPO deficiency aggravates airspace elargement and modulates tissue remodeling mechanisms}

In this chapter we describe a study in which we used a chronic LPS-induced lung inflammatory model to investigate the role of MPO in the development of chronic lung inflammation and airspace enlargement. We furthermore made an attempt to elucidate underlying remodeling mechanisms. The following endpoints were measured 1) MPO activity and localization, 2) inflammatory cell infiltration, 3) airspace enlargement, 4) lung function, 5) anti-oxidant status of the lung, 6) MMP expression patterns, 7) apoptosis and 8) cytokine and chemokine expression patterns. Repeated LPS exposure resulted in similar chronic lung inflammation in WT and $\mathrm{Mpo}^{-/-}$mice with increased MPO levels 1 day after the last exposure in WT animals. Morphological analysis revealed airspace enlargement after chronic LPS exposure. This airspace enlargement was significantly higher in $\mathrm{Mpo}^{-/-}$mice compared to WT mice. Measurable lung function alterations were however not found. The anti-oxidant GSH was significantly increased after chronic LPS exposure and further enhanced in $\mathrm{Mpo}^{-/-}$ animals compared to WT mice. The anti-oxidant vitamin C was also increased after LPS exposure but demonstrated a trend towards a decrease in $\mathrm{Mpo}^{-/-}$ mice compared to WT. MMP-2, -8 and -12 were enhanced in $\mathrm{Mpo}^{-/}$mice compared to WT mice. Apoptosis was not found in the lungs of sham or LPS 
treated WT and $\mathrm{Mpo}^{-/}$animals. Lastly, cytokine and chemokine expression patterns were equal in WT and $\mathrm{Mpo}^{-/}$mice after chronic LPS exposure.

\section{Airway epithelial NF-KB activation modulates asbestos-induced inflam- mation and mucin production in vivo}

Here we tested the hypothesis that the induction of NF-kB in airway epithelium is a critical event associated with epithelial cell alterations, inflammation and fibrogenesis in a murine model of chrysotile asbestos-induced inflammation. This hypothesis was tested by determining 1) NF-KB activation after chrysotile asbestos exposure, 2) epithelial cell proliferation in the different lung compartments 3) mucin production and localization, 4) inflammatory cell profile, 5) levels of fibrosis and profibrotic gene expression and 6) cytokine and chemokine levels in the lung. Chrysotile asbestos exposure resulted in translocation of Rel A, the transcriptionally active subunit of NF-kB, in WT (Tg-) but not CC10-IkBasr ( $\left.\mathrm{Tg}^{+}\right)$mice. Ki-67 immunostaining revealed decreased bronchiolar proliferation in $\mathrm{Tg}+$ mice compared to $\mathrm{Tg}$ - mice after 40 days of asbestos exposure. Mucin production was increased in $\mathrm{Tg}+$ mice compared to $\mathrm{Tg}$ mice after 9 days of chrysotile exposure. BALF cell content revealed a shift in inflammatory cell profile in $\mathrm{Tg}+$ mice compared to $\mathrm{Tg}$ - mice, which was confirmed by the cytokine and chemokine pattern found in $\mathrm{Tg}+$ animals.

\section{Closing remarks}

From the studies conducted here we can conclude that MPO causes damage to protein and molecular cell structures. MPO furthermore contributes to the development of acute lung inflammation. The type of primary trigger responsible for the influx of neutrophils contributes to the way lung epithelial cells respond during neutrophilia. This means that a better understanding of lung diseases where neutrophilia plays a role in will have to come from unraveling the different underlying pathogenic processes of these diseases. Future research using cell culture and animal models in combination with different pathogenic substances related to the development of neutrophilia will contribute to a better understanding of the different human lung diseases. This will help to identify suitable therapeutic targets for each disease. 

SAMENVATTING 
Chapter 9 


\section{SAMENVATTING}

\section{Achtergrond}

Het luchtwegoppervlak van humane longen wordt regelmatig blootgesteld aan potentieel schadelijke stoffen en micro-organismen. Dit oppervlak is bedekt met luchtwegepitheelcellen. Deze epitheelcellen spelen een zeer belangrijke rol in de afweer tegen mogelijk schadelijke stoffen. In gezonde personen is er niet of nauwelijks schade aan het luchtwegepitheel, maar in patiënten met een ontsteking gerelateerde longaandoening is dit vaak wel het geval. De schade bij deze individuen kan veroorzaakt zijn door blootstelling aan factoren van buitenaf, maar kan ook het gevolg zijn van aanwezige ontstekingscellen. Deze ontstekingscellen zijn aangetrokken door een soort van "lokeiwitten", chemokinen en cytokinen genaamd, geproduceerd door o.a. het luchtwegepitheel. Een van de voornaamste ontstekingscellen is de neutrofiel. Neutrofielen zijn gespecialiseerde cellen van het aangeboren immuunsysteem. Zij vormen de eerste verdediging ten tijde van een infectie. De voornaamste functie van neutrofielen is het vernietigen van micro-organismen en schadelijke stoffen.

\section{Neutrofilie in chronische en acute longaandoeningen}

Neutrofilie (door neutrofielen gedomineerde ontsteking) is een onderdeel van verschillende longziekten. Chronisch obstructief longlijden (COPD) is een aandoening aan de longen, die zich meestal op latere leeftijd uit in een geleidelijk en grotendeels onomkeerbare verslechterde longfunctie. Roken wordt gezien als de belangrijkste risicofactor voor de ontwikkeling van COPD. 80$85 \%$ van de patiënten met COPD is dan ook een jarenlange roker (geweest). Belangrijk is echter wel om te vermelden dat maar $10-20 \%$ van alle rokers COPD ontwikkeld. Dit betekent dat ook tot nu toe onbekende genetische factoren een rol spelen bij de ontwikkeling van COPD. Patiënten met COPD hebben longemfyseem, chronische bronchitis of een combinatie van beide. Emfyseem wordt veroorzaakt door de afbraak van elastisch steunweefsel in de long, waardoor er uiteindelijk minder gasuitwisseling in de longen kan plaatsvinden.

Asbest-geïnduceerde fibrose, ook wel asbestose genaamd, is een tweede voorbeeld van een chronische longaandoening waarbij neutrofielen een belangrijke rol spelen. De ziekte ontwikkelt zich in verschillende fasen. Gedurende de blootstelling aan asbest is er continu ontsteking aanwezig in de long. Op lange termijn, soms wel tientallen jaren, zullen de asbestvezels fibrose (toename van bindweefsel) in de long tot gevolg hebben. Dit resulteert wederom in verminderde gasuitwisseling in de longen.

Een voorbeeld van een acute longaandoening waarbij neutrofielen een belangrijke rol spelen is acuut respiratoir stress syndroom. Deze aandoening kan zich ontwikkelen als gevolg van een bestaande longziekte, maar ook als gevolg van bloedvergiftiging of zwaar lichamelijk letsel na een ongeluk. $40 \%$ van de patiënten komt te overlijden als gevolg van deze acute longaandoening en helaas is er tot op heden nog geen volledig effectieve therapie gevonden. 


\section{Ontwikkeling van neutrofilie in de long}

Neutrofilie ontwikkelt zich in de long als longepitheel gestimuleerd wordt tot het maken van de al eerder genoemde chemokinen en cytokinen. Deze productie zet een signaal cascade inwerking, die tot gevolg heeft dat de in de bloedbaan circulerende neutrofielen aangetrokken worden tot de bron van de chemokinen en cytokinen. Zij zullen de bloedbaan uittreden en het betreffende weefsel, in dit geval de long, betreden. Aangekomen op de plaats van bestemming, zullen zij proberen de bron van de ontsteking uit te schakelen. De neutrofiel doet dit door het fagocyteren, "opeten en vernietigen" van schadelijke deeltjes en micro-organismen en door verschillende enzymen los te laten in de directe omgeving. Een van deze enzymen is myeloperoxidase (MPO).

\section{Myeloperoxidase}

Enzymatische activiteit van MPO zorgt voor de productie van $\mathrm{HOCl}$. $\mathrm{HOCl}$, vergelijkbaar met huishoud chloor, is een effectief middel in het bestrijden van schadelijke indringers, zoals virussen en bacteriën. Daarom zijn neutrofielen ook vaak als eerste cellen aanwezig wanneer er een ontsteking ontwikkelt. De enzymatische activiteit van MPO zorgt ook voor de ontwikkeling van zuurstofen stikstofradicalen. Radicalen zijn zeer reactieve deeltjes welke, indien in grote hoeveelheden aanwezig, schade kunnen toebrengen aan DNA en eiwit in hun directe omgeving.

Naast het onschadelijk maken van geïnhaleerde stoffen en micro-organismen, heeft neutrofilie ook effecten op de aanwezige epitheelcellen. Het is van groot belang om de gevolgen van neutrofilie en MPO blootstelling, voor deze longepitheelcellen te onderzoeken. Ook moet de reactie van longepitheelcellen op de aanwezigheid van neutrofielen en MPO onderzocht worden, omdat neutrofilie in belangrijke mate bijdraagt aan verscheidene longziekten en hierdoor klinisch zeer relevant is.

\section{Doel van het onderzoek}

Het doel van dit promotie traject was om de respons van longepitheelcellen op infiltrerende neutrofielen te onderzoeken op molecuul, eiwit en cel niveau. Er is speciaal gekeken naar de bijdrage van myeloperoxidase.

Celkweek studies en verschillende muismodellen van acute en chronische longontsteking zijn gebruikt om de bovengenoemde doelen na te komen. De resultaten van de verrichte studies zijn hieronder kort weergegeven.

\section{Effecten van acute neutrofilie en MPO op longepitheelcellen}

Om acute effecten van MPO tijdens neutrofilie te kunnen onderzoeken, hebben we gebruik gemaakt van een celkweek model. In dit model lieten we longcellen in een petrischaal groeien en werden stoffen toegevoegd die in de humane situatie neutrofilie veroorzaken. Vervolgens werd MPO toegevoegd aan de cellen, alsof er neutrofielen aanwezig waren. 
Uit deze celkweek studies (hoofdstuk 2) is naar voren gekomen dat MPO blootstelling leidt tot zowel genetische schade (DNA) als ook schade aan eiwitstructuren in longepitheelcellen. Verder is gebleken dat de reactie van long - op MPO beïnvloed wordt door de stimulus die de ontsteking veroorzaakt. Kortom, de reactie van asbest voorgestimuleerde epitheelcellen op MPO is niet gelijk aan de reactie van lipopolysaccharide (LPS, een onderdeel van de celwand van sommige bacteriën) voorgestimuleerde epitheelcellen op MPO.

Omdat celkweek systemen niet zo complex zijn als levende organismen, zijn er ook muisstudies uitgevoerd. Hierbij is gebruik gemaakt van speciale muizen die geen MPO in de neutrofielen hebben, zogenaamde MPO knock-out muizen. Uit de dierstudies waarbij acute neutrofilie (door een eenmalige LPS toediening, hoofdstuk 4) of (4 dagen asbest inhalatie, hoofdstuk 3) werd geïnduceerd, is heel duidelijk naar voren gekomen dat MPO bijdraagt aan het infiltreren van neutrofielen in de long. Dit blijkt uit het feit dat MPO knock-out muizen veel minder neutrofielen in de long hadden na LPS of asbest blootstelling dan normale (wild-type) muizen die wel MPO hebben. Verder hebben we in deze studies de resultaten van de celkweek studies kunnen bevestigen. Asbest geïnduceerde neutrofilie laat epitheelcellen anders reageren dan LPS geïnduceerde neutrofilie.

\section{Effecten van chronische ontsteking en MPO blootstelling op de long}

De effecten van MPO in chronische ontsteking zijn op twee verschillende manieren onderzocht. In de eerste studie (hoofdstuk 3) hebben wild-type en MPO knock-out muizen 30 dagen asbest ingeademd. Uit deze studie is gebleken dat, in tegenstelling tot acute neutrofilie, gebrek aan MPO het ontstaan van chronische longontsteking niet tegen kan gaan. Op het gebied van structurele verandering in de long is naar voren gekomen dat asbest geïnduceerde fibrose in wild-type dieren niet verschillend is van fibrose in MPO knock-outs.

In de tweede chronische studie (hoofdstuk 5) hebben wild-type en MPO knock-out muizen om de 3 dagen gedurende 4 maanden LPS in de longen gekregen. Ook in deze studie had MPO geen effect op het ontstaan van chronisch ontsteking. Hiermee werden de resultaten van de chronische asbest studie bevestigd. Dit in tegenstelling tot de structurele veranderingen na langdurige LPS blootstelling. In MPO knock-out muizen was er namelijk wel meer longemfyseem ontstaan na langdurige LPS blootstelling in vergelijking met wild-type dieren die met LPS waren behandeld. Ondanks dat de LPS behandelde muizen emfyseem hadden, is er geen verslechterde longfunctie gevonden bij deze dieren.

In het laatste hoofdstuk hebben we onder andere getest of de verhoogde activiteit van het signaaleiwit NF-KB in longepitheelcellen van grotere luchtwegen een kritieke stap is in de ontwikkeling van neutrofilie als gevolg van asbest blootstelling. Hiervoor zijn wild-type muizen vergeleken met muizen de geen NF-kB activiteit kunnen hebben in de longepitheelcellen van de grotere luchtwegen, zogenaamde transgene muizen. Resultaten van deze studie laten zien dat de transgene muizen minder neutrofielen in de long hebben en meer eo- 
sinofielen (een ander soort ontstekingscel) in vergelijking tot wild-type muizen. Hieruit kan geconcludeerd worden dat NF-KB inderdaad bijdraagt aan de productie van de cytokinen en chemokinen die verantwoordelijk zijn voor het infiltreren van neutrofielen in de long.

\section{Slotopmerking}

Uit de hier beschreven studies kunnen we concluderen dat het van belang is de oorzaak van de neutrofilie mee te nemen in de ontwikkeling van therapieën. De reactie van longepitheelcellen tijdens neutrofilie hangt namelijk mede af van de oorzaak van de neutrofilie. Toekomstig onderzoek, gebruikmakend van celkweek en diermodellen in combinatie met verschillende neutrofilie veroorzakende stoffen, zal bijdragen aan een betere kennis van de verschillende humane longziekten en aan het identificeren van passende therapieën voor deze longziekten. 
DANKWOORD / ACKNOWLEDGEMENTS 


\section{DANKWOORD / ACKNOWLEDGEMENTS}

Onderzoek doe je nooit alleen en een proefschrift tot stand laten komen al helemaal niet! Ik denk dat ik dan ook maar gewoon vooraan ga beginnen met mensen bedanken en maar zie hoe lang dit hoofdstuk gaat worden. Daar gaatíe dan......

Prof. Wouters, mijn promotor. Toen u vernam waar mijn onderzoek in Vermont zich op had toegespitst, was het voor $u$ direct duidelijk hoe deze samenwerking voort te zetten en de onderzoekslijn door te trekken naar het lopende onderzoek in Maastricht. Ik bewonder uw overkoepelde visie en wil u hartelijk danken voor uw vertrouwen en steun de afgelopen vier jaar.

And then a special thanks for my other promotor. Brooke, when I first started as an intern in your lab in Vermont, you gave me the freedom to further develop my interest in research. You had faith in me and encouraged me to get my PhD here in Maastricht. You have been a role model for me and I hope we'll stay in touch in the future.

Juanita, we hadden elkaar een keer gesproken over de telefoon en ik wist niet wie me op zou staan te wachten in de hal van het ziekenhuis. Nu zijn we zomaar ruim 4 jaar verder. Dank je wel voor je begeleiding en ondersteuning.

Verder gaat mijn dank uit daar de beoordelingscommissie van mijn proefschrift, onder voorzitterschap van Prof. Cohen Tervaert en verder bestaande uit Prof. Bruggeman, Prof. Brusselle, Prof. Hiemstra en Prof. van Schooten. Hartelijk dank voor het kritisch beoordelen van mijn proefschrift.

Omdat laboratorium dieren een zeer significant (hoewel ik niet weet welke toets ik hierop los zou moeten laten om dit te testen...) onderdeel van mijn onderzoek zijn, gaat mijn dank uit naar alle mensen werkzaam op de experimentele gang van het CPV. Een aantal kan ik niet, niet bij naam noemen. Menig uurtje heb ik in 'de kelder' doorgebracht en altijd stonden Harry, Allard en Rik voor mij klaar. Heren mijn dank is groot! Verder uiteraard mijn dank aan de dames van het CPV-secretariaat Nadine en Marlies. Paulien dankjewel voor het mee coördineren van de $\mathrm{Mpo}^{-/-}$fok. Ondanks al die uurtjes in de kelder heb ik mij het "muis" nog niet eigen kunnen maken, dus de communicatie ging soms wat stroef (ik zou ook proberen te bijten als ik proefdier was), toch een "dankjewel" aan alle proefdieren, het is zeker niet voor niets geweest.

Weer uit 'de kelder' omhoog gekomen stonden mijn PUL collega's altijd voor mij klaar. Nadja and Johanna thanks for your good-fellowship and friendship, I hope it will last a long time. Marco en Jodil jullie uiteraard ook bedankt voor jullie hulp en de gezellige babbels in de OBP. Mieke, dank je wel voor een goede sfeer op ons kamertje, dat dit maar zo mag blijven! Harry, geen statistische uitdaging of computer probleem was te groot of onoplosbaar. Ik snap nog steeds niet hoe je het soms doet! Mijn dank is een vierkante meter zelfge- 
bakken kruimelpudding vlaai groot (helaas voor jou is mijn oven dat niet). Ramon, we hebben heel wat tijd vol gemaakt met dierexperimenten. Je was tijdens deze dagen op de muizen O-"Ka" niet alleen een gezellige collega, even enthousiast over onderzoek als ik, maar ook een luisterend oor en ik kon je altijd om (wijze) raad vragen. Op het moment dat $i k$ dit schrijf, heb ik de overstap naar het spieronderzoek (nog niet) gemaakt, maar wanneer jij dit leest al wel. Toch ga ik nu gewoon al schrijven dat er een hele leuke, onderzoekstechnisch uitdagende tijd aan zit te komen. Heb er veel zin in! Niki en Dily, jullie ook hartelijk dank. Uiteraard wil ik hier ook mijn mede (oud)-aio's op onze groep bedanken. Erica, Jos en Evi (suc-6 in het buitenland!). En voor degene die er ook bijna zijn of nog even moeten, Alex (zet 'm op), Pascal (nog ff), Mieke (altijd gezellig als je op de uni bent). Celine, Ine en Bettine, succes! En last but not least, uiteraard de dames op het PUL-secretariaat, dank jullie wel.

Wie ik ook zeker wil bedanken, zijn de mensen waar ik mee heb mogen samen werken hier op de Uni en in het ziekenhuis. Robert Jan, mijn dank is groot voor alle leerzame uurtjes achter de microscoop. Peter, altijd fijn met je samengewerkt. Jammer dat je al weer een tijdje in Groningen zit, maar ik hoop dat we contact houden. Liesbeth (succes in Utrecht), Sofia (thanks for a good time and even better science, we'll keep in touch) en last, but not least Nejla (MPO rules).

Uiteraard was dit boekje er niet geweest als ik niet op zijn tijd had kunnen relaxen en een luisterend oor had gevonden in mijn vriendenkring. Botje, samen zijn we door alle leuke en minder leuke kanten van het aio-schap heen gefietst, ook voor jou komt het eind in zicht. Dank je wel voor je vriendschap en alle gezellige uurtjes, maar vooral ook voor het luisteren naar mijn oeverloze geklets! Ik had me geen betere paranimf kunnen wensen. Lot(tie) en Marjolein ook jullie wil ik speciaal bedanken. We gaan al heel wat jaartjes terug en daar gaan nog heel wat jaartjes bijkomen! Maar niet alleen vriendinnen (ver(der)) weg, ook vriendinnen vlak bij (soms zelfs aan de overkant van de straat), altijd in voor een bakkie, een kletsje of een middagje relaxen in de thermen. Martien \& Marcella, dank jullie wel voor alles! 't Is nu tijd om eens goed te gaan feesten.

And not only science but also friendship crosses boarders. So here we go.... Trisha, Marcella, Luca and Sabrina thanks for everything, especially for sending me those hard to get papers. And a very special thanks for you, Masha. For lots of good times in VT, we'll stay in touch.

Verder uiteraard een speciale dankjewel voor familie. Alex, ondertussen een bonk van een vent, toch altijd een beetje mijn kleine broertje. Lief dat je er altijd voor mij bent, of het nu gaat om een ritje naar Schiphol, zomaar even bijkletsen of een (te) zonnig maar erg leuk middagje kanoën op de Maas (toch maar zonnebrand volgende keer!). En uiteraard, mijn grote broer Gijs, ook jij bedankt voor je support en interesse! Ondanks dat moeders het maar niets 
vinden als de kids zover van huis gaan, toch ook altijd interesse van jou, José. Ook jij, bedankt voor je smsjes en belletjes vlak voor presentaties en congressen de afgelopen jaren.

Moeke en Jan, dank jullie wel voor de kans die jullie mij gegeven hebben om te gaan studeren en voor jullie interesse de afgelopen jaren. Ik ben blij dat ik met jullie steun iets heb gevonden dat echt mijn ding is!

Echt ons ding moet ik eigenlijk zeggen, want er is er maar een die mij zo goed begrijpt en kent als jij, Roy. Dank je wel voor alles! 



\section{PUBLICATIONS}




\section{PUBLICATIONS}

1. Ramon-Nino, M.E., Haegens, A., Shukla, A., Mossman, B.T. (2002) Role of mitogen-activated protein kinases (MAPK) in cell injury and proliferation by environmental particles. Mol Cell Bioch 234-235, 111-118.

2. Ramos-Nino, M.E., Heintz, N., Scappoli, L., Martinelli, M., Land, S., Nowak, N., Haegens, A., Manning, B., Manning, N., MacPherson, M., Stern, M., Mossman, B. (2003) Gene profiling and kinase screening in asbestos-exposed epithelial cells and lungs. Am J Respir Cell Mol Biol 29, S51-58.

3. Haegens, A., van der Vliet, A., Butnor, K.J., Heintz, N., Taatjes, D., Hemenway, D., Vacek, P., Freeman, B.A., Hazen, S.L., Brennan, M.L., Mossman, B.T. (2005) Asbestos-induced lung inflammation and epithelial cell proliferation are altered in myeloperoxidase null mice. Cancer Res 65, 9670-9677.

4. Vernooy, J.H., Reynaert, N., Wolfs, T.G., Cloots, R.H., Haegens, A., de Vries, B., Dentener, M.A., Buurman, W.A., Wouters, E.M. (2005) Rapid pulmonary expression of acute-phase reactants after local lipopolysaccharide exposure in mice is followed an interleukin- 6 mediated systemic acute-phase response. Exp Lung Res 31, 855-871.

5. Haegens, A., Barrett, T.F., Gell, J., Shukla, A., MacPherson, M., Vacek, P., Poynter, M.E., Butnor, K.J., Janssen-Heininger, Y.M., Steele, C., Mossman, B.T. (2007) Airway epithelial NF-kappaB activation modulates asbestos-induced inflammation and mucin production in vivo. J Immunol 178, 1800-1808.

6. Haegens, A., Vernooy, J.H., Heeringa, P., Mossman, B.T., Wouters, E.F.M. (2008) Myeloperoxidase modulates lung epithelial responses to pro-inflammatory agents. Eur Respir J 31, 252-260.

7. Haegens, A., Vernooy, J.H.J., Heeringa, P., van Suylen, R.J., Steele, C., Aratani, Y., Mossman, B.T., Wouters, E.F.M. (2008) Myeloperoxidase deficiency attenuates LPS induced acute lung inflammation and subsequent epithelial injury. (submitted)

8. Haegens, A., Vernooy, J.H.J, Cloots, R.H.E., Kelders, M.C.J.M., Drummen, N. E.A., Xanthoulea S., Bast, A., Fehrenbach, H., Poynter M. E., Mossman, B.T., Wouters E.F.M. (2008) Myeloperoxidase attenuates LPS induced airspace enlargement. (submitted)

9. Geraets, L., Haegens, A., Brauers, K., Haydock, J.A., Vernooy, J.H.J., Wouters, E.F.M., Wouters, Bast, A., Hageman, G.J. (2008) Assessment of in vivo anti-inflammatory effects of specific PARP-1 inhibiting flavonoids in a mouse model of lipopolysaccharide induced acute pulmonary inflammation. (submitted)

10. Geraets, L., Haegens, A., Weseler, A.R., Brauers, K., Vernooy, J.H.J., Wouters, E.F.M., Bast, A., Hageman, G.J. (2008) 1,7-Dimethylxanthine inhibits the lipopolysaccharide-induced inflammatory response in vivo and ex vivo in whole blood. (submitted) 
11. Dentener, M.A., Haegens, A., Vernooy, J.H.J., Jörgensen, J.J., Bracke, K.R., Brusselle, G.G., Cleutjens, J.P.M., van Suylen R.J., Wouters, E.F.M. (2008) Hyaluronan deposition during experimental lung inflammation: role of hyaluronan modulating enzymes (submitted) 


\section{CURRICULUM VITAE}




\section{CURRICULUM VITAE}

Astrid Haegens was born on the twenty-fourth of December 1979 in Roosendaal (NL). After she finished highschool in 1997 at the Gertrudis Lyceum in Roosendaal, she started her biomedical laboratory education (HLO, Hogeschool Brabant). In August of 2001 she moved to the USA to start her internship and graduation work at the University of Vermont (Burlington, VT, USA), where she investigated the role of NF-KB in an in vitro model and an in vivo mouse model of asbestosis. In the summer of 2002 she graduated with a specialization in biotechnology and an article 12 certificate for working with laboratory animals. She joined the Department of Respiratory Medicine of the University of Maastricht as a PhD student in December 2003. Her project focused on the damaging effects on lung epithelium of acute and chronic neutrophilia, with a special interest for the contribution of myeloperoxidase to these effects. She investigated this, using in vitro and in vivo approaches. Currently, she is working as a post-doctoral fellow at the Department of Respiratory Medicine. Her research will focus on anabolic effects of amino acids on muscle growth. 